\title{
IN-SITU ANALYSIS OF INCIPIENT MELTING AND CHARACTERIZATION OF A NOVEL Al-Cu ALLOY FOR CYLINDER HEAD APPLICATIONS
}

by

Bernoulli Andilab,

B.Eng, Ryerson University, 2016

\author{
A thesis \\ presented to Ryerson University \\ in partial fulfillment of \\ the requirements for the degree of
}

Master of Applied Science

in the program of

Mechanical and Industrial Engineering

Toronto, Ontario, Canada, 2019

(C) Bernoulli Andilab, 2019 


\section{AUTHOR'S DECLARATION}

I hereby declare that I am the sole author of this thesis. This is a true copy of the thesis, including any required final revisions, as accepted by my examiners. I authorize Ryerson University to lend this thesis to other institutions or individuals for the purpose of scholarly research. I further authorize Ryerson University to reproduce this thesis by photocopying or by other means, in total or in part, at the request of other institutions or individuals for the purpose of scholarly research. I understand that my thesis may be made electronically available to the public. 


\title{
IN-SITU ANALYSIS OF INCIPIENT MELTING AND CHARACTERIZATION OF A NOVEL Al-Cu ALLOY FOR CYLINDER HEAD APPLICATIONS
}

\author{
Bernoulli Andilab \\ Master of Applied Science 2019 \\ Mechanical and Industrial Engineering \\ Ryerson University, Toronto, Ontario, Canada
}

\begin{abstract}
Incipient melting of secondary phases during solution heat treatment of $\mathrm{Al}$ alloys is detrimental to their mechanical properties. In this research, incipient melting was analyzed in-situ using a high temperature Laser Scanning Confocal Microscope (LSCM) in a novel Al-Cu alloy. Thermal analysis and microstructural analysis were carried out on the alloy cast at fast and slow cooling rates to examine the resulting solidification and microstructural characteristics. The results showed that incipient melting was accompanied by a clustering liquid droplets followed by a complete melting of $\mathrm{Al}_{2} \mathrm{Cu}$ which occurred at approximately $548{ }^{\circ} \mathrm{C}$. Additionally, the use of LSCM enabled an understanding of the underlying mechanisms behind incipient melting. It was also found that incipient melting led to microstructure that consisted of a higher presence of ultra-fine eutectic clusters, needle-like $\mathrm{Al}_{2} \mathrm{Cu}$ and porosity along the grain boundaries. Lastly, the solution heat treatment temperature was optimized for the Al-Cu alloy using the data from LSCM, Differential Scanning Calorimetry and solution heat treatment experiments.
\end{abstract}




\section{ACKNOWLEDGEMENTS}

I would like to express my deepest gratitude to my supervisor, Professor C. Ravindran, for his kindness, support, guidance, and motivation throughout my graduate studies.

I am very grateful to Dr. Ricardo Gutierrez, Dr. Glenn Byczynski, Dr. Rob MacKay, and Dr. Anthony Lombardi for providing the material used in this research. I am also thankful for the technical discussions of the results for this project.

I am also especially thankful to Dr. Neslihan Dogan of McMaster University for her support and guidance, and the use of facilities at the McMaster Steel Research Center. I would also like to thank Mr. Mukesh Sharma for his kind friendship and training in the use of the facilities.

I am very grateful to Mr. Alan Machin for his technical knowledge, advice, and assistance with experiments and meaningful discussions.

I am also very thankful to Dr. Raja Roy, Mr. Eli Vandersluis, Mr. Payam Emadi and Mr. Michael Rinaldi and of the Centre for Near-net-shape Processing of Materials for their technical knowledge, meaningful discussions, and assistance with experiments.

I am also thankful to Mr. Joseph Amankrah and Mr. Qiang Li for their technical assistance.

Finally, I am very thankful to my family and friends for their constant support and motivation throughout my graduate studies. 


\section{Table of Contents}

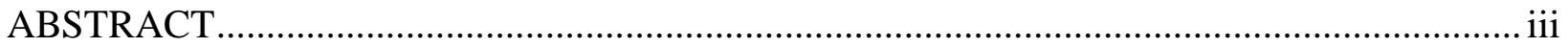

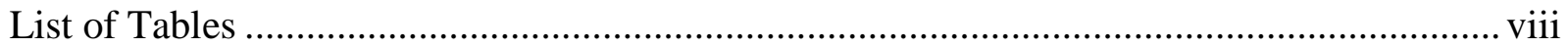

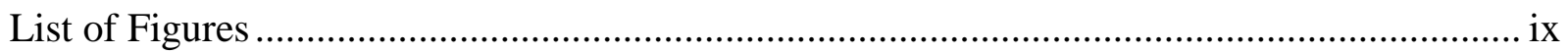

List of Appendices ……………………....................................................................... xii

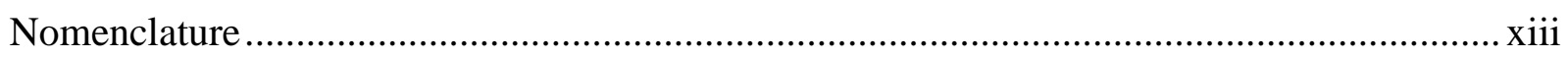

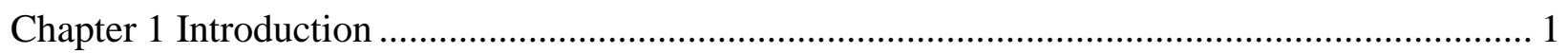

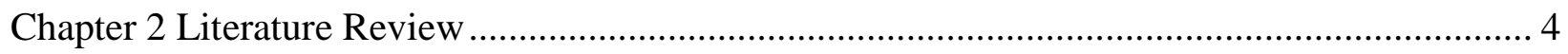

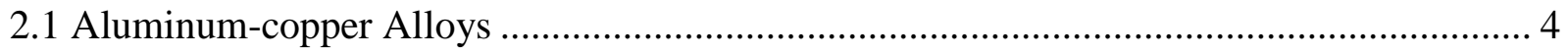

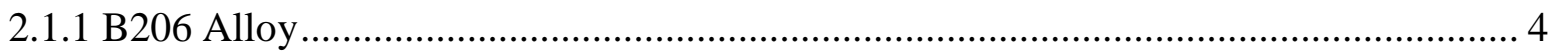

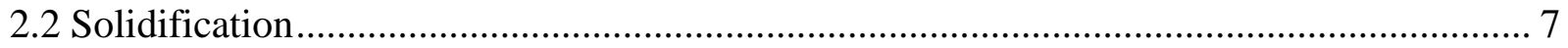

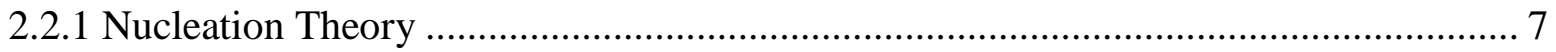

2.2.1.1 Homogeneous Nucleation .................................................................................. 8

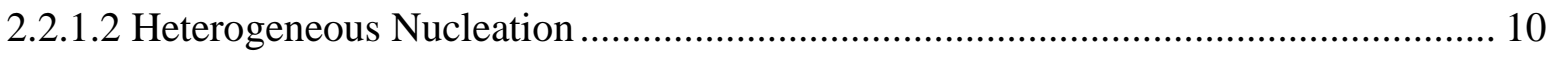

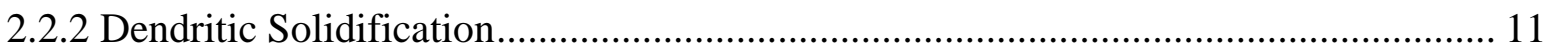

2.3 Heat Treatment of Aluminum Alloys ..................................................................... 12

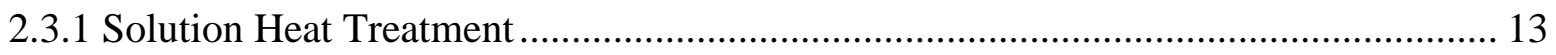

2.3.1.1 Incipient Melting ........................................................................................ 14

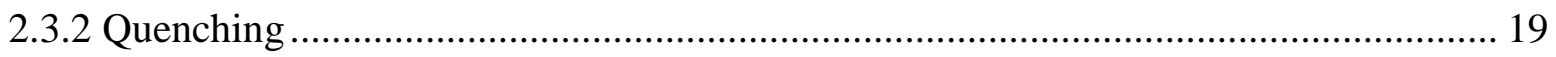

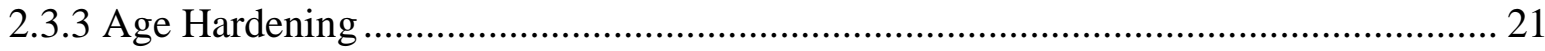

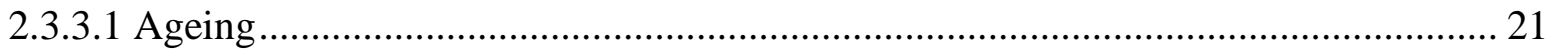

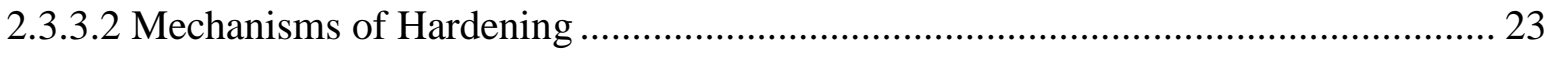

2.3.3.2 Effect of Ageing on Mechanical Properties ........................................................... 24

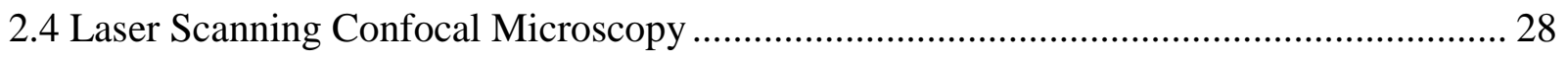

2.4.1 Instrument and Procedure ................................................................................. 28 


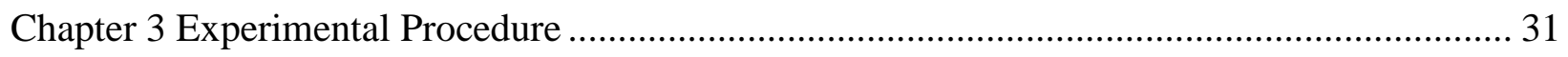

3.1 Alloy Melting and Casting............................................................................................... 31

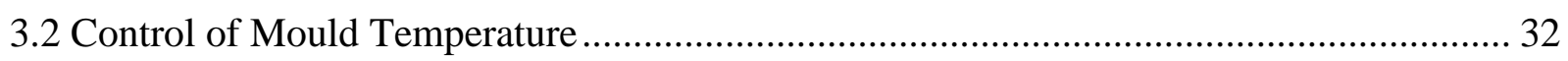

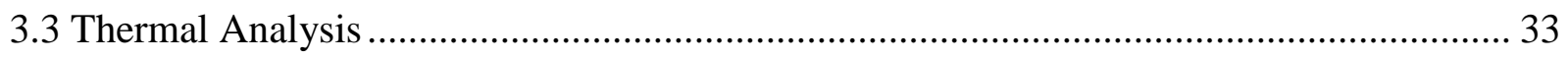

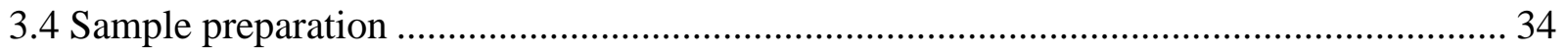

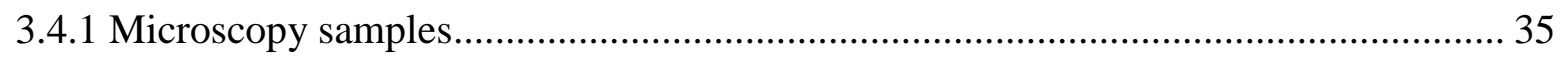

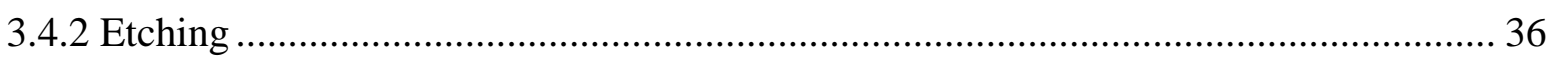

3.5 Microstructural Analysis ............................................................................................ 36

3.5.1 Quantitative Image Analysis..................................................................................... 37

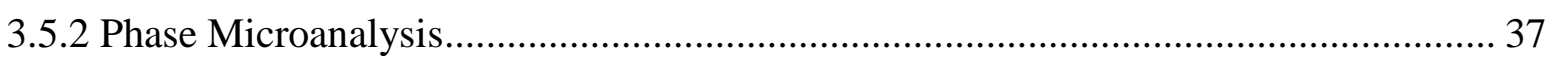

3.6 Laser Scanning Confocal Microscopy (LSCM) ……………………………………........ 38

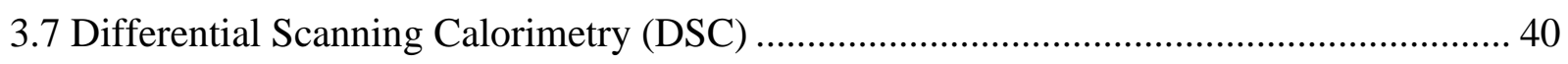

3.8 Solution Heat Treatment of HT200 alloy …………........................................................ 41

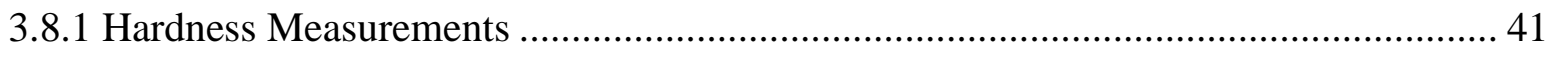

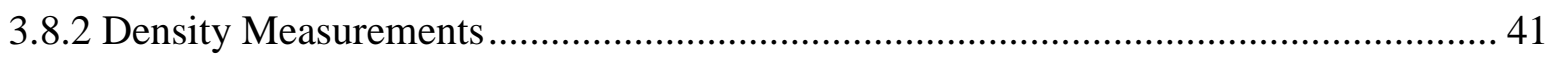

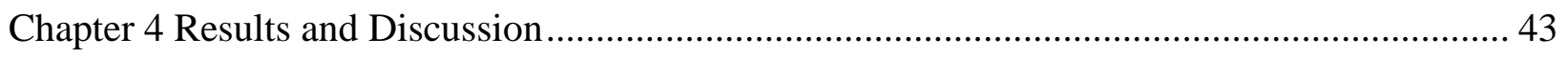

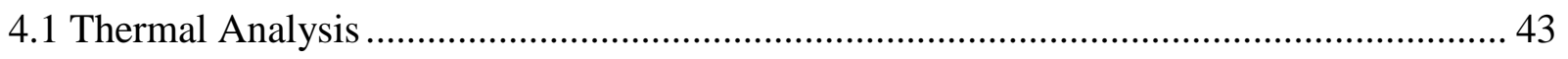

4.1.1 $500^{\circ} \mathrm{C}$ Mould Castings .............................................................................................. 44

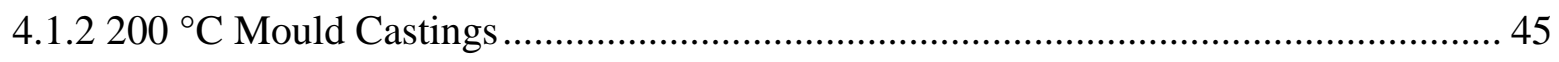

4.1.3 Differential Scanning Calorimetry (DSC) - Solidification Analysis .......................... 46

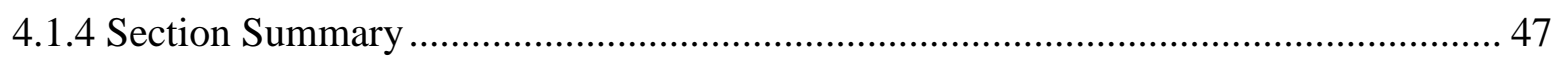

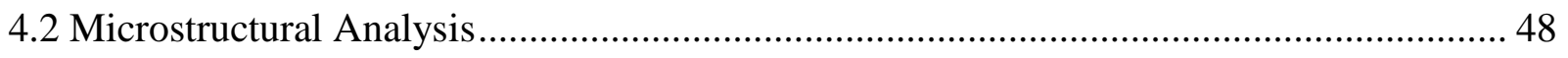

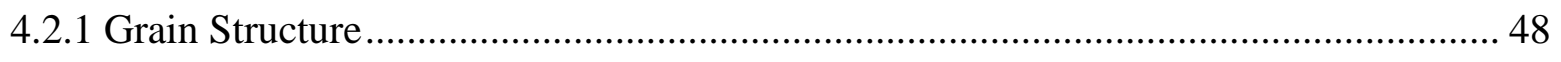

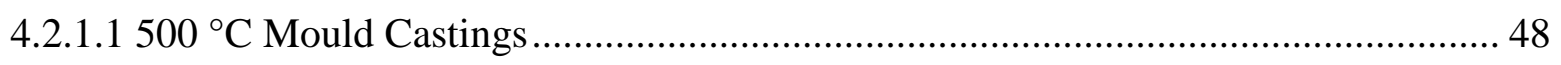

4.2.1.2 200 ${ }^{\circ} \mathrm{C}$ Mould Castings .......................................................................................... 49 


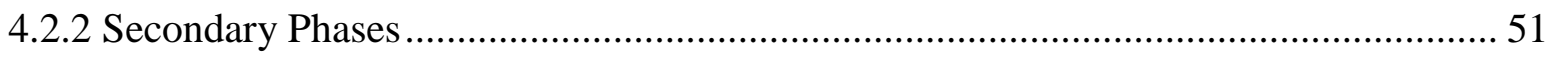

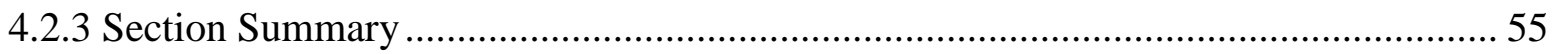

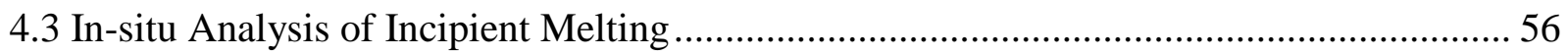

4.3.1 Laser Scanning Confocal Microscopy (LSCM) ………………................................ 56

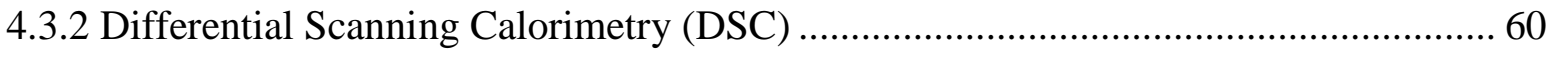

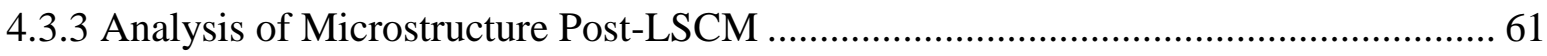

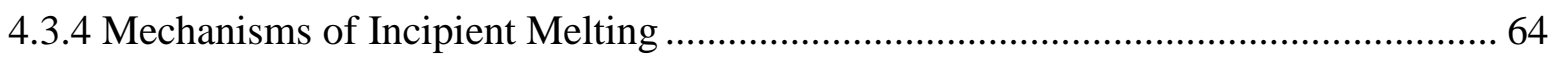

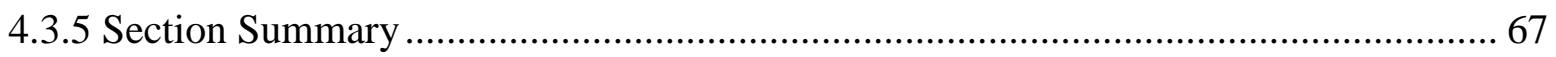

4.4 Solution Heat Treatment (SHT) of HT200 Alloy ……….................................................... 68

4.4.1 Effect of SHT Temperature on Density and Hardness ............................................... 68

4.4.2 Post-Solution Heat Treatment Analysis ........................................................................ 71

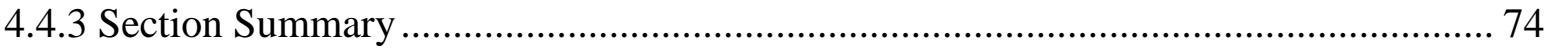

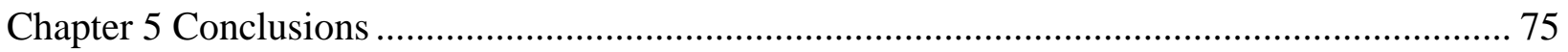

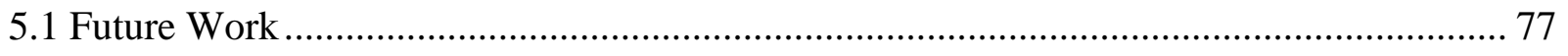

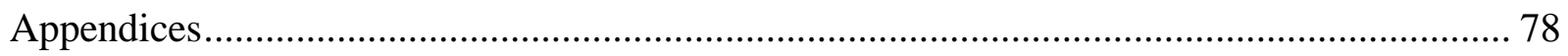

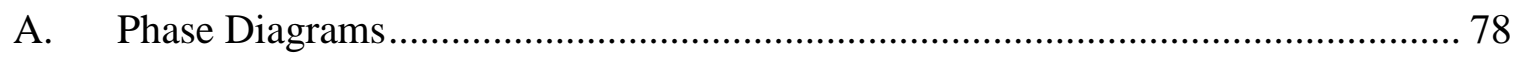

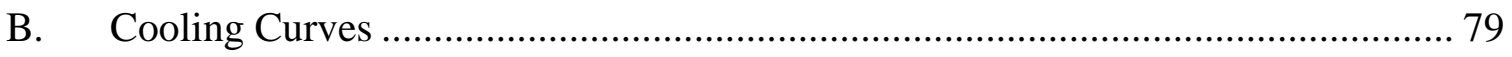

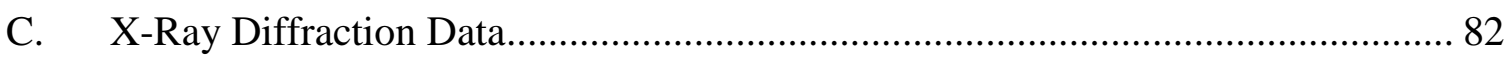

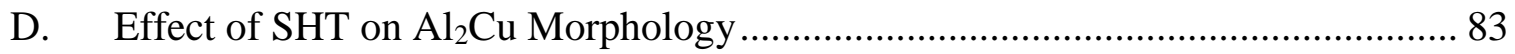

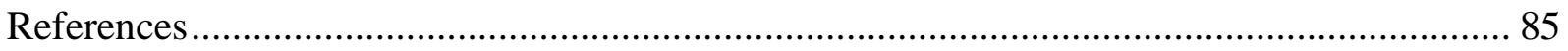




\section{List of Tables}

Table 2-1: Nominal composition of B206 aluminum alloy [9] ........................................... 5

Table 2-2: Phase transformation reactions during solidification of B206 alloy [14].................. 7

Table 3-1: Average experimental composition of HT200 alloy .......................................... 32

Table 3-2: Average experimental composition of HT200 alloy with TiBor addition. ................ 32

Table 3-3: Composition Al-5Ti-B standard cut rods (Batch Analysis from KB Alloys)............ 32

Table 3-4: Polishing procedure for microstructure analysis. ................................................. 36

Table 4-1: Experimental solidification parameters........................................................... 44 


\section{List of Figures}

Figure 1-1: Thesis outline 3

Figure 2-1: Backscattered electron image of (a) B206 as-cast microstructure and (b) eutectic

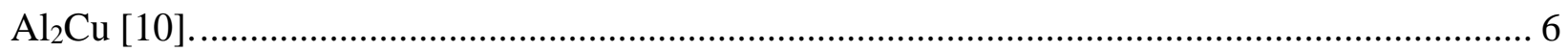

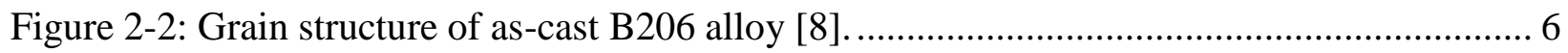

Figure 2-3: Change in free energy with formation of a particle of radius, $\mathrm{r}$ [15]..................... 9

Figure 2-4: Cooling curve of typical Al alloy showing homogenous nucleation [14] ................ 10

Figure 2-5: Schematic of heterogeneous nucleation of a solid from a liquid [15].................... 11

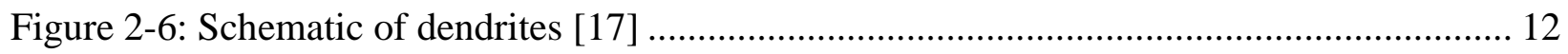

Figure 2-7: Dissolution process of eutectic $\mathrm{Al}_{2} \mathrm{Cu}$ (left) and blocky $\mathrm{Al}_{2} \mathrm{Cu}$ (right) as described by

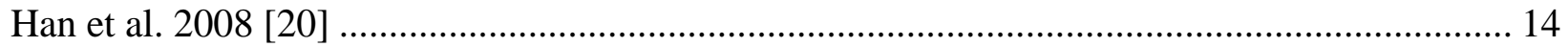

Figure 2-8: Experimental data relating UTS to SHT temperature by Samuel et. al [21] ............ 15

Figure 2-9: Incipient melting of $\mathrm{Al}_{2} \mathrm{Cu}$ at the grain boundaries for samples solution heat treated

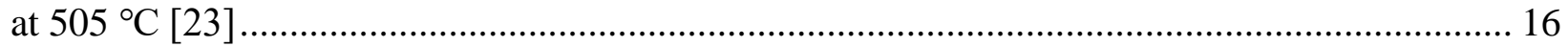

Figure 2-10: LSCM micrographs showing melting of $\mathrm{Al}_{2} \mathrm{Cu}$ at 100x [10] ............................. 17

Figure 2-11: LSCM micrographs at 350x magnification showing melting of $\mathrm{Al}_{-} \mathrm{Al}_{2} \mathrm{Cu}-$

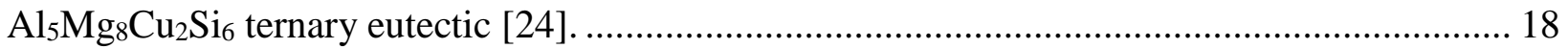

Figure 2-12: Hardness values for Jominy sample aged at $160{ }^{\circ} \mathrm{C}$ for $6 \mathrm{hrs}$. [27]..................... 20

Figure 2-13: Schematic representation of the stages of the formation of the $\theta$ phase [15]........ 23

Figure 2-14: Mechanism of hardening; dislocation (a) shearing through particle and (b)

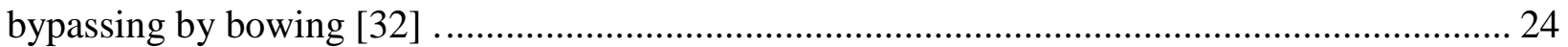

Figure 2-15: Yield strength (left) and ultimate tensile strength (right) in relation to artificial

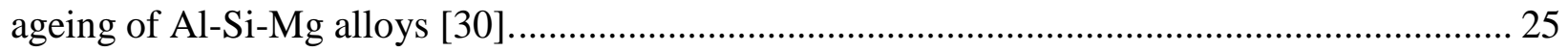

Figure 2-16: Yield strength (left) and ultimate tensile strength (right) varying with ageing time

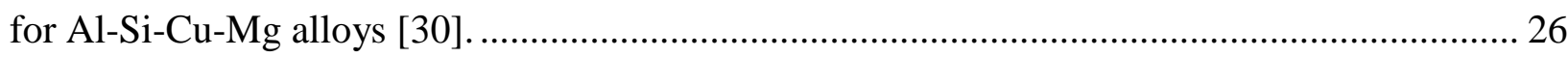

Figure 2-17: Evolution of storage rate, uniform elongation, and yield strength as a function of

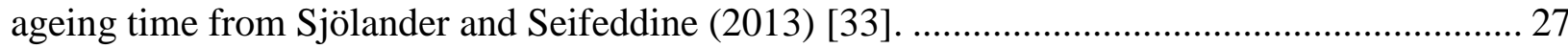

Figure 2-18: A schematic diagram of the components of a high temperature LSCM [34] ......... 29

Figure 3-1: Placement of thermocouples in permanent mould................................................ 33

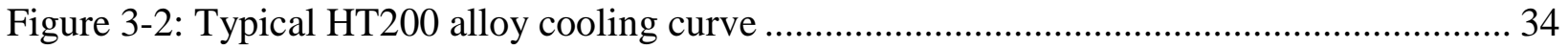


Figure 3-3: Locations of samples for microstructure analysis, thermal analysis, solution heat

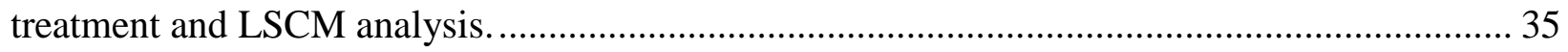

Figure 3-4: Experimental setup of LSCM heating chamber ............................................. 38

Figure 3-5: LSCM heating profile for analysis of incipient melting in HT200 alloy................. 40

Figure 4-1: Experimental cooling curves for HT200 and HT200 with $0.25 \mathrm{wt} \%$ TiBor at $500{ }^{\circ} \mathrm{C}$ mould temperature.

Figure 4-2: Experimental cooling curves for HT200 and HT200 with $0.25 \mathrm{wt} \%$ TiBor at $200{ }^{\circ} \mathrm{C}$

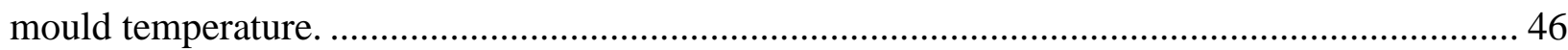

Figure 4-3: DSC cooling curve of HT200 alloy for a cooling rate of $10{ }^{\circ} \mathrm{C} / \mathrm{min}$.

Figure 4-4: Optical micrographs of base HT200 alloy from $500{ }^{\circ} \mathrm{C}$ mould castings at (a) 50x magnification and (b) 100x magnification.

Figure 4-5:Optical micrographs showing grain structure of (a) base HT200 alloy and (b) HT200 with TiBor at $100 \mathrm{x}$ magnification from $500{ }^{\circ} \mathrm{C}$ mould castings.

Figure 4-6: Optical micrographs showing grain structure of (a) base HT200 alloy and (b) HT200 with TiBor at $50 \mathrm{x}$ magnification from $200^{\circ} \mathrm{C}$ mould castings. 50 Figure 4-7: Optical micrographs showing grain structure of (a) base HT200 alloy and (b) HT200 with TiBor at $100 x$ magnification from $200{ }^{\circ} \mathrm{C}$ mould castings. 51 Figure 4-8: Backscattered electron images of intermetallic compounds for $500{ }^{\circ} \mathrm{C}$ castings of (a) base HT200 alloy and (b) HT200 alloy with TiBor at 200x magnification............................... 52 Figure 4-9: Backscattered electron images of intermetallic compounds for $200{ }^{\circ} \mathrm{C}$ castings of (a) base HT200 alloy and (b) HT200 alloy with TiBor at 200x magnification.............................. 53 Figure 4-10: Higher magnification backscattered electron image showing the internal structure of eutectic $\mathrm{Al}_{2} \mathrm{Cu}$. .53

Figure 4-11: Backscattered electron image showing Al-Fe-Mn and Al-Zr intermetallic compounds embedded in $\mathrm{Al}_{2} \mathrm{Cu}$..... 54

Figure 4-12: EDX analysis of (a) $\mathrm{Al}_{2} \mathrm{Cu}$, (b) Al-Cu-Fe-Mn, and (c) Al-Zr secondary phases.... 54 Figure 4-13: LSCM micrographs showing the sequence of incipient melting of $\mathrm{Al}_{2} \mathrm{Cu}$ in the HT200 alloy at 100x magnification: (a-c) onset of incipient melting and formation of liquid droplets, (d-f) spreading of liquid phase, increase in size of microstructure and formation of cavities. 
Figure 4-14: LSCM micrographs showing the sequence of incipient melting of $\mathrm{Al}_{2} \mathrm{Cu}$ in the HT200 alloy refined with TiBor at 100x magnification: (a-c) onset of incipient melting and formation of liquid droplets, (d-f) spreading of liquid phase, increase in size of microstructure and formation of cavities. 58

Figure 4-15: LSCM micrographs showing the sequence of incipient melting of $\mathrm{Al}_{2} \mathrm{Cu}$ in the HT200 alloy at 200x magnification: (a-c) melting at $\mathrm{Al}+\mathrm{Al}_{2} \mathrm{Cu}$ interface and formation of liquid phase, (d-f) increase in size of microstructure and formation of cavities. 59

Figure 4-16: LSCM micrographs showing the sequence of incipient melting of $\mathrm{Al}_{2} \mathrm{Cu}$ in the HT200 alloy refined with TiBor at 200x magnification: (a-c) melting at $\mathrm{Al}+\mathrm{Al}_{2} \mathrm{Cu}$ interface and formation of liquid phase, (d-f) increase in size of microstructure and formation of cavities. .... 60 Figure 4-17: DSC analysis of HT200 alloy heated to $700{ }^{\circ} \mathrm{C}$ at a heating rate of $10{ }^{\circ} \mathrm{C} / \mathrm{min} . \ldots 61$ Figure 4-18: SEM images showing microstructure of HT200 alloy (a) before incipient melting and (b) after incipient melting at 100x magnification.

Figure 4-19: Microstructure of LSCM HT200 alloy sample after incipient melting at (a) 200x

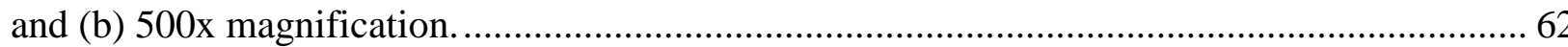

Figure 4-20: EDX analysis of ultra-fine eutectic cluster and surrounding Al matrix. 63

Figure 4-21: Backscattered SEM image of HT200 alloy showing (a) surface microstructure and EDX elemental maps for (b) Al, (c) $\mathrm{Cu}$, (d) Zr, (e) Mn and (f) Fe after incipient melting. ........ 64 Figure 4-22: Variation in $\mathrm{Cu}$ content in eutectic $\mathrm{Al}_{2} \mathrm{Cu}$ measured from $\mathrm{EDX}$. 66

Figure 4-23: Backscattered SEM image showing extracted $\mathrm{Al}_{2} \mathrm{Cu}$ particles on carbon tape and EDX analysis.

Figure 4-24: Variation in density of HT200 alloy as a function of solution heat treatment temperature.

Figure 4-25: Variation in Rockwell hardness (HRE) of HT200 alloy as a function of solution heat treatment temperature.

Figure 4-26: Variation in $\mathrm{Al}_{2} \mathrm{Cu}$ vol.\% as a function of solution heat treatment temperature. .... 71 Figure 4-27: Macro images of HT200 alloy after solution heat treatment at a) 530, b) 540, c) 550 and d) $560{ }^{\circ} \mathrm{C}$.

Figure 4-28: Backscattered electron image of solution heat treated HT200 sample before repolishing showing: (a) surface microstructure and EDX elemental maps of (b) Al, (c) $\mathrm{Cu}$ and (d) O. 
Figure 4-29: Backscattered electron images of HT200 alloy after solution heat treatment at (a)

540 and (b) $550{ }^{\circ} \mathrm{C}$ 73

\section{List of Appendices}

Figure A-1: Aluminum-rich side of aluminum-copper (Al-Cu) phase diagram....................... 78

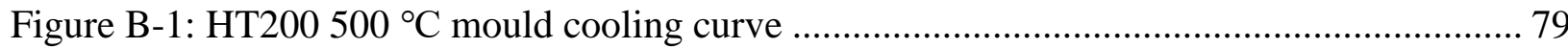

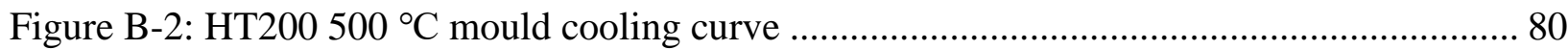

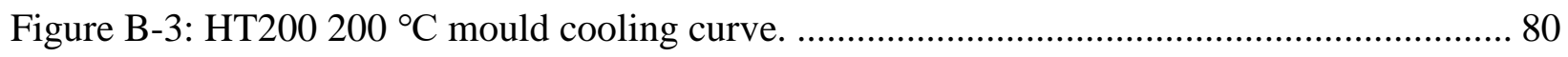

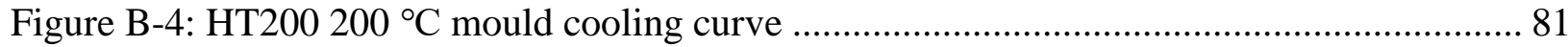

Figure C-1: X-ray diffraction analysis of HT200 alloy .................................................... 82

Figure D-1: Average circular diameter of $\mathrm{Al}_{2} \mathrm{Cu}$ as a function of SHT temperature ................ 83

Figure D-2: Average aspect ratio of $\mathrm{Al}_{2} \mathrm{Cu}$ as a function of SHT temperature ........................ 84

Figure D-3: Average sphericity of $\mathrm{Al}_{2} \mathrm{Cu}$ as a function of SHT temperature.......................... 84 


\section{Nomenclature}

$\begin{array}{lll}\text { Greek } & & \text { Units } \\ \gamma & \text { Surface free energy } & \mathrm{J} / \mathrm{m}^{2} \\ \gamma_{I L} & \text { Liquid-surface interfacial energy } & \mathrm{J} / \mathrm{m}^{2} \\ \gamma_{S I} & \text { Solid-surface interfacial energy } & \mathrm{J} / \mathrm{m}^{2} \\ \gamma_{S L} & \text { Solid-liquid interfacial energy } & \mathrm{J} / \mathrm{m}^{2} \\ \theta & \text { Contact angle } & \text { degrees } \\ \lambda_{1} & \text { Primary dendrite arm spacing } & \mu \mathrm{m} \\ \lambda_{2} & \text { Secondary dendrite arm spacing } & \mu \mathrm{m} \\ \rho & \text { Density } & \mathrm{g} / \mathrm{cm}^{3}\end{array}$

English

$\mathrm{r}$

r* Critical radius

$\Delta \mathrm{G} \quad$ Total free energy change

$\Delta \mathrm{G}_{\mathrm{v}} \quad$ Free energy change per unit volume

$\mathrm{T}_{\mathrm{E}} \quad$ Equilibrium liquidus temperature

$\mathrm{T}_{\mathrm{G}} \quad$ Growth temperature

$\mathrm{T}_{\mathrm{N}} \quad$ Nucleation temperature

$\mathrm{m}_{\mathrm{s}} \quad$ Mass of sample in air

$\mathrm{m}_{\mathrm{sw}}$

$\mathrm{m}_{\mathrm{W}}$

Apparent mass of the sample in a container of water

Units

$\mathrm{m}$

$\mathrm{m}$

J

$\mathrm{J} / \mathrm{m}^{3}$

${ }^{\circ} \mathrm{C}$

${ }^{\circ} \mathrm{C}$

${ }^{\circ} \mathrm{C}$

g

g

g 


$\begin{array}{ll}\text { Abbreviations } \\ \text { EDX } & \text { Energy Dispersive X-ray Spectroscopy } \\ \text { SEM } & \text { Scanning Electron Microscopy } \\ \text { LSCM } & \text { Laser Scanning Confocal Microscopy } \\ \text { DSC } & \text { Differential Scanning Calorimetry } \\ \text { OES } & \text { Optical Emission Spectrometer } \\ \text { SHT } & \text { Solution Heat Treatment } \\ \text { SSSS } & \text { Supersaturated Solid Solution } \\ \text { FCC } & \text { Face Center Cubic } \\ \text { GP } & \text { Guinier Preston Zone } \\ \text { AOD } & \text { Acoustic Optic Deflector } \\ \text { CCD } & \text { Charged Coupled Device } \\ \text { HRE } & \text { Rockwell Hardness E } \\ \text { UFE } & \text { Ultrafine Eutectic } \\ \text { TiBor } & \text { Al-5Ti-B Grain Refiner }\end{array}$

\section{Elements and Intermetallics}

$\begin{array}{ll}\mathrm{Al} & \text { Aluminum } \\ \mathrm{Cu} & \text { Copper } \\ \mathrm{Mn} & \text { Manganese } \\ \mathrm{Zr} & \text { Zirconium } \\ \mathrm{Fe} & \text { Iron } \\ \mathrm{Ti} & \text { Titanium } \\ \mathrm{V} & \text { Vanadium } \\ \mathrm{Mg} & \text { Magnesium } \\ \mathrm{Si} & \text { Silicon } \\ \mathrm{O} & \text { Oxygen }\end{array}$

$\mathrm{Al}_{2} \mathrm{Cu}$

Intermetallic in $\mathrm{Cu}$ containing $\mathrm{Al}$ alloys

$\mathrm{Al}_{7} \mathrm{FeCu}$

Intermetallic in B206

$\mathrm{Al}_{20} \mathrm{Mn}_{3} \mathrm{Cu}_{2}$

Intermetallic in B206

$\mathrm{Al}_{2} \mathrm{Mn}_{3} \mathrm{Cu}_{2}$

Intermetallic in B206 


$\begin{array}{ll}\mathrm{Al}_{6}(\mathrm{MnFeCu}) & \text { Intermetallic in B206 } \\ \mathrm{Al}_{2} \mathrm{MgCu} & \text { Intermetallic in B206 } \\ \mathrm{Mg}_{2} \mathrm{Si} & \text { Intermetallic in A319 } \\ \mathrm{Al}_{5} \mathrm{Cu}_{2} \mathrm{Mg}_{8} \mathrm{Si}_{6} & \text { Intermetallic in A319 } \\ \mathrm{Al}_{-}-\mathrm{Al}_{2} \mathrm{Cu}-\mathrm{Al}_{5} \mathrm{Mg}_{8} \mathrm{Cu}_{2} \mathrm{Si}_{6} & \text { Intermetallic in A319 } \\ \mathrm{Al}_{3} \mathrm{Sc} & \text { Intermetallic A319 with Scandium addition } \\ \mathrm{Al}_{3} \mathrm{Zr} & \text { Intermetallic in Al alloys with Zirconium addition } \\ \mathrm{Na}_{2}\left(\mathrm{SiF}_{6}\right) & \text { Sodium fluorosilicate degassing flux }\end{array}$




\section{Chapter 1 Introduction}

Lightweight engineering materials are crucial in improving the fuel economy of automotive vehicles, while also ensuring safety and performance are not compromised. The efficiency of vehicles can be improved by reducing the weight, thus requiring less energy. Studies have shown that, a $10 \%$ reduction in weight can improve the fuel economy by approximately 6-8\% [1]. Additionally, the use of lightweight components and high efficiency engines in just $25 \%$ of U.S. vehicles can save approximately 5 billion gallons of fuel annually by 2030 [1]. The use of aluminum (Al) alloys for automotive components replacing iron alternatives, such as engine blocks and cylinder heads, would lead to significant weight reduction and improved fuel efficiency. This research project focuses on the development of a novel high temperature Al casting alloy for high performance engines, in collaboration with Nemak (North America and Europe Division).

Al-Si casting alloys such as A319 and A356 are most commonly used in the automotive industry for engine blocks and cylinder heads. However, these alloys are known to soften and have reduced strength at high temperatures [2]. A356 alloys are known to have a rapid reduction in strength at temperatures above $200{ }^{\circ} \mathrm{C}[3,2]$. A319 Al alloys have better high temperature properties, but prolonged exposure at $\sim 250{ }^{\circ} \mathrm{C}$ also results in softening [2]. This reduction in strength at high temperatures is attributed to brittle intermetallic phases, including precipitates, such as $\beta$ - $\mathrm{Al}_{5} \mathrm{FeSi}$ that are unstable at temperatures above $200{ }^{\circ} \mathrm{C}$ [3]. The novel Al-Cu alloy developed by Nemak has unique composition which differentiates it from commercial $\mathrm{Al}$ alloys, and is designed for high temperature applications such as cylinder heads and engine blocks. Moreover, the addition of $\mathrm{Zr}$ alters its behaviour compared to other alloys, because of the stability of the $\mathrm{Zr}$ containing phases at elevated temperatures [4]. In the industry it is a common practice to subject cast Al alloys to a heat treatment to achieve desired mechanical properties (strength and ductility). However, one of the factors limiting solution heat treatment is the maximum usable temperature due to incipient melting. Extensive research has been carried out on the incipient melting of secondary phases in Al alloys such as A319 and A356, i.e. Al-Si casting alloys. Moreover, the techniques used to determine and observe incipient melting were limited to differential scanning calorimetry and scanning electron microscopy. Thus, there is a need for extensive studies to gain a fundamental understanding of the high temperature behaviour during heat treatment processing. This will be 
done using high temperature laser scanning confocal microscopy (LSCM) as a tool for in-situ observation of the microstructural evolution of the alloy at elevated temperature. Understanding incipient melting of secondary phases in the alloy will aid in the optimization of heat treatment process parameters for optimal mechanical properties. The main objective is to analyze incipient melting of secondary phases in the Al-Cu alloys using LSCM. Subsequently, the alloy's microstructure and solidification characteristics and its relation to incipient melting will be studied.

The thesis has been structured as follows:

Chapter 2 presents a literature review that describes the fundamentals of alloy solidification and available work on the casting characteristics Al-Cu alloys. Additionally, a review on the solution heat treatment of aluminum alloys is discussed. This includes details on past studies on the incipient melting of secondary phases and the experimental methods used for the analyses.

Chapter 3 describes the experimental methodology of the research work. This includes the melting and casting experiments, thermal analysis, sample preparation, characterization techniques, solution heat treatment experiments and mechanical property evaluation.

Chapter 4 presents and analyzes the results found in this study. Specifically, the solidification characteristics gathered from thermal analysis and the associated microstructures observed. The microstructures were analyzed using optical microscopy and scanning electron microscopy (SEM). Furthermore, the use of high temperature laser scanning confocal microscopy (LSCM) for in-situ analysis of incipient melting is presented. An analysis on the effect of solution heat treatment temperature on properties is also discussed.

Chapter 5 provides the conclusions obtained from the experimental results.

Chapter 6 offers suggestions for future work.

The thesis outline is shown in Figure 1-1. 


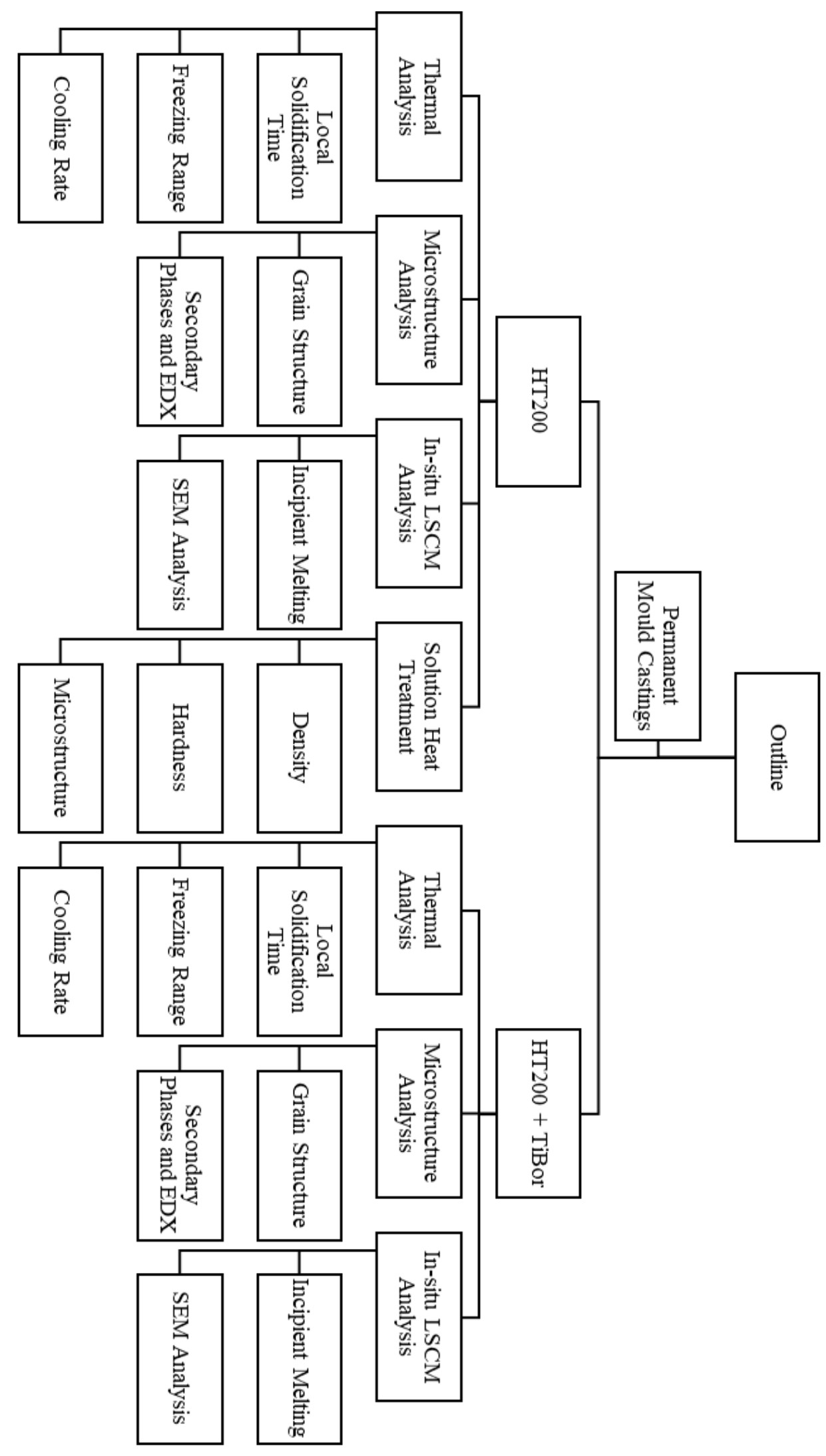

Figure 1-1: Thesis outline. 


\section{Chapter 2 Literature Review}

This chapter begins with an introduction on aluminum alloys, specifically the B206 alloy and A319 aluminum alloy and their casting characteristics. This is followed by a review on the fundamentals of alloy solidification, including a discussion on nucleation theory and dendritic solidification. The heat treatment of aluminum alloys, including solution heat treatment, quenching and age hardening is then discussed. A detailed review on the studies of incipient melting in aluminum alloys is also provided. Finally, the chapter concludes with a discussion on methods used to characterize incipient melting.

\subsection{Aluminum-copper Alloys}

Lightweighting is one of many solutions to improving the environmental impact of automotive vehicles and aircraft by reducing gas emissions. Hence, there is an increased interest in the application of aluminum alloys in the automotive and aerospace industry. One of the most commonly cast aluminum alloys in the industry are aluminum-copper ( $\mathrm{Al}-\mathrm{Cu}$ ) alloys. These alloys are used extensively for components that require high strength and toughness. The main alloying element, copper $(\mathrm{Cu})$, promotes increased strength and toughness at room and elevated temperatures. The solidification and microstructural characteristics of the B206 alloy is described in this section.

\subsubsection{B206 Alloy}

The aluminum-copper ( $\mathrm{Al}-\mathrm{Cu}$ ) alloy system is commonly used for components that require high strength and toughness. Hence, these alloys have garnered interest for application in the automotive and aerospace industries. Specifically, the B206 alloy has been recently developed and used in the industry. The B206 alloy is an $\mathrm{Al}-\mathrm{Cu}$ alloy with $\mathrm{Cu}$ concentration ranging from 4.2 to $5.0 \mathrm{wt} . \%$. The nominal composition of the alloy is presented in Table 2-1. The addition of $\mathrm{Cu}$ makes the alloy precipitation hardenable and can have enhanced properties with appropriate heat 
treatment processing. Interestingly, after heat treatment, this alloy is known to have mechanical properties that approach that of ductile iron with one third of density [5, 6]. Despite advantages in mechanical properties, during the final stages of solidification liquid metal flow is limited due to $\mathrm{Al}_{2} \mathrm{Cu}$ phases forming close to the solidus temperature [7]. As a result, the B206 alloy is highly susceptible to hot tearing. In recent studies by D'Elia et al. [7, 8], grain refinement by the addition of Ti was used to eliminate hot tearing in the B206 alloy. It was found that grain refinement effectively refined the grains and microstructure while also improving liquid metal feeding by delaying the onset of dendrite coherency.

Table 2-1: Nominal composition of B206 aluminum alloy [9].

\begin{tabular}{|c|c|c|c|c|c|c|c|c|}
\hline Element & $\mathbf{C u}$ & $\mathbf{M g}$ & $\mathbf{M n}$ & $\mathbf{F e}$ & $\mathbf{S i}$ & $\mathbf{Z n}$ & $\mathbf{T i}$ & $\mathbf{A l}$ \\
\hline Wt. \% & $4.2-5.0$ & $0.15-0.35$ & $0.2-0.5$ & 0.1 & 0.05 & 0.1 & 0.1 & $\mathrm{Bal}$ \\
\hline
\end{tabular}

The microstructure of $\mathrm{B} 206$ consists primarily of $\alpha-\mathrm{Al}$ dendrites and $\mathrm{Al}_{2} \mathrm{Cu}$ embedded with Al$\mathrm{Fe}-\mathrm{Cu}$ or $\mathrm{Al}-\mathrm{Fe}-\mathrm{Mn}$ intermetallics as studied by Lombardi et. al [10]. The $\mathrm{Al}_{2} \mathrm{Cu}$ was found to be present as both a blocky type morphology and eutectic and distributed within the interdendritic regions, as shown in Figure 2-1. The eutectic $\mathrm{Al}_{2} \mathrm{Cu}$ was observed to consist of pockets of eutectic $\mathrm{Al}$ that were surrounded by $\mathrm{Al}_{2} \mathrm{Cu}$. In previous studies, other intermetallic compounds identified included Fe-rich $\mathrm{Al}_{7} \mathrm{FeCu}$ and $\mathrm{Mn}$-bearing $\mathrm{Al}_{20} \mathrm{Mn}_{3} \mathrm{Cu}_{2}$ and $\mathrm{Al}_{2} \mathrm{Mn}_{3} \mathrm{Cu}_{2}[11,12,13]$. Additionally, Figure 2-2 shows the grain structure of B206, where it can be seen that the grains are coarse and dendritic [8]. Microstructural analysis of B206 at varying cooling rates also revealed a direct correlation between cooling rate and secondary dendrite arm spacing (SDAS). High cooling rates resulted in significant microstructural refinement in terms of SDAS [11]. The following relationship, $S D A S=C(C R)^{-n}$, was empirically formulated where $\mathrm{CR}$ is the cooling rate in $\mathrm{K} / \mathrm{s}$ and $\mathrm{C}$ and $\mathrm{n}$ are constants. Haghdad et. al [11] calculated C and $\mathrm{n}$ for B206 to be $37 \mu \mathrm{m}$ and 0.325 respectively. 

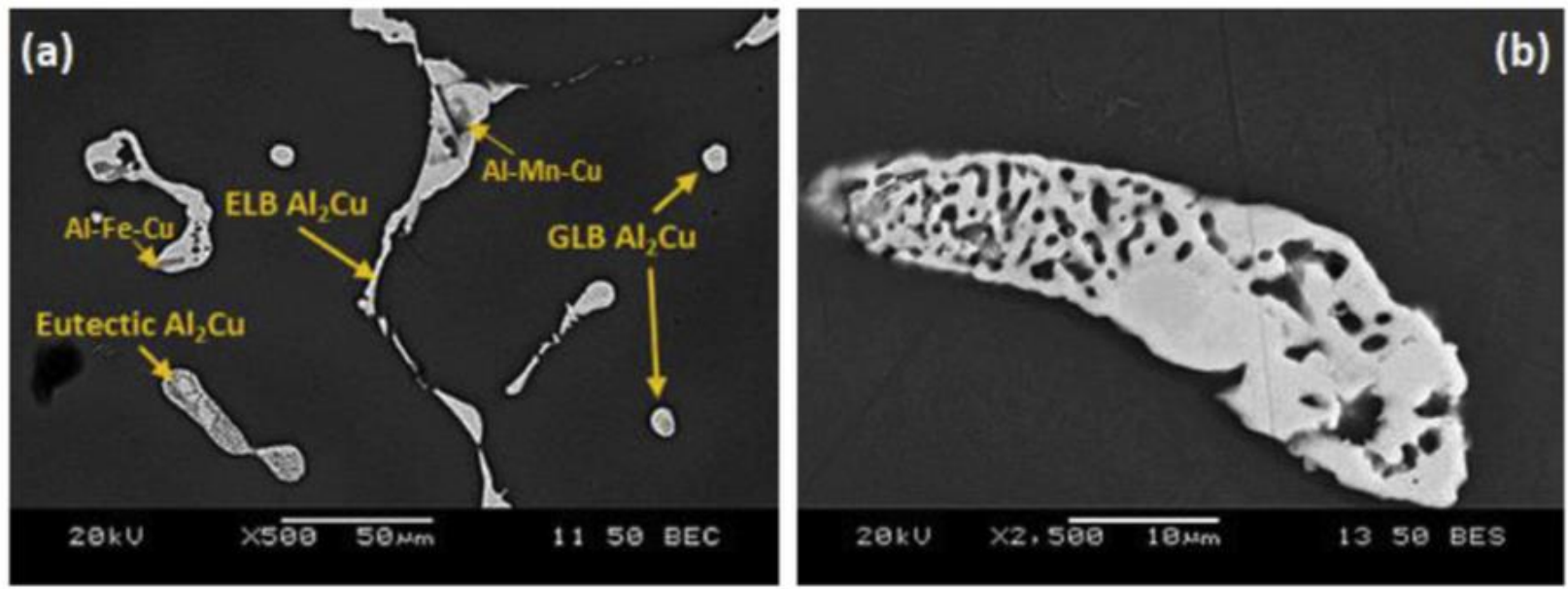

Figure 2-1: Scanning electron image of (a) B206 as-cast microstructure and (b) eutectic $\mathrm{Al}_{2} \mathrm{Cu}$ [10].

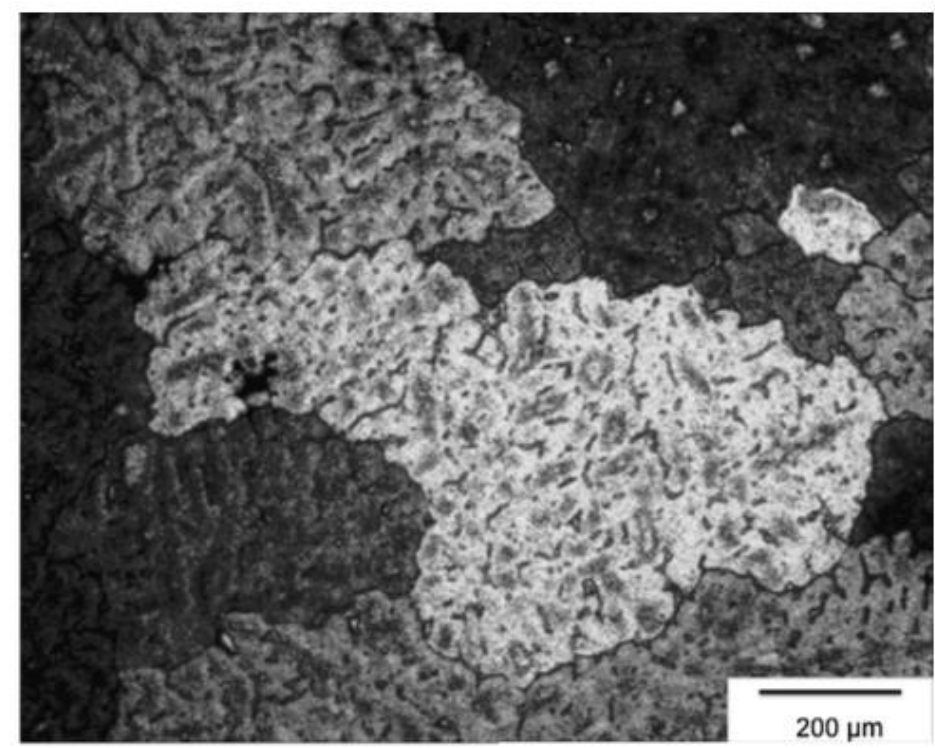

Figure 2-2: Light optical image showing grain structure of as-cast B206 alloy [8].

The solidification of B206 begins with the formation of $\alpha$-Al dendrites at approximately 649-651 ${ }^{\circ} \mathrm{C}$. Afterwards, $\mathrm{Al}_{6}(\mathrm{MnFeCu})$ intermetallic phases start to precipitate at $649{ }^{\circ} \mathrm{C}$. This is followed by a peritectic reaction and its transformation to $\mathrm{Al}_{20} \mathrm{Mn}_{3} \mathrm{Cu}_{2}$. The eutectic reaction then occurs at $537{ }^{\circ} \mathrm{C}$ where $\mathrm{Al}_{2} \mathrm{Cu}, \mathrm{Al}_{20} \mathrm{Mn}_{3} \mathrm{Cu}_{2}$ and $\mathrm{Al}_{7} \mathrm{FeCu}_{2}$ start to precipitate. The solidification sequence of B206 is summarized in Table 2-2. It should be noted that reaction 5 is only found to occur at fast cooling rates. 
Table 2-2: Phase transformation reactions during solidification of B206 alloy [14].

\begin{tabular}{|c|c|c|}
\hline Reaction No. & $\begin{array}{c}\text { Suggested } \\
\text { Temperature }\left({ }^{\circ} \mathbf{C}\right)\end{array}$ & Reactions \\
\hline 1 & 651-649 & Development of dendritic network \\
\hline 2 & 649 & $\mathrm{~L} \rightarrow \mathrm{Al}+\mathrm{Al}_{6}(\mathrm{MnFeCu})$ \\
\hline 3 & 616 & $\mathrm{~L}+\mathrm{Al}_{6}(\mathrm{MnFeCu}) \rightarrow \mathrm{Al}+\mathrm{Al}_{20} \mathrm{Mn}_{3} \mathrm{Cu}_{2}$ \\
\hline 4 & 537 & $\mathrm{~L} \rightarrow \mathrm{Al}+\mathrm{Al}_{2} \mathrm{Cu}+\mathrm{Al}_{20} \mathrm{Mn}_{3} \mathrm{Cu}_{2}+\mathrm{Al}_{7} \mathrm{FeCu}_{2}$ \\
\hline 5 & 500 & $\mathrm{~L} \rightarrow \mathrm{Al}+\mathrm{Al}_{2} \mathrm{Cu}+\mathrm{Al}_{2} \mathrm{MgCu}+\mathrm{Mg}_{2} \mathrm{Si}$ \\
\hline
\end{tabular}

The solidification sequence of B206 has also been studied using differential scanning calorimetry (DSC). Using DSC, it was found that there were three onset temperatures during the solidification of B206. The three onset transformation temperatures identified occurred at 643,557 , and $530{ }^{\circ} \mathrm{C}$ [11]. These corresponded to the liquidus temperature and nucleation of primary phase, nucleation of a $\beta$-Fe rich intermetallics, and formation of $\mathrm{Al}_{2} \mathrm{Cu}$ respectively. Additionally, the nucleation of these phases showed different trends depending on the cooling rate. When the solidification rate increased, there was a decrease in the nucleation temperatures of $\beta-\mathrm{Fe}$ and $\mathrm{Al}_{2} \mathrm{Cu}$ phase. This was also shown in the fraction of solid curves, whereby the curves were shifted to the left with increasing cooling rate.

\subsection{Solidification}

Solidification has a major influence on the material properties. This section describes the mechanisms of phase nucleation and growth. This includes a discussion on the differences in the thermodynamic phenomena between homogeneous and heterogeneous nucleation. Lastly, the kinetics for dendritic growth will be described.

\subsubsection{Nucleation Theory}

Solidification involves a sequence of phase transformations from a liquid metal to a crystalline solid structure. The transformation begins with the nucleation of very small particles, called nuclei, 
of the new phase which grow in size until the phase reaches its equilibrium fraction [15]. Nucleation is the primary process of solidification that dictates the morphology of the crystals formed. The properties of an alloy are often dependent on the conditions by which these crystals are nucleated. Nucleation theory is composed of two types: homogeneous and heterogeneous nucleation. These two phenomena are discussed in the following sections.

\subsubsection{Homogeneous Nucleation}

In homogeneous nucleation, the nucleus of a new phase develops from the bulk of the liquid melt. During this process, there is a synergistic balance between two types of energy that influence the formation of a nucleating particle. The first is known as the volume free energy $\left(\Delta G_{v}\right)$, while the other is the surface free energy. The volume free energy corresponds to the energy associated with the transformation from liquid to solid state. The surface free energy corresponds to the energy required in the formation of a surface between solid and liquid. The sum of the two described energies is the total free energy $(\Delta G)$ change of a nucleating particle, with a radius $r$. Homogeneous nucleation can occur only if sufficient number of atoms in the liquid cluster together to form a particle that will continue to grow spontaneously. Hence, this means that there must be reduction in total free energy as a result of the growth of a nucleating particle. Assuming a spherical nucleating particle, the total free energy change can be expressed by the following equation [15]:

$$
\Delta G=\frac{4}{3} \pi r^{3} \Delta G_{v}+4 \pi r^{2} \gamma
$$

Where,

$\frac{4}{3} \pi r^{3}=$ Volume of nucleating particle

$\Delta G_{v}=$ Free energy per unit volume

$4 \pi r^{2}=$ Surface area of nucleating particle

$\gamma=$ Surface free energy per unit area of the solid-liquid interface 
As illustrated in Figure 2-3, as the size of a nucleating particle increases, the volume free energy decreases whereas the surface free energy increases. Consequently, there exists a critical radius for a nucleating particle $\left(r^{\star}\right)$ such that additional growth will reduce the total free energy. Above this critical radius, the particle will become a stable nucleant and continue to grow spontaneously. However, below this size, the particle becomes unstable and will dissolve back into the liquid melt.

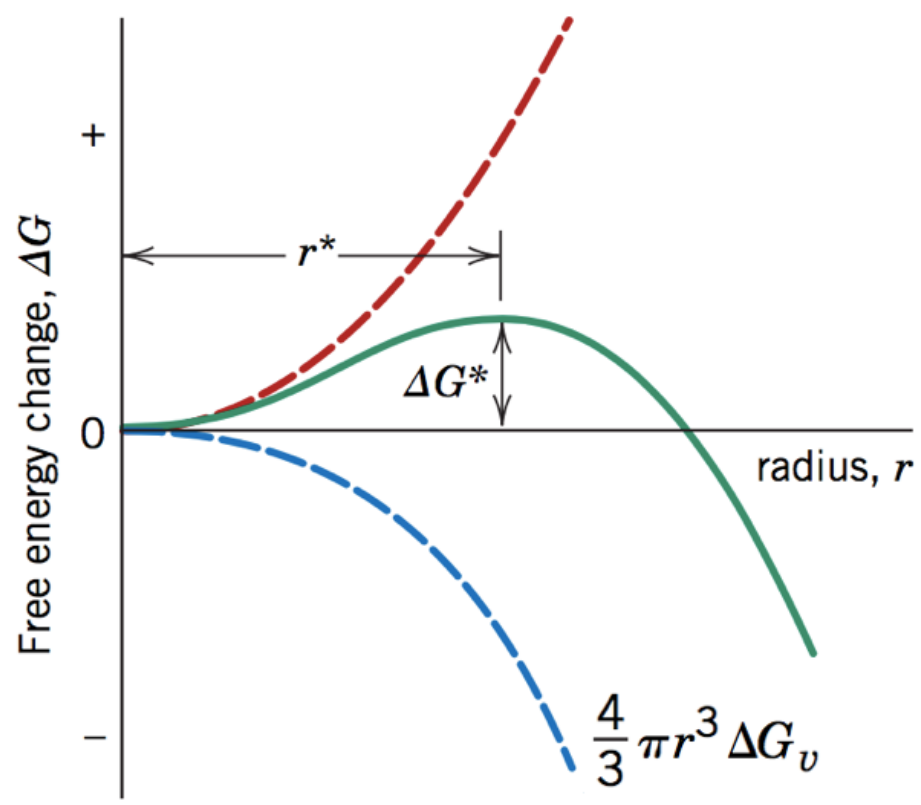

Figure 2-3: Change in free energy with formation of a particle of radius, $r$ [15].

During solidification of an alloy without the addition of innoculants, the alloy does not solidify at the equilibrium freezing temperature. In this case, undercooling of the liquid is required for nucleation to occur. This is because, the critical nucleus radius is a function of temperature. In this case, at the equilibrium freezing temperature, the critical radius for homogeneous nucleation is too large to initiate nucleation. However, as the undercooling from the equilibrium solidification temperature increases, the critical radius decreases, which improves the possibility for nucleation. As illustrated in Figure 2-4, as a liquid metal cools, it decreases in temperature below the equilibrium freezing temperature $\left(T_{\mathrm{E}}\right)$ to an undercooled nucleation temperature $\left(T_{\mathrm{N}}\right)$. Due to the growth of crystals, latent heat is continuously evolved thus promoting a rise in melt temperature, a phenomenon known as recalescence [14]. The continued growth of crystals occurs approximately at the recalescence temperature $\left(T_{\mathrm{G}}\right)$. 


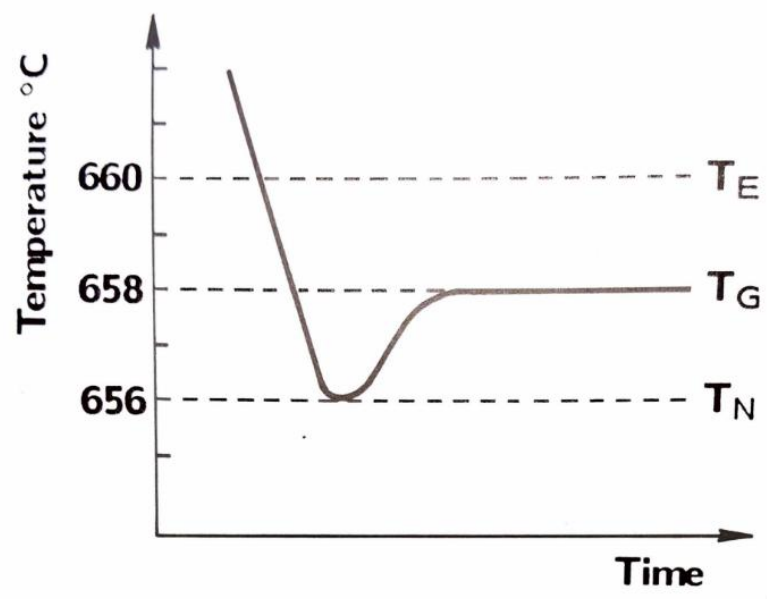

Figure 2-4: Cooling curve of typical Al alloy showing homogenous nucleation [14].

\subsubsection{Heterogeneous Nucleation}

Heterogeneous nucleation occurs because of nucleation caused by foreign substrates introduced into the melt, such as impurities, inclusions, mould walls, or alloying additions (modifiers and grain refiners). In this case, the nucleus requires fewer atoms because it is only a fragment of sphere rather than a complete sphere [16]. Additionally, the pre-existing surface reduces the surface free energy, which lowers the critical radius of the nucleus. As a result, nucleation is easily enabled and with minimal undercooling. The effectiveness of a substrate for heterogeneous nucleation is determined by the contact angle between the surface and the solid nucleus $(\theta)$. As illustrated in Figure 2-5, the contact angle is defined from the balance of surface tensions at the interfaces between the surface, solid, and liquid [15]:

$$
\gamma_{I L}=\gamma_{S I}+\gamma_{S L} \cos \theta
$$

Where,

$\gamma_{I L}=$ Liquid-surface interfacial energy

$\gamma_{S I}=$ Solid-surface interfacial energy

$\gamma_{S L}=$ Solid-liquid interfacial energy

$\theta=$ Contact angle between surface and solid nucleus 


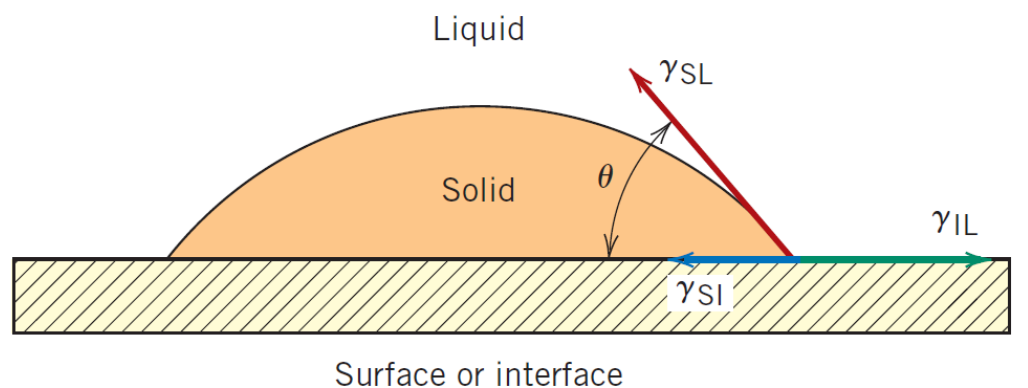

Figure 2-5: Schematic of heterogeneous nucleation of a solid from a liquid [15].

A lower contact angle indicates better wettability between the solid nucleant and the surface. Therefore, a contact angle of $0^{\circ}$ suggests complete wetting and is therefore most favourable for heterogeneous nucleation. Conversely, a contact angle of $180^{\circ}$ suggests that the nucleus is a complete sphere thereby promoting homogeneous nucleation. Lower contact angles and better wettability occurs when the substrate crystal structures and lattice parameters closely match those of the nucleating solid. As a result, this minimizes the interfacial energy between them. Inoculants are ideally selected based on this condition, and thus are added to liquid melts to promote heterogeneous nucleation, causing grain refinement. With the addition of these inoculants, minimal undercooling is obtained, therefore the growth temperature is usually lower than the nucleation temperature.

\subsubsection{Dendritic Solidification}

It is common for grains to solidify as dendrites in the casting of $\mathrm{Al}-\mathrm{Cu}$ alloys. Dendrites are characterized as long and thin spikes that grow along favourable crystallographic directions. The driving force for dendritic growth is the extent of constitutional undercooling present in the melt, wherein compositional factors affect the equilibrium solidification of the alloy [16]. During the solidification of an alloy, a solidifying primary phase rejects solute in front of the solid-liquid interface, thus forming a concentration gradient in the liquid. In this case, the liquid directly ahead of the interface is richer in solute than the liquid further ahead of the interface. As a result, a small perturbation at the interface will be in solute rich liquid with higher undercooling, thus causing the expansion and formation of a dendrite. The dendrite forms in order to displace solute away from the solidifying interface, which reduces the concentration gradient. As illustrated in Figure 2-6, 
dendrites can be characterized by its primary dendrite arm spacing $\left(\lambda_{1}\right)$ and secondary dendrite arm spacing $\left(\lambda_{2}\right)$. The secondary dendrite arm spacing (SDAS) can be measured using the

following equation, $\lambda_{2}=\frac{L}{n-1}$, as seen in the figure below. In addition to these parameters, the dendrite tip radius and mushy zone depth can also be used to determine a relationship with the solidification characteristics of an alloy [17].

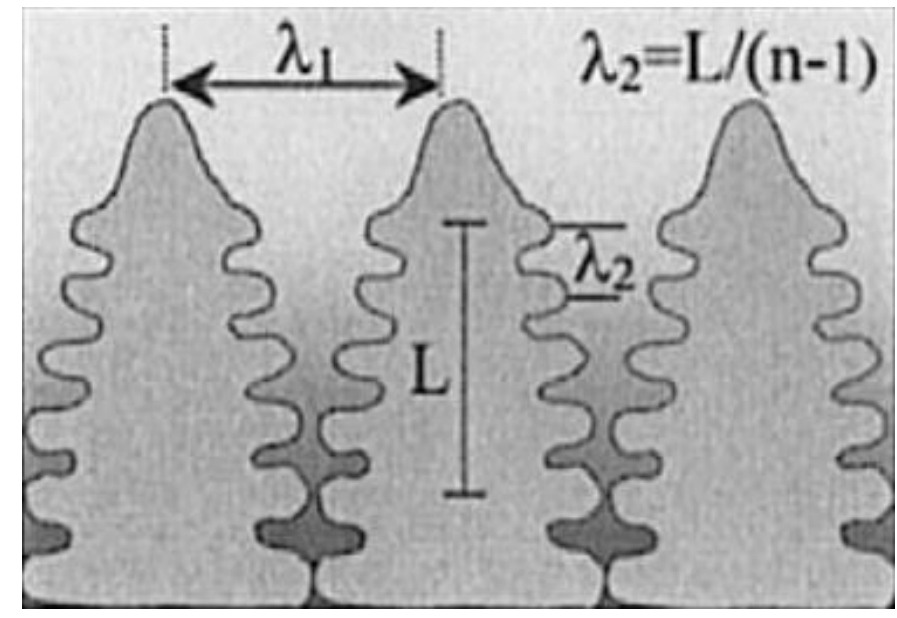

Figure 2-6: Schematic of dendrites [17].

\subsection{Heat Treatment of Aluminum Alloys}

Once $\mathrm{Al}$ alloys are cast, depending on their application, the mechanical properties of the as-cast condition usually need further improvement to meet certain design requirements. A commonly used process for improving mechanical properties is through heat treatment. This is especially effective for precipitation hardenable alloys such as $\mathrm{Al}$ alloys containing $\mathrm{Cu}$. In this section, a review of the main steps in heat treatment will be discussed. This includes solution heat treatment, quenching and age hardening. A detailed review of incipient melting of secondary phases in Al alloys is also discussed. 


\subsubsection{Solution Heat Treatment}

The purpose of a solution heat treatment (SHT) is to dissolve soluble phases, such as $\mathrm{Al}_{2} \mathrm{Cu}$, and achieve a single phase solid solution. Additionally, in Al-Si alloys, this process also spheroidize eutectic Si microstructure. In order to achieve a single phase, the temperature that solution heat treatment must be carried out at is relatively high, close to the eutectic temperature. Maximizing the dissolution of phases is important in the final process of strengthening by ageing, because there must be sufficient amount of solute phases available for precipitation to occur [18]. Thus, a high temperature must be used to reach the single-phase region. This must also be done in the shortest amount of time; as economics is also an important parameter in the industry. The phases that form during solidification in the as-cast condition are important, since these phases play a role in the solution heat treatment process. Certain phases are more soluble than other phases, such as the $\theta$ $\mathrm{Al}_{2} \mathrm{Cu}$ and $\beta-\mathrm{Mg}_{2} \mathrm{Si}$. However, not all phases are soluble in $\mathrm{Al}$ alloys such as 319; for example, the $\mathrm{Q}-\mathrm{Al}_{5} \mathrm{Cu}_{2} \mathrm{Mg}_{8} \mathrm{Si}_{6}$ phase. Additionally, phases that contain $\mathrm{Fe}$ are difficult to dissolve and are unstable at high temperatures [19].

Moreover, it is known that in $\mathrm{Al}-\mathrm{Cu}$ or $\mathrm{Al}-\mathrm{Si}-\mathrm{Cu}$ cast alloys, the $\mathrm{Al}_{2} \mathrm{Cu}$ phase can be present in the as-cast state in different morphologies. High solidification rates typically produce eutectic $\mathrm{Al}_{2} \mathrm{Cu}$ phase, while in the case of Al-Si-Cu alloys, $\mathrm{Sr}$ modification results in formation of blocky $\mathrm{Al}_{2} \mathrm{Cu}$. The type of $\mathrm{Al}_{2} \mathrm{Cu}$ formed is important in solution heat treatment, because the eutectic morphology is easier to dissolve compared to the blocky shaped $\mathrm{Al}_{2} \mathrm{Cu}$. Han et al. [20] investigated the dissolution process of eutectic and blocky $\mathrm{Al}_{2} \mathrm{Cu}$, as seen in Figure 2-7, and determined that the amount of $\mathrm{Cu}$ dissolved in $\mathrm{Al}$ can be maximized by increasing the solution heat treatment temperature solutionizing time [20]. Eutectic $\mathrm{Al}_{2} \mathrm{Cu}$ is the preferred microstructure in the as-cast condition, as dissolution by fragmentation is more easily attainable compared to a gradual dissolution of blocky $\mathrm{Al}_{2} \mathrm{Cu}$ phases, which in turn increases SHT time [19]. 

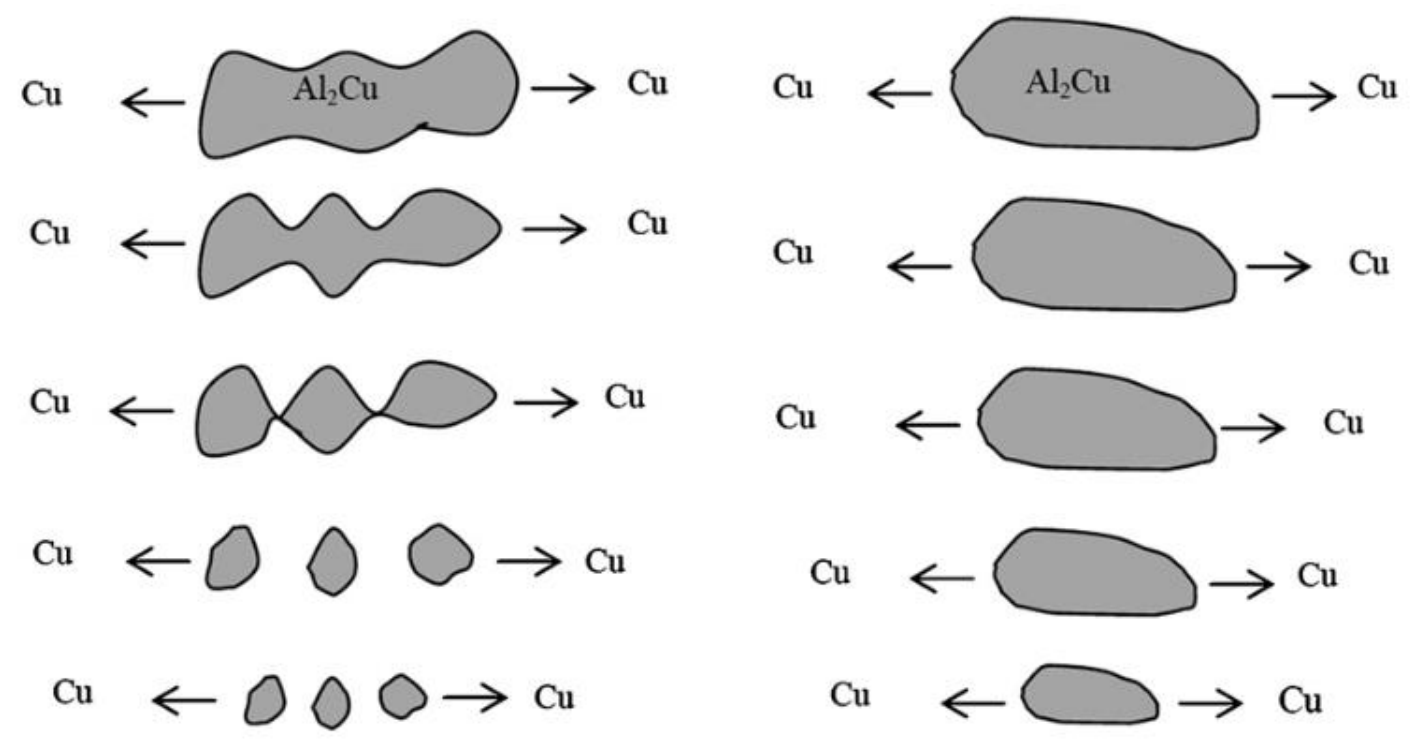

Figure 2-7: Dissolution process of eutectic $\mathrm{Al}_{2} \mathrm{Cu}$ (left) and blocky $\mathrm{Al}_{2} \mathrm{Cu}$ (right) as described by Han et al. 2008 [20].

The solution heat treatment process is an important parameter when trying to improve the mechanical properties of an alloy such as A319 alloy. Lombardi et al. [19] performed a study to optimize the solution treatment step for A319 engine blocks using billet castings. The use of billet castings provided a precise and economic replication of an engine block casting at the cylinder bridge. It was found that, $500{ }^{\circ} \mathrm{C} \mathrm{SHT}$ temperature resulted in optimal dissolution of eutectic $\mathrm{Al}_{2} \mathrm{Cu}$ phase by fragmentation $[18,19]$. Furthermore, longer SHT times ( $8 \mathrm{hrs}$.) significantly reduced the volume fraction of $\mathrm{Al}_{2} \mathrm{Cu}$ dissolved up to $70 \%$ after solution heat treatment. Lastly, $500{ }^{\circ} \mathrm{C} \mathrm{SHT}$ temperature for $2 \mathrm{hrs}$. was found to optimize strength while reducing production time [18]. However, a limiting parameter known as incipient melting is an important factor to consider during solution heat treatment due to its negative impact on the alloy mechanical integrity.

\subsubsection{Incipient Melting}

Incipient melting is the localized melting of secondary phases along the grain boundaries. It is well known that the solution heat treatment temperature is limited by incipient melting. Excessive temperatures, in an attempt to dissolve all amenable phases, are likely to cause melting of secondary phases such as $\mathrm{Al}_{2} \mathrm{Cu}$. This is detrimental to the mechanical properties of the alloy. Han 
et al. [20] found that undissolved $\mathrm{Al}_{2} \mathrm{Cu}$ melts at temperatures of $520{ }^{\circ} \mathrm{C}$, when performing a solution heat treatment on $319 \mathrm{Al}$. This is also in agreement with the work done by Lombardi et al. $[18,19]$, as incipient melting occurred between SHT temperatures of $515-530{ }^{\circ} \mathrm{C}$. However, additional work using DSC analysis showed that the melting of the $\mathrm{Al}_{2} \mathrm{Cu}$ phase began at approximately $507^{\circ} \mathrm{C}$, where the melting process continued up to $525^{\circ} \mathrm{C}$ [19]. Studies also showed that there is a correlation between the occurrence of incipient melting and the formation of porosity in Al-Si-Cu-Mg cast alloys [21, 22]. With increasing SHT temperature, the percentage porosity increased by approximately $1.5 \%$, while the average pore size was also found to increase [21]. Thus, the increase in porosity further supports past data that increase in SHT temperature reduces the tensile strength. This relationship is illustrated below in Figure 2-8. Incipient melting in Al alloys has also been found to be dependent on the alloy composition. For example, Samuel [23] showed that an Al-Si-Cu alloy containing $\sim 0.04 \mathrm{wt} \% \mathrm{Mg}$ resulted in incipient melting of eutectic $\mathrm{Al}_{2} \mathrm{Cu}$ at $\sim 540{ }^{\circ} \mathrm{C}$. However, increasing the magnesium content to $\sim 0.5 \mathrm{wt} \%$ in the alloy lead to the incipient melting of $\mathrm{Al}_{5} \mathrm{Mg}_{8} \mathrm{Si}_{6} \mathrm{Cu}_{2}$ at $505{ }^{\circ} \mathrm{C}$, which is a significant decrease compared to the Al-Si-Cu alloy with lower $\mathrm{Mg}$ content [23]. The incipient melting of the secondary phases was also found to occur along the grain boundaries and interdendritic regions (Figure 2-9). As a result, when samples were solution heat treated above the incipient melting temperature, fracture surfaces showed large voids and massive conglomerated areas of eutectic $\mathrm{Al}_{2} \mathrm{Cu}$ [23]. The fracture mechanism was by fragmentation of $\mathrm{Al}_{5} \mathrm{Mg}_{8} \mathrm{Si}_{6} \mathrm{Cu}_{2}$ and $\mathrm{Al}_{2} \mathrm{Cu}$.

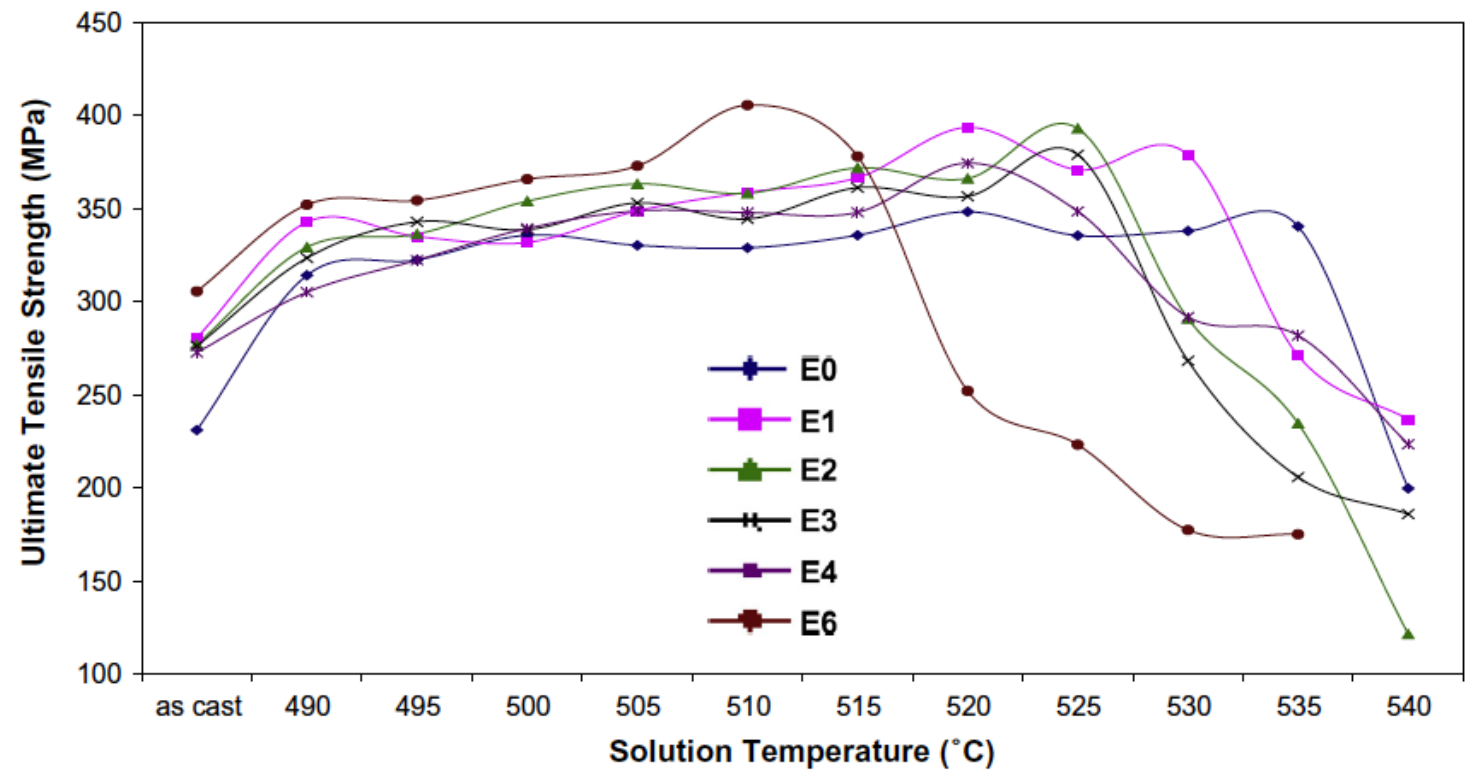

Figure 2-8: Experimental data relating UTS to SHT temperature by Samuel et. al [21]. 

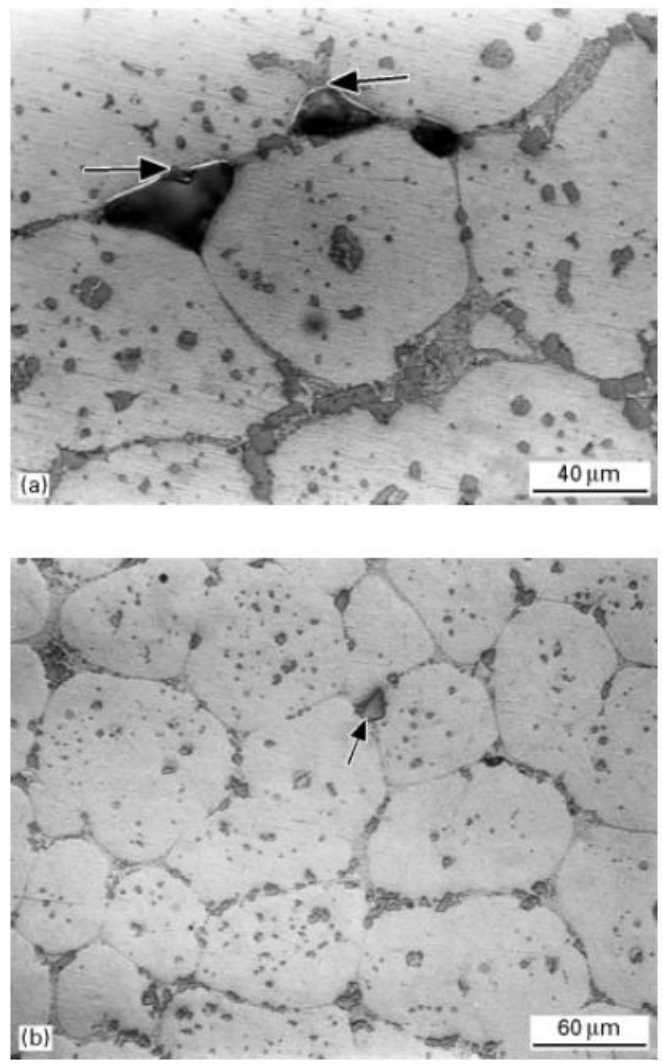

Figure 2-9: Incipient melting of $\mathrm{Al}_{2} \mathrm{Cu}$ at the grain boundaries for samples solution heat treated at $505{ }^{\circ} \mathrm{C}[23]$.

Previous studies on the incipient melting of secondary phases typically involved the use of SEM and DSC on solution heat treated samples to characterize incipient melting. However, this resulted usually in the analysis of incipient melting after the phase transformation had occurred, as illustrated in Figure 2-9. This did not provide a full understanding of the mechanisms of incipient melting. Recently, high temperature LSCM was used to carry out an in-situ analysis of incipient melting in B206 and A319 aluminum alloys [10, 24]. In-situ observations on B206 revealed interfacial pre-melting at the interface of the $\mathrm{Al}$ and $\mathrm{Al}_{2} \mathrm{Cu}$, where a rapid propagation of a liquid film was observed at the eutectic $\mathrm{Al}_{2} \mathrm{Cu}$ particles. The melting process began at approximately 530 ${ }^{\circ} \mathrm{C}$, followed by continued expansion of the phases and complete melting at $540{ }^{\circ} \mathrm{C}$. Melting of blocky $\mathrm{Al}_{2} \mathrm{Cu}$ particles had a slower film propagation rate $(\sim 0.2 \mu \mathrm{m} / \mathrm{s})$ compared to the eutectic phase $(\sim 1.2 \mu \mathrm{m} / \mathrm{s})$. It was suggested that the eutectic $\mathrm{Al}_{2} \mathrm{Cu}$ had higher interfacial energy due to its morphology, thus resulting in the more rapid film propagation during melting [10]. It was also 
found that incipient melting resulted in oxidation and the presence of $\mathrm{Al}-\mathrm{Mg}-\mathrm{O}$ type oxides across the sample surface. Figure 2-10 shows the melting of $\mathrm{Al}_{2} \mathrm{Cu}$ in the $\mathrm{B} 206$ alloy.

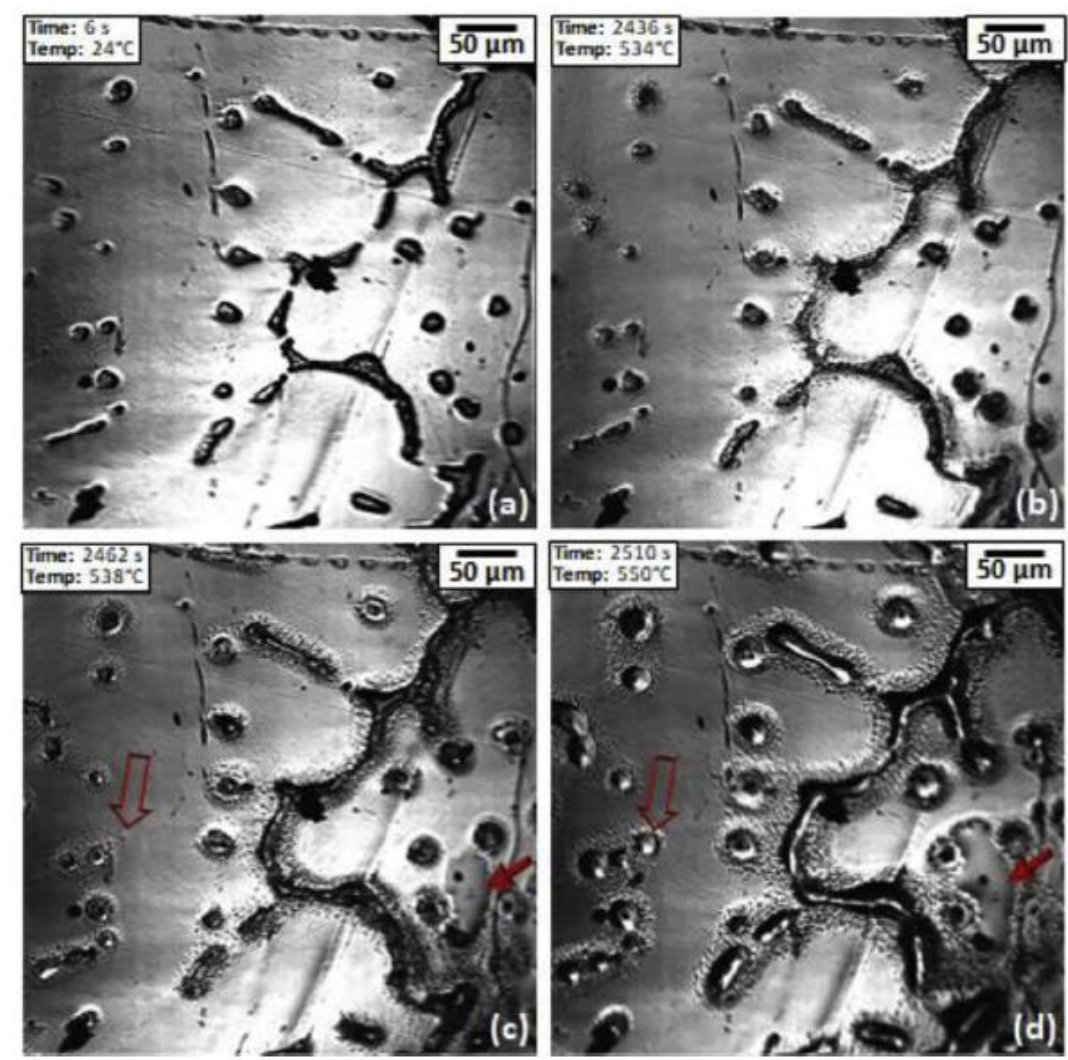

Figure 2-10: LSCM micrographs showing melting of $\mathrm{Al}_{2} \mathrm{Cu}$ at 100x [10].

Additionally, incipient melting was well observed in the A319 alloy using LSCM. The results from the LSCM showed the incipient melting of $\mathrm{Al}-\mathrm{Al}_{2} \mathrm{Cu}-\mathrm{Al}_{5} \mathrm{Mg}_{8} \mathrm{Cu}_{2} \mathrm{Si}_{6}$ ternary eutectic phases [24]. The melting temperature was found to range from 484 to $518^{\circ} \mathrm{C}$. The melting mechanism was described to have three stages of melting. First, there was an initial melting of the eutectic $\mathrm{Al}$ and the formation of a thin film. This was followed by the rapid propagation of an $\mathrm{Al}$ rich liquid film from the clusters of $\mathrm{Al}-\mathrm{Al}_{2} \mathrm{Cu}-\mathrm{Al}_{5} \mathrm{Mg}_{8} \mathrm{Cu}_{2} \mathrm{Si}_{6}$ ternary eutectic. Lastly, the complete melting of the secondary phase was the final stage [24]. Furthermore, the heating rate was varied, at $10^{\circ} \mathrm{C} / \mathrm{min}$ and $100{ }^{\circ} \mathrm{C} / \mathrm{min}$, between the 400 to $500{ }^{\circ} \mathrm{C}$ range during experiments, which resulted in an increased film propagation rate with increasing heating rate. The melting of the $\mathrm{Al}_{-} \mathrm{Al}_{2} \mathrm{Cu}-$ $\mathrm{Al}_{5} \mathrm{Mg}_{8} \mathrm{Cu}_{2} \mathrm{Si}_{6}$ ternary eutectic can be seen in Figure 2-11. 


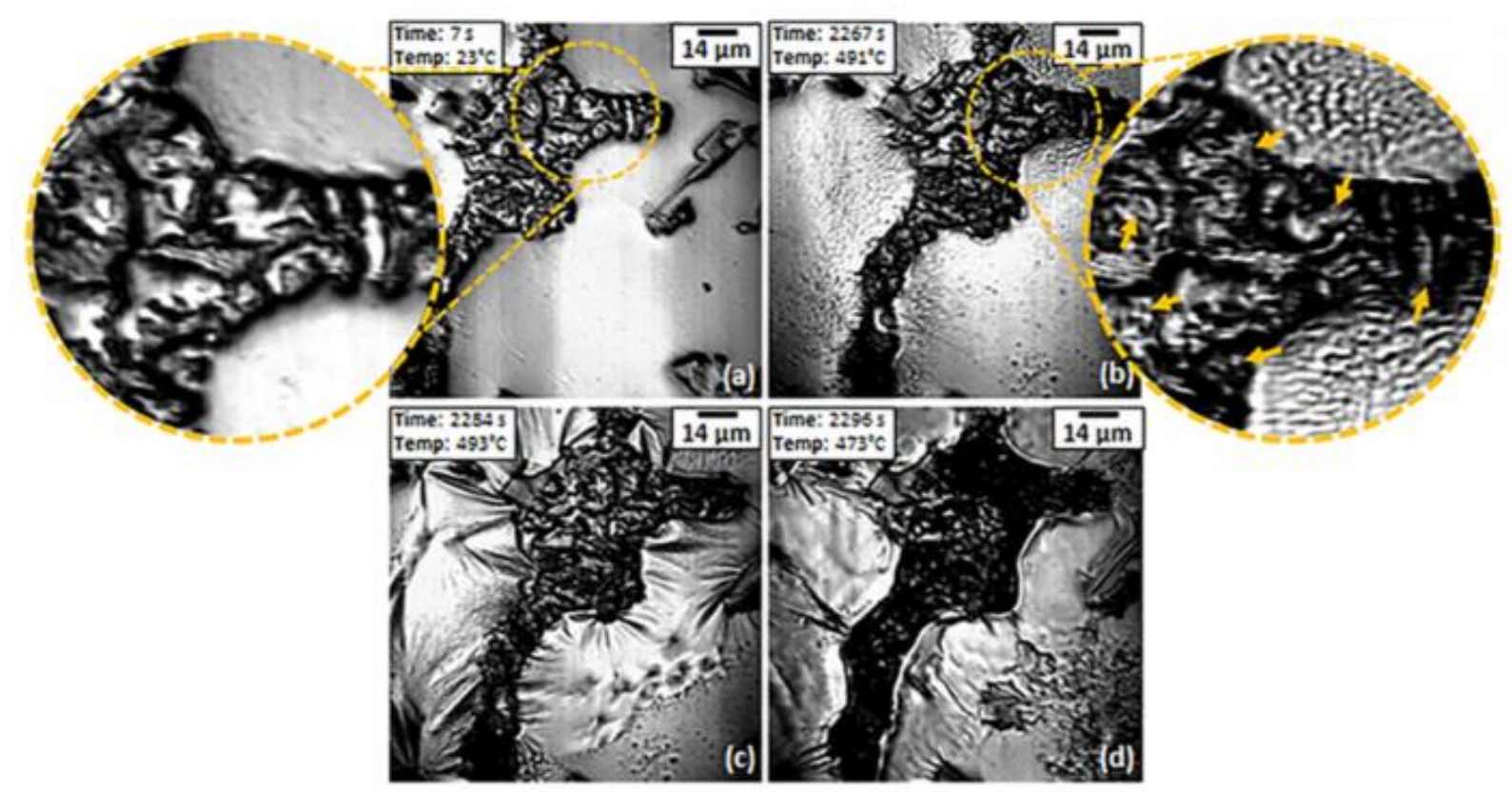

Figure 2-11: LSCM micrographs at 350x magnification showing melting of $\mathrm{Al}-\mathrm{Al}_{2} \mathrm{Cu}-\mathrm{Al}_{5} \mathrm{Mg}_{8} \mathrm{Cu}_{2} \mathrm{Si}_{6}$ ternary eutectic [24].

With the development of new casting technology, shorter solution heat treatment times are possible. Casting is typically done through conventional liquid and solid processing. A new technology known as semi-solid forming has given the automotive industry the potential to cast automotive components with good surface finish, almost zero porosity, while doing so in a shorter production time [25]. Menargues et al. [25] conducted a study optimizing the solution heat treatment temperature and time after semi-solid casting, rather than a conventional permanent mould casting. The heat treatment response to the new casting technique differed that of conventional casting techniques. The study was performed on A356/357 Al alloys, where it was determined that a solution heat treatment can be carried out at $540{ }^{\circ} \mathrm{C}$ [25]. This was found to ensure maximum dissolution of $\mathrm{Mg}_{2} \mathrm{Si}$ phases. However, a more interesting finding was that the solution heat treatment time was significantly shorter than other heat treatments carried out after conventional casting methods. The complete dissolution of $\mathrm{Mg}_{2} \mathrm{Si}$ occurred after 10 minutes., and the globulization of eutectic Si occurred after 5 minutes. Thus, it was determined that a new shorter heat treatment schedule is possible after semi-solid casting, where hardness was found to be optimal at SHT temperature of $540{ }^{\circ} \mathrm{C}$ at a time of 15 minutes [25]. However, it was found that at 
any time during SHT and artificial aging up to $8 \mathrm{hrs}$, at temperatures of $160{ }^{\circ} \mathrm{C}$ and $170{ }^{\circ} \mathrm{C}$, the hardness values are lower. Thus, increased time is required to improve the hardness value [25].

Solution heat treatment is an important step in the heat treatment of Al-Si based cast alloys. This step is important in achieving optimal strength for specific engineering applications. Various work has been done by researchers to determine the optimal conditions of the SHT step (i.e. temperature and time). SHT is vital in the ageing process as enough soluble phases must be dissolved into the matrix to ensure an ample amount of precipitates is produced. Furthermore, this must be done without inducing incipient melting, which is detrimental to the mechanical properties of the alloy. Optimization of this step ensures a more efficient and effective quenching and age hardening process.

\subsubsection{Quenching}

The purpose of quenching is to obtain a supersaturated solid solution (SSSS). In the case of Al-Si$\mathrm{Cu}$ or Al-Si-Mg based cast alloys, quenching obtains a supersaturated solid solution of $\mathrm{Al}_{2} \mathrm{Cu}$ or $\mathrm{Mg}_{2} \mathrm{Si}$ phases. Quenching suppresses the precipitation of solutes and vacancies, upon cooling after solution heat treatment at high temperatures [26]. Higher quench rates allow for a sufficient quantity of solutes to be retained. However, if the quench rate is too slow, precipitation of particles occurs due to diffusion. Thus, the strength is significantly decreased after ageing, because not enough fine precipitates will form during the process [26]. These precipitates play a role in hindering movement of dislocations during plastic deformation. Water is typically used as a quenching medium due to its accessibility and low cost. However, an issue with fast cooling is it induces thermal stresses in the casting. Slower cooling rates usually require the use of a medium such as oil [26].

There have been studies regarding the effect of quench sensitivity of an alloy on the strength after ageing. Additionally, different elements such as $\mathrm{Cu}$ and $\mathrm{Mg}$ play a role in the quenching of $\mathrm{Al}-\mathrm{Si}$ $\mathrm{Mg}$ alloys. Tzeng et al. [27] investigated the effect of Sc on the quench sensitivity of an Al-Si-Mg

alloy, wherein the Jominy end quench method was used to demonstrate these effects. It was found that rapid quench rates produce higher supersaturated solution solute in the Al matrix, which is in 
line with past works [27]. This resulted in an improvement in the age hardening behaviour of the alloy (Figure 2-12). A quench rate of $160{ }^{\circ} \mathrm{C} / \mathrm{s}$ resulted in the formation $\beta "-\mathrm{Mg}_{2} \mathrm{Si}$ phases which have needle like morphology and were small in size (3-4 $\mathrm{nm}$ in diameter). The fast quench rate minimized the time for solid state diffusion and precipitation of the solute phases [26, 27]. Conversely, at slower quench rates $\left(2.5^{\circ} \mathrm{C} / \mathrm{s}\right)$ coarse $\beta^{\prime}-\mathrm{Mg}_{2} \mathrm{Si}$ phases precipitated out of solution. This had a negative effect on the mechanical properties after age hardening, because of the large and coarse phases that are less effective in hindering dislocation motion during plastic deformation. Lastly, the addition of Sc reduced the quench sensitivity of the alloy and produced $\mathrm{Al}_{3} \mathrm{Sc}$ phase at slow quench rates, which was found to be important in hindering recrystallization at high temperatures [27]. The mechanism behind this phenomenon was found to be the trapping of vacancies available for $\mathrm{Mg}$ diffusion.

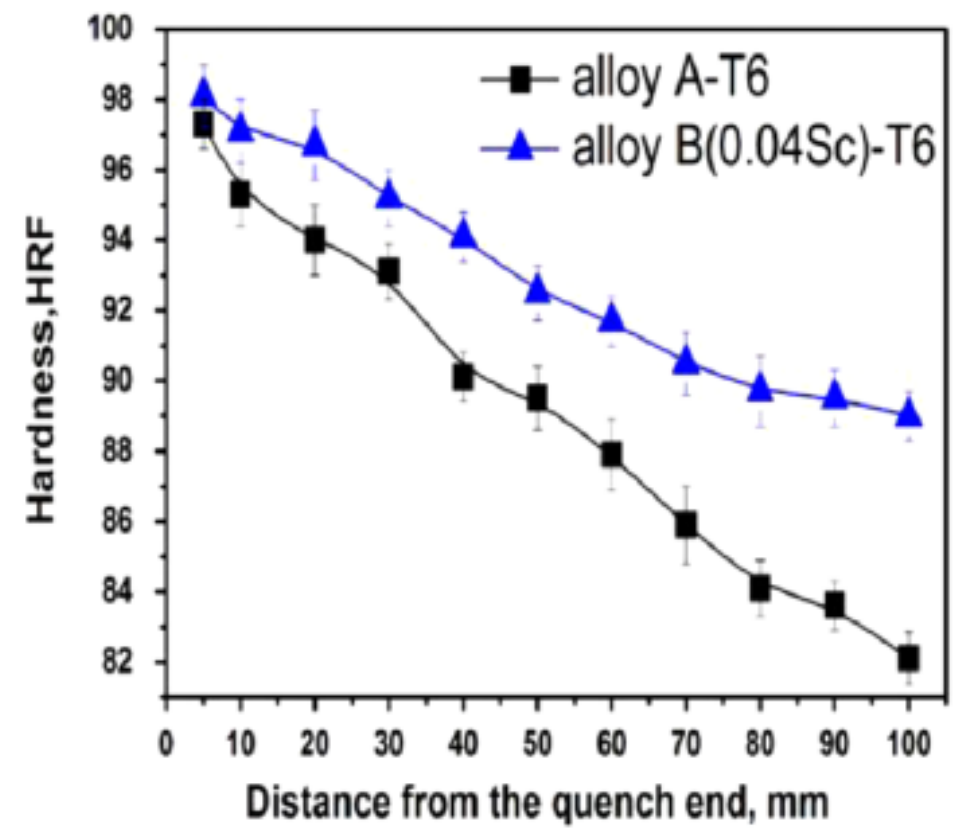

Figure 2-12: Hardness values for Jominy sample aged at $160^{\circ} \mathrm{C}$ for 6 hrs. [27].

A more recent study by Chaudhury [26], investigated the effects of $\mathrm{Cu}$ and $\mathrm{Mg}$ on the quench sensitivity of Al-Si-Mg alloy. This study confirmed past studies stating that increased $\mathrm{Mg}$ content, increases the quench sensitivity of $\mathrm{Al}-\mathrm{Si}-\mathrm{Mg}$ alloys. The quench factor of $\mathrm{Al}-\mathrm{Si}-\mathrm{Cu}-\mathrm{Mg}$ casting alloys was found to increase with higher $\mathrm{Mg}$ content. The results showed that a $\mathrm{Mg}$ content of 0.57 
wt.\% resulted in a quench factor of approximately 145, compared to 34.8 for $0.35 \mathrm{wt} . \% \mathrm{Mg}$ and and 34.8 for $0.45 \mathrm{wt} \% \mathrm{Mg}$ [25]. However, the addition of $0.8 \mathrm{wt} \% \mathrm{Cu}$ decreased the quench sensitivity of the alloy [26]. Hence, in order to increase the age hardening ability of the alloy, the ageing time must be a minimum of $20 \mathrm{hrs}$. to compensate for the reduction in quench sensitivity of the alloy.

After dissolving amenable phases during SHT, careful control of quenching can result in superior properties due to its direct relation to the age hardening process. The recent works found showed that the quench sensitivity of an alloy is important for the age hardening process of that alloy to achieve maximum strength. This is dependent on the amount of alloying elements present, such as $\mathrm{Cu}$ and $\mathrm{Mg}$. $\mathrm{Cu}$ and $\mathrm{Mg}$ containing phases usually form as precipitates during aging of the alloy. The fine dispersion of precipitates after aging act as obstacles for mobile dislocations, thus improving the strength of the alloy. Age hardening will be discussed in the following section.

\subsubsection{Age Hardening}

The final process of the heat treatment of $\mathrm{Al}$ alloys is age hardening, or precipitation hardening. When ageing is performed at room temperature, it is known as natural ageing. While ageing at elevated temperatures $\left(\sim 150-210{ }^{\circ} \mathrm{C}\right)$ is termed artificial ageing. The objective of ageing is to produce a finely dispersed distribution of precipitates, which plays an important role in the strengthening mechanisms of the alloy.

\subsubsection{Ageing}

The ageing process causes many stages of intermediate metastable phases to precipitate from the supersaturated solid solution (SSSS) rather than the direct precipitation of the equilibrium phase. The main reason for this is that metastable phases have lower strain energy due to the coherent or semi-coherent interface with the matrix. The preferential formation of metastable phases occurs to

minimize free energy. Therefore, the lower strain energy allows metastable phases to precipitate prior to the incoherent equilibrium phases [28]. In the aging of Al-Cu alloys, the supersaturated 
solid solution is followed by three metastable secondary phases prior to the formation of the equilibrium $\theta-\mathrm{Al}_{2} \mathrm{Cu}$.

Due to the supersaturation caused by rapid quenching, meaning a high retention of solutes and vacancies, over time Guiner Preston (GP) zones form. GP zones are clusters containing solute atoms, that are finely dispersed over the $\mathrm{Al}$ matrix [29, 30]. In Al-Cu alloys, GP zones are clusters of copper atoms that form thin plates along the $\{100\}$ planes of the face center cubic (FCC) aluminum lattice. These zones are typically one or two atoms thick, approximately 25 atoms in diameter and coherent with the aluminum matrix [15, 28, 31]. Diffusion is limited at room temperature, thus allowing for the atoms to precipitate out of solution. GP zones create a lattice distortion and stress field due to the difference in size between solute and solvent atoms [29]. This distortion and stress field hinder dislocation motion, thus improving the strength of the alloy. It has been found that $\mathrm{Al}-\mathrm{Si}$ alloys containing $\mathrm{Mg}$ are highly susceptible to natural ageing, where a response can be observed within $1 \mathrm{hr}$ [30]. Both the alloying addition of $\mathrm{Mg}$ and $\mathrm{Cu}$ are known to promote the ageing response of $\mathrm{Al}$ alloys. With respect to artificial ageing, the mechanisms are similar, however the process occurs at elevated temperatures. At higher temperatures, diffusion rates are higher and thus atoms can move over larger distances [29]. In turn, the precipitates formed are also significantly larger than GP zones formed during natural ageing.

Following the formation of GP zones, continued ageing results in the precipitation of the $\theta$ " phase. The $\theta$ " phase, which has a platelet morphology, consists of alternating layers of aluminum and copper atoms along the $\{100\}$ planes. The $\theta$ " phase replaces GP zones in the microstructure provided sufficient ageing has been performed on the alloy [28]. The replacement of the GP zones with $\theta$ " is due to diffusion induced movement of atoms with time. Growth of $\theta$ " occurs to a thickness of approximately 2-3 nm and a diameter of 10-20 nm, which is significantly larger than GP zones [28]. Similar to the GP zones, the $\theta$ " phase is coherent with the aluminum matrix. The formation of $\theta$ " precipitates indicate that the peak aging condition has been achieved, which coincides with maximum strength. Overageing results in the formation of $\theta^{\prime}$ and $\theta$ phases, which lead to a reduction in strength. The age hardening process is typically designed with the aim of achieving maximum strength and hardness, although this is accompanied by a decrease in ductility. 


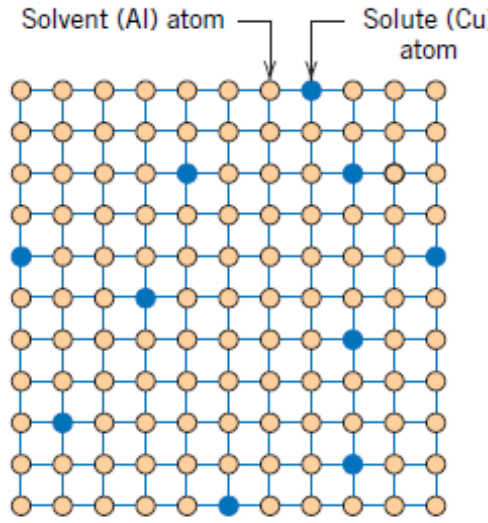

(a)

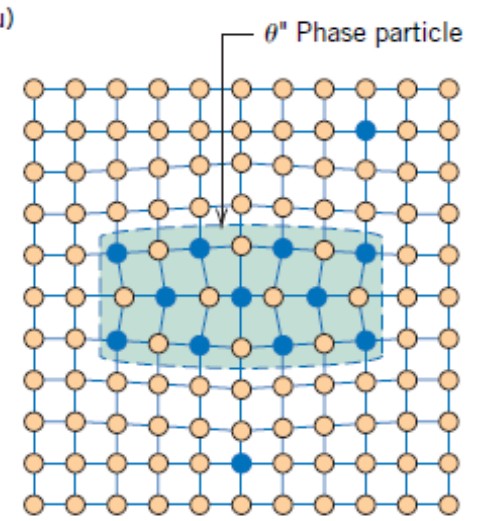

(b)

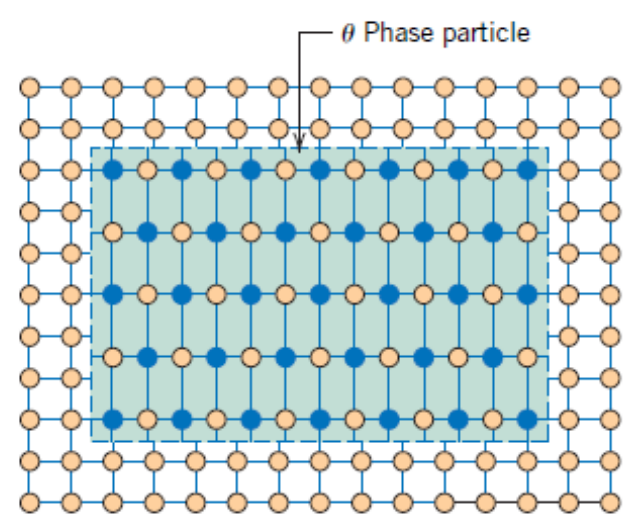

(c)

Figure 2-13: Schematic representation of the stages of the formation of the $\theta$ phase [15].

\subsubsection{Mechanisms of Hardening}

A material's ability to stop dislocation motion plays a major role in the mechanisms of hardening. Dislocations are linear crystalline defects present in crystalline solids that are responsible for plastic deformation. The size, distribution and coherency of precipitates within the Al matrix, formed during ageing determine the strength of the alloy [29]. A fine dispersion of precipitates increases the strength of the alloy, because there are many particles that obstruct mobile dislocations. However, if the particles are soft, it is easy for dislocations to shear through them; this is known as the Friedel effect [29, 32]. If the precipitates are large and harder, dislocations bypass the particles by bowing, known as the Orowan effect [29, 32]. However, if particles are too large, bypass bowing makes it easy for dislocations to overcome the obstruction of precipitates (Figure 2-14). Consequently, the strength is significantly decreased. There must be a balance between the shearing mechanism and bowing mechanism to achieve optimal strength by dispersion hardening [29]. Thus, dislocation theory is an important concept in the understanding of how age hardening of Al-Si-Cu-Mg alloys is used to improve the strength of the alloy. This will be furtherer discussed in the following section. 


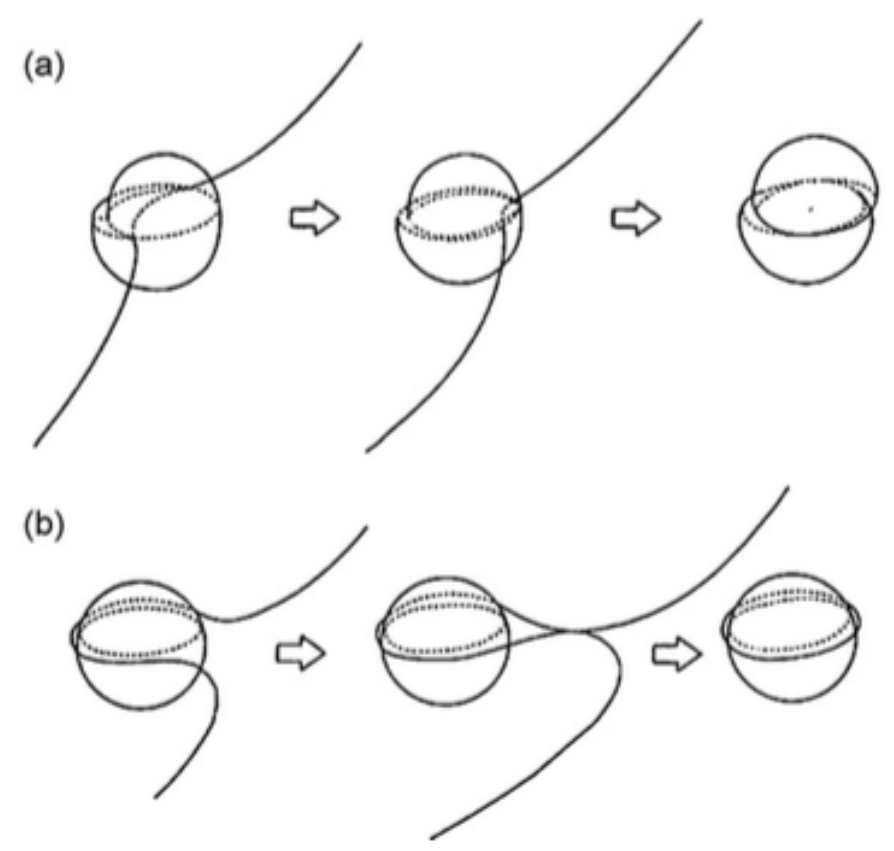

Figure 2-14: Mechanism of hardening; dislocation (a) shearing through particle and (b) bypassing by bowing [32].

\subsubsection{Effect of Ageing on Mechanical Properties}

Various works have been done on ageing of $\mathrm{Al}$ alloys due to their excellent aging response. Alloying elements such as $\mathrm{Cu}$ are added to $\mathrm{Al}$ for solid solution strengthening and subsequent age hardening. Furthermore, the addition of $\mathrm{Mg}$ has been known to improve the ageing capability of the alloy. It has been found that different types of precipitates form in $\mathrm{Al}-\mathrm{Si}-\mathrm{Cu}-\mathrm{Mg}$ alloys. Age hardening precipitates formed in these types of alloys include Q"- $\mathrm{Al}_{5} \mathrm{Mg}_{8} \mathrm{Si}_{6} \mathrm{Cu}_{2}, \theta^{\prime}-\mathrm{Al}_{2} \mathrm{Cu}$, and $\beta "-\mathrm{Mg}_{2} \mathrm{Si}$. These precipitates play an important role in the strengthening of the alloy, as they impede dislocation motion. Sjolander and Seifeddine [33] performed an extensive study comparing the ageing behaviour of $\mathrm{Al}-\mathrm{Si}-\mathrm{Mg}, \mathrm{Al}-\mathrm{Si}-\mathrm{Cu}$, and $\mathrm{Al}-\mathrm{Si}-\mathrm{Cu}-\mathrm{Mg}$ alloys. The yield strength values over varying ageing times at $170{ }^{\circ} \mathrm{C}$ and $210^{\circ} \mathrm{C}$ can be seen in Figure 2-15. It was found that with increasing ageing time, the strength also increases. However, it reaches a maximum strength (peak aged), and eventually the strength begins to decrease with further increased time (over-aged). The results were found to be similar for the ultimate tensile strength of the alloy. 

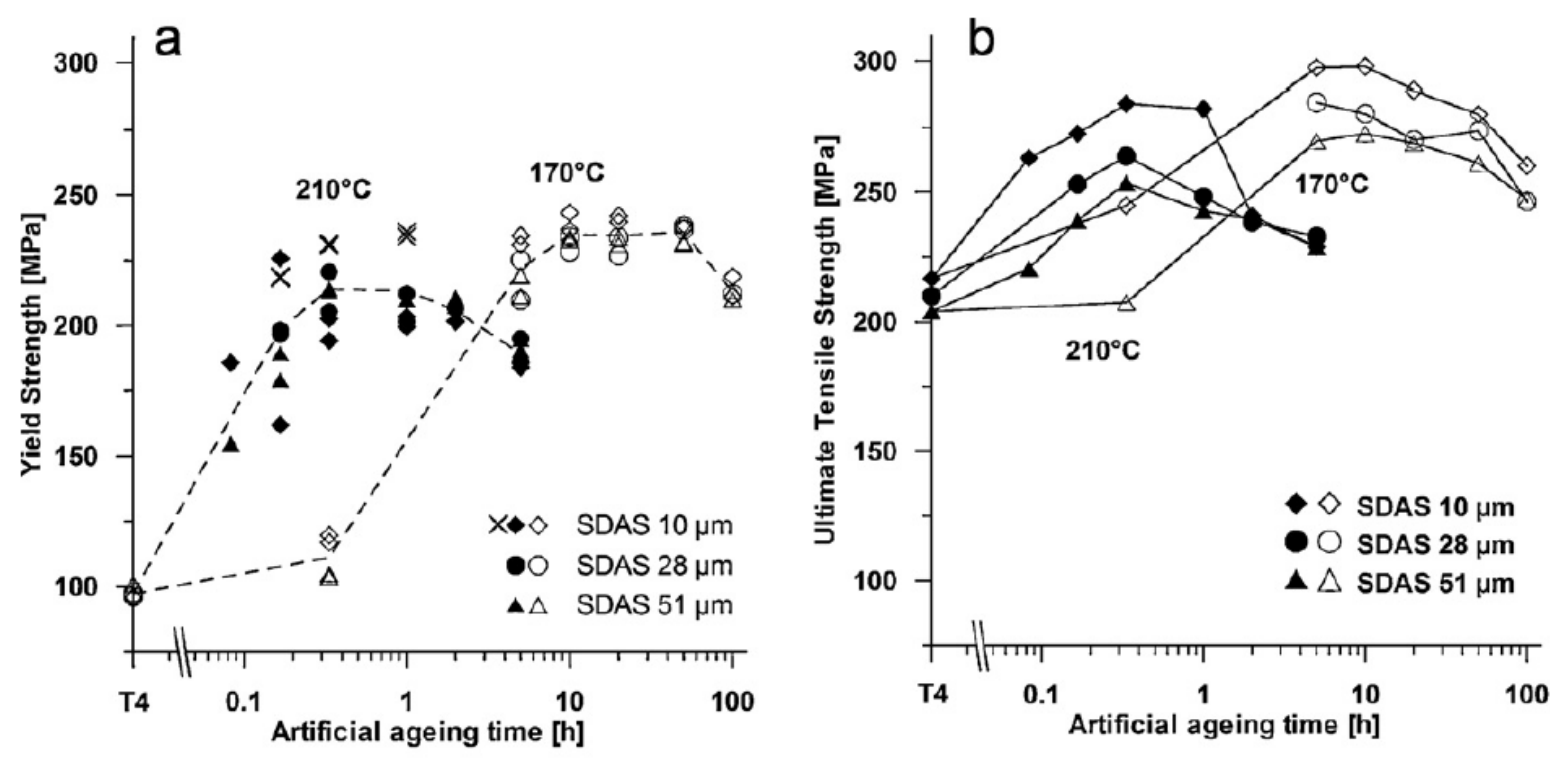

Figure 2-15: Yield strength (left) and ultimate tensile strength (right) in relation to artificial ageing of $\mathrm{Al}-\mathrm{Si}$-Mg alloys [30].

It was determined that $\mathrm{Al}-\mathrm{Si}-\mathrm{Cu}$ alloys had progressive increase in yield strength as well, however the process is significantly slower compared to $\mathrm{Al}-\mathrm{Si}-\mathrm{Cu}-\mathrm{Mg}$ alloys. Over $100 \mathrm{hrs}$. the ageing curve does not seem to reach the peak ageing condition [30]. As seen in Figure 4 for Al-Si-Mg alloys, at 100 hrs. a full ageing curve can be plotted. Additionally, it was determined that for Al$\mathrm{Si}-\mathrm{Cu}-\mathrm{Mg}$ alloys the time to reach peak ageing was longer than in $\mathrm{Al}-\mathrm{Si}-\mathrm{Mg}$ alloys, however the results were also significantly more promising compared to $\mathrm{Al}-\mathrm{Si}-\mathrm{Cu}$ alloys. At $170{ }^{\circ} \mathrm{C}$, the time to reach peak ageing for $\mathrm{Al}-\mathrm{Si}-\mathrm{Cu}-\mathrm{Mg}$ alloys was $20 \mathrm{hrs}$, compared to $10 \mathrm{hrs.} \mathrm{[30],} \mathrm{as} \mathrm{seen} \mathrm{in}$ Figure 2-16. It was concluded that, $\mathrm{Al}-\mathrm{Si}-\mathrm{Mg}$ alloys have improved ageing properties compared to $\mathrm{Al}-\mathrm{Si}-\mathrm{Cu}$ and $\mathrm{Al}-\mathrm{Si}-\mathrm{Cu}-\mathrm{Mg}$ alloys. 

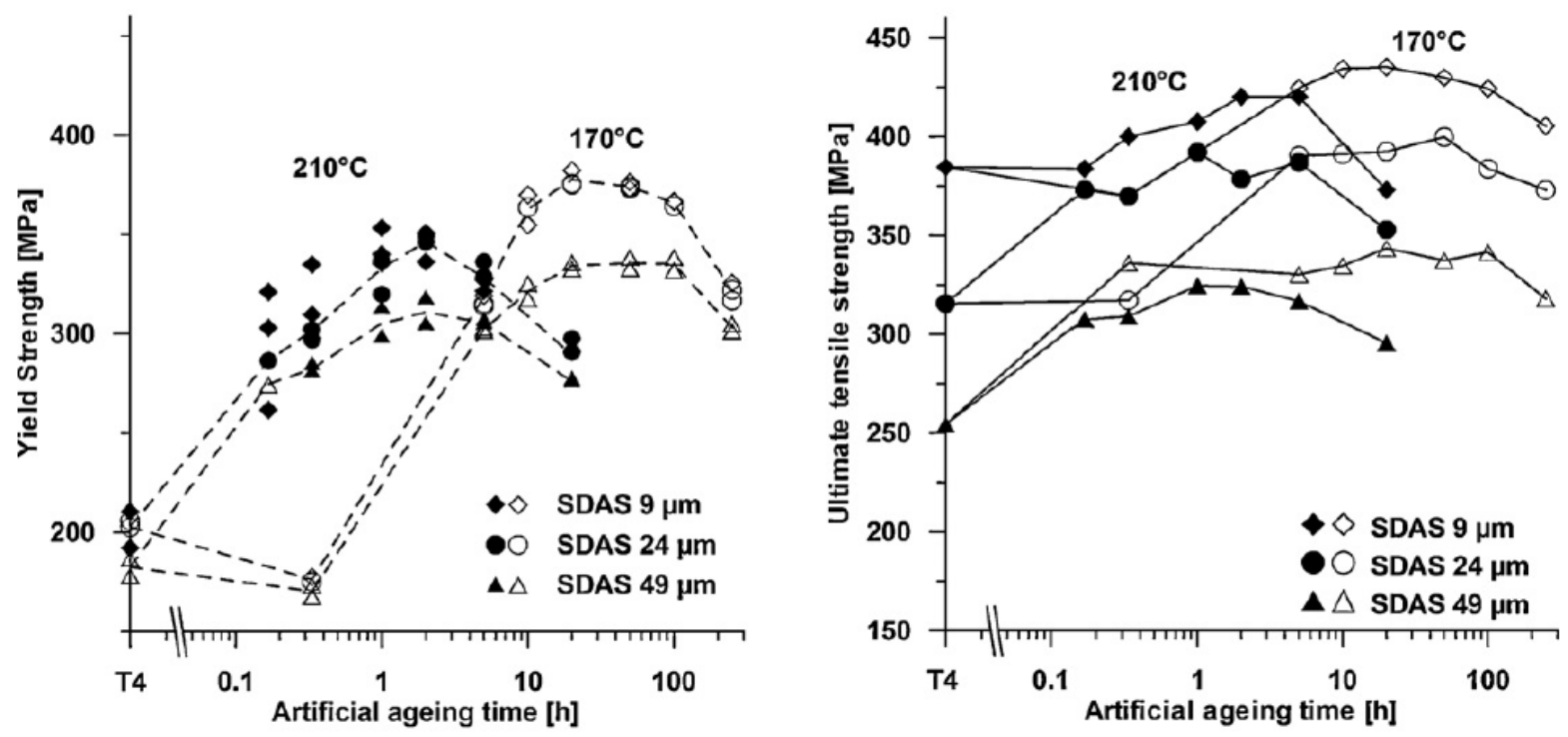

Figure 2-16: Yield strength (left) and ultimate tensile strength (right) varying with ageing time for Al-Si-Cu-Mg alloys [30].

A more recent study by Sjölander and Seifeddine investigated the effect of ageing on the plastic deformation behavior of Al-Si-Cu-Mg casting alloys. The basis of their analysis was determined by using the Kocks-Mecking strain hardening theory. This theory describes the change in dislocation density $(\rho)$ during plastic deformation [33]. Higher strain hardening rates are obtained when a sample consists of a supersaturated solid solution. In turn, higher strain hardening rates result in higher storage of dislocations. This is due to the pinning of dislocations by the precipitates formed after aging.

In the study it was determined that for $\mathrm{Al}-\mathrm{Si}-\mathrm{Mg}$ casting alloys, the strain hardening rate was the highest for the underaged condition. However, for longer aging times the strain hardening rate decreases (Figure 2-17) [33]. It was found that Al-Si-Cu-Mg alloys also behaved similarly. Additionally, the storage rate of dislocations was minimal for the peak aged condition. At, this stage the precipitates become more stable and are in equilibrium state, and thus they easily shear. However, with over-aging the storage rate of dislocations increases. This was found to be attributed to the formation of non-coherent precipitates. These precipitates are looped by dislocations, which in turn creates dislocation rings around the precipitates. In addition, with increased aging time larger $(\sim 40 \mathrm{~nm}) \beta$ - $\mathrm{Mg}_{2}$ Si precipitates form, which are also passed by looping of dislocations, creating more dislocation rings [33]. This showed indication that the precipitates 
lose coherency with the Al matrix as ageing time is increased, specifically into the over-aged condition. Although, both Al-Si-Mg and Al-Si-Cu-Mg casting alloys behave similarly in terms of the evolution of storage rate, the magnitude in storage differs. This is due to the difference in solute concentrations within each of the alloys; the higher the solute concentration the greater the density of obstacles for dislocations to bypass [33].
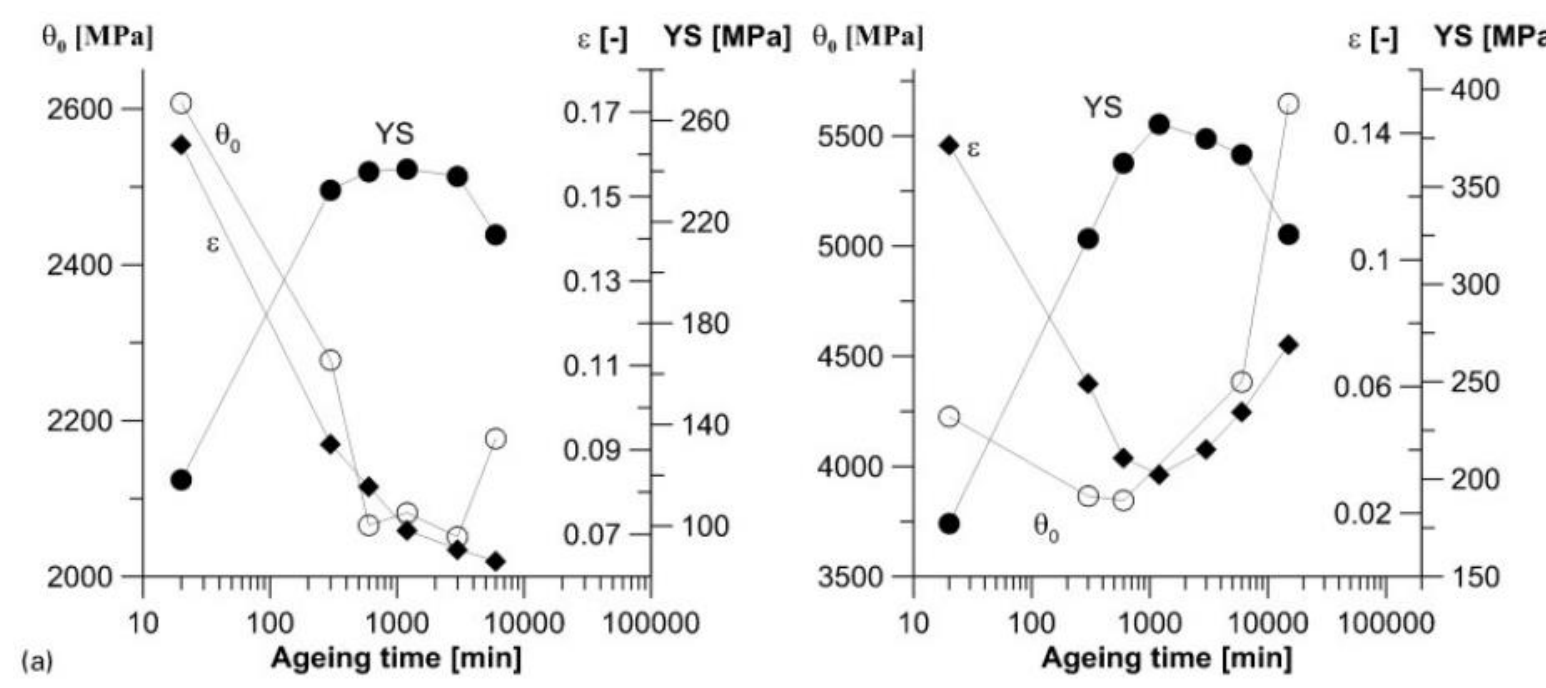

Figure 2-17: Evolution of storage rate, uniform elongation, and yield strength as a function of ageing time from Sjölander and Seifeddine (2013) [33].

In summary, the ability of an Al-Si-Cu-Mg alloy to be age hardened derives from the concentration of $\mathrm{Cu}$ and $\mathrm{Mg}$ solutes present in the alloy. The alloy has a higher aging response with increased $\mathrm{Mg}$ content. $\mathrm{Cu}$ is also an important element in the age hardening process, however compared to $\mathrm{Mg}$, it has a slower aging response. Thus, longer aging times are required to achieve the peak-aged condition, with optimal strength. Age hardening is the final step in the heat treatment process of $\mathrm{Al}-\mathrm{Si}-\mathrm{Cu}-\mathrm{Mg}$ casting alloys. It is used to form a fine dispersion of precipitates within the $\mathrm{Al}$ matrix. These particles act as obstacles to mobile dislocations, thus increasing the strength of the alloy. 


\subsection{Laser Scanning Confocal Microscopy}

Several techniques have been developed to understand and analyze phase transformation behaviour. Some of these techniques include differential scanning calorimetry (DSC), differential thermal analysis (DTA) or step-wise analysis of samples using electron microscopy. High temperature laser scanning confocal microscopy (LSCM) has become a valuable tool for analysis of phase transformations. It is a robust and useful method that provides real time in-situ studies of phase transformations. This section will discuss the instrumentation behind LSCM and past investigations that show the value of LSCM.

\subsubsection{Instrument and Procedure}

The VL2000DX-SVF17SP is a high temperature LSCM and is manufactured by Lasertec Corporation and Yonekura Manufacturing Corporation. A schematic of a typical LSCM as illustrated by Mu et al. [34] is shown in Figure 2-18. The LSCM utilizes a helium-neon (He-Ne) laser beam with a wavelength of $0.405 \mathrm{~nm}$. A major component of the LSCM is the infrared furnace, which acts as a heating chamber. The furnace is ellipsoid shaped and coated with gold. It is primarily designed to radiate heat at a focal point, where the sample is located. Additionally, the furnace has a halogen infrared heating lamp that is positioned beneath the bottom of the sample holder. The sample holder is attached to a thermocouple that is directly connected to a PID controller. The imaging system is another important component of the LSCM. The He-Ne laser is first projected through a series of lenses before being redirected by a mirror through an acoustic optic deflector (AOD) and polarized beam splitter (Figure 2-18). The beam splitter directs the initially projected beam towards another set of mirrors and finally focused onto the sample through the objective lens. Additionally, the beam splitter takes the reflected beam from the sample and directs it towards a charged-coupled device (CCD) image sensor through a pinhole. The pinhole filters out spectrums of light other than the He-Ne laser, which allows the CCD sensor to construct a clear image [34]. The AOD is used to scan the laser in a raster mode across the sample. 


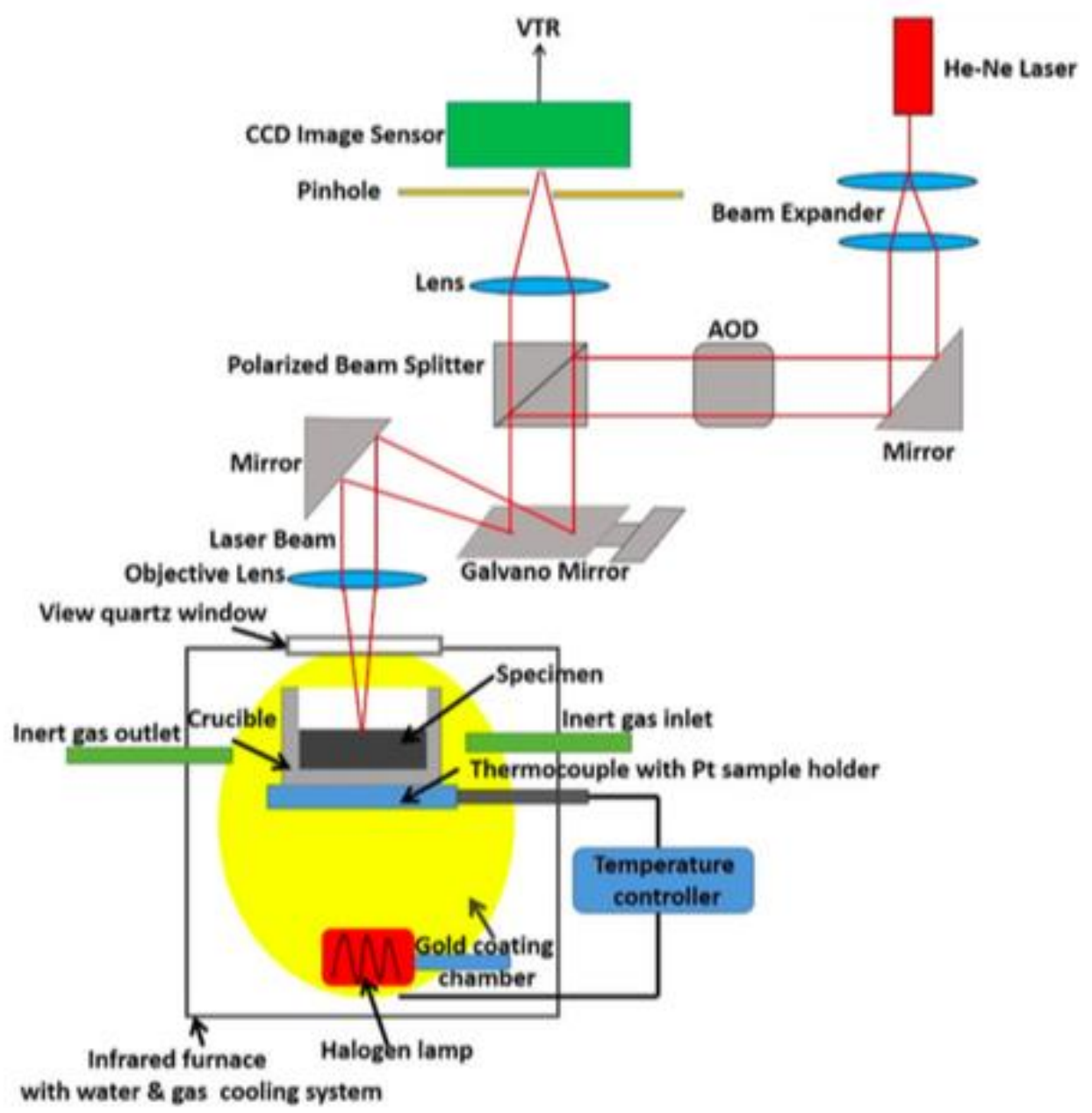

Figure 2-18: A schematic diagram of the components of a high temperature LSCM [34].

A high temperature LSCM can be operated at a maximum temperature of $1800^{\circ} \mathrm{C}$. Furthermore, a maximum heating rate of $1200{ }^{\circ} \mathrm{C} / \mathrm{min}$ can be obtained, while rapid cooling at approximately $3000{ }^{\circ} \mathrm{C} / \mathrm{min}$ is possible when using $\mathrm{He}$ gas for forced cooling [34]. Prior to performing an experiment studying surface phenomena, it is required that the samples are polished to a mirror finish. Sample sizes vary from 4 to $8 \mathrm{~mm}$ in diameter depending on the available standard crucible sizes. The temperature of the furnace can be set using the primary thermocouple, that is located underneath the crucible. A heating profile can be generated from the computer software according to the desired experimental parameters. However, there is a temperature difference between the thermocouple underneath the crucible and the sample surface. Thus, it is suggested that this temperature is calibrated using a known phase transformation temperature of a metal [34]. 
Alternatively, a second thermocouple can be spot welded on the sample surface to measure the temperature.

It is also important to prevent oxidation of samples from occurring during heat treatment experiments. Oxidation of the sample surface may inhibit the observation of surface phenomena being studied. This is prevented by using a vacuum and purging system that is attached to the LSCM. The vacuum system utilizes rotary pumps to remove any oxygen in the LSCM furnace. Vacuuming is then followed by purging with high purity inert argon (Ar) gas to further reduce the oxygen content. The process of vacuuming and purging is repeated multiple times to ensure safe operating conditions. This is especially important with materials that exhibit sensitivity to oxygen and require very low oxygen partial pressure, on the order of $10^{-15}$ to $10^{-20} \mathrm{~Pa}$ [34].

Advancements in technology have led to the development of high temperature LSCMs capable of capturing images with high resolution. LSCM has enabled in-situ characterization of solidification and phase transformations in steels and other non-ferrous alloys. This method has been especially useful in the study of inclusion formation in liquid steel making [35, 36]. In these studies, LSCM has enabled in-situ observation of the dissolution of inclusions such as calcium aluminate [35]. Recently, high temperature LSCM was used for non-ferrous alloys such as B206 and A319 to study incipient melting of secondary phases, as previously discussed in section 2.3.1.1 [10, 24]. Previously, the technique was used to observe the incipient melting of primary $\gamma^{\prime}$ in a Ni-based superalloy [37]. Nonetheless, the use of high temperature LSCM is a relatively new method in the study of solidification and phase transformation phenomena in both ferrous and non-ferrous alloys. In this study, the LSCM will be used to analyze incipient melting in a novel Al-Cu alloy for the application of high performance cylinder heads in automotive vehicles. 


\section{Chapter 3 Experimental Procedure}

\subsection{Alloy Melting and Casting}

The HT200 alloy was cast at mould temperatures of $500{ }^{\circ} \mathrm{C}$ and $200{ }^{\circ} \mathrm{C}$ to obtain both fine and coarse microstructure; a casting of HT200 alloy with addition of TiBor grain refiner was also carried out at each mould temperature. This was done to determine the effect of mould temperature and alloying on solidification parameters, microstructure and incipient melting of secondary phases. The alloy was obtained as ingots from Nemak Corporation (Linz Plant).

Each casting was carried out by using separate silicon-carbide crucibles; one for unrefined HT200 alloy and the other was used to add TiBor to the HT200 melt. For each case, approximately $1 \mathrm{~kg}$ of metal was charged and melted in the crucibles. The crucibles were heated in an electric resistance furnace at $810^{\circ} \mathrm{C}$ for at least $1.5 \mathrm{~h}$ until the metal reached molten state. Prior to pouring, each crucible was skimmed and then treated with 0.25 wt.\% sodium fluorosilicate $\left(\mathrm{Na}_{2}\left(\mathrm{SiF}_{6}\right)\right)$ degassing flux in the form of powder. This was done to remove inclusions and hydrogen porosity in the castings. $\mathrm{Na}_{2}\left(\mathrm{SiF}_{6}\right)$ powder was plunged in the melt then mechanically stirred under a fume hood for $1 \mathrm{~min}$ and then allowed to settle for 5-10 mins. For the castings with TiBor addition, the melt was skimmed and then $0.8 \mathrm{wt} . \%$ of Al-5Ti-B discs (cut from rods) were added into the melt. The chemical composition of the TiBor is presented in Table 3-3. The melt was then mechanically stirred for approximately $1 \mathrm{~min}$ and then allowed to settle for $5 \mathrm{mins}$. Once each mould reached the desired temperature, the melt was skimmed, followed by transporting the crucible from the heating furnace to the mould where the melt was then poured into a single cavity. The pouring temperature was approximately $780{ }^{\circ} \mathrm{C}$. The composition of the castings was measured using an Oxford Instruments Foundry Master Pro Spark Optical Emission Spectrometer (OES) at the CNPM lab. The composition of the castings is presented below in Table 3-1 and Table 3-2. 
Table 3-1: Average experimental composition of HT200 alloy.

\begin{tabular}{|l|c|c|c|c|c|c|c|c|}
\hline Element & Cu & Mn & Zr & Fe & Si & Ti & V & Al \\
\hline Wt. \% & 6.66 & 0.459 & 0.22 & 0.051 & 0.049 & 0.084 & 0.014 & Bal. \\
\hline
\end{tabular}

Table 3-2: Average experimental composition of HT200 alloy with TiBor addition.

\begin{tabular}{|l|c|c|c|c|c|c|c|c|}
\hline Element & Cu & Mn & Zr & Fe & Si & Ti & V & Al \\
\hline Wt. \% & 6.69 & 0.435 & 0.213 & 0.042 & 0.055 & 0.124 & 0.014 & Bal. \\
\hline
\end{tabular}

Table 3-3: Composition Al-5Ti-B standard cut rods (Batch Analysis from KB Alloys).

\begin{tabular}{|l|c|c|c|c|c|c|}
\hline Element & Ti & B & V & Fe & Si & Al \\
\hline Wt. \% & 5.0 & 1.0 & 0.01 & 0.10 & 0.06 & Bal. \\
\hline
\end{tabular}

\subsection{Control of Mould Temperature}

The moulds used in this work were developed and manufactured at Ryerson by E. Vandersluis [38]. The moulds were heated in a muffle furnace for at least $1 \mathrm{~h}$ to ensure even heating of the mould. The furnace was set to a temperature of $700{ }^{\circ} \mathrm{C}$. Once the moulds were completely soaked in the furnace, they were carefully removed, transported and placed on bricks. Four K-type thermocouples, insulated with $3.175 \mathrm{~mm}$ diameter ceramic sleeves, were then inserted into holes in the four outer walls of the mould. Additionally, a thermocouple was also suspended in each of the two cavities of a mould such that the thermocouple is in the center of the casting. This allowed for the collection of thermal data for cooling curves of each casting. The thermocouples were connected to a Daytronic System 10 data acquisition system to monitor and record temperature. 
The experimental set-up of the thermocouple placement in the permanent mould can be seen in Figure 3-1.

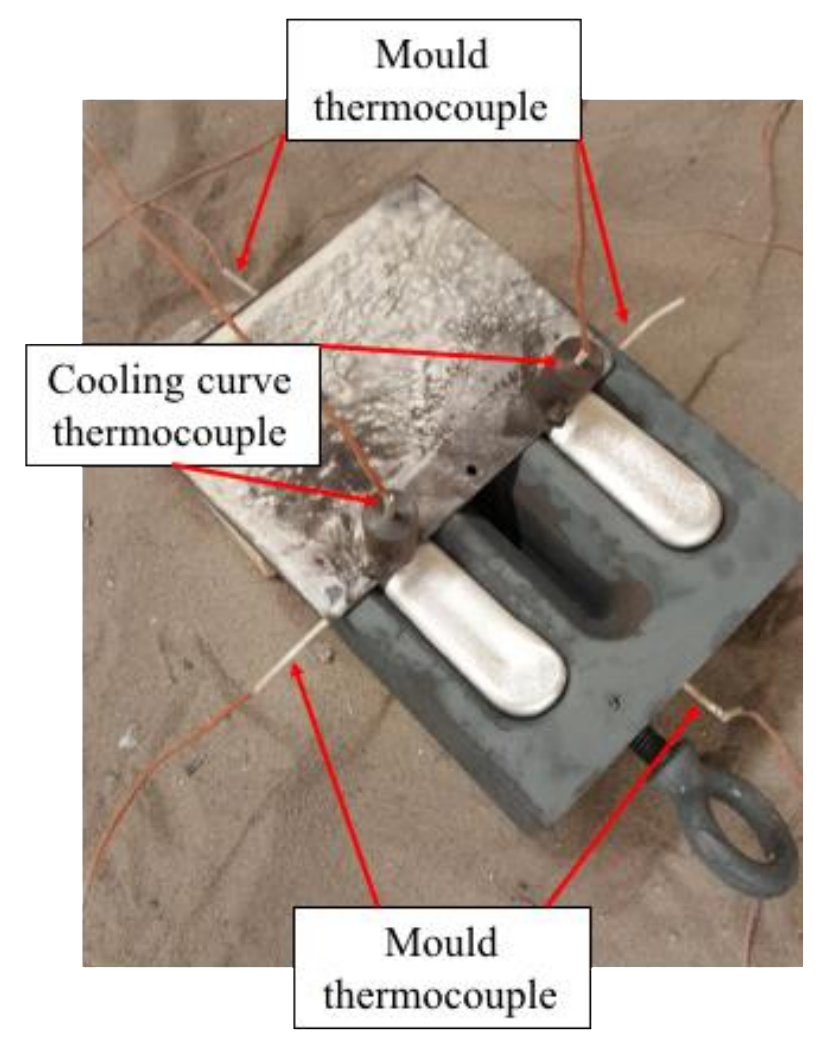

Figure 3-1: Placement of thermocouples in permanent mould.

\subsection{Thermal Analysis}

Thermal analysis was carried out by recording data from the thermocouples suspended at the center of the mould cavities. Afterwards, cooling curves were obtained from the recorded timetemperature data. The cooling curves were analyzed to obtain temperature and time of the liquidus, $\mathrm{Al}-\mathrm{Cu}$ eutectic, and solidus points. Additionally, the local solidification time, freezing range, and solidification rate were calculated using the collected data. The local solidification time was interpreted to be the time required to transition from the liquidus to the solidus point. The freezing range is calculated as the temperature difference between the liquidus and solidus. Lastly, the solidification rate was determined as the change in temperature with respect to time from the 
liquidus to the solidus. The analysis of the cooling curves is depicted in Figure 3-2. Type Kthermocouples were used throughout all casting experiments in this work.

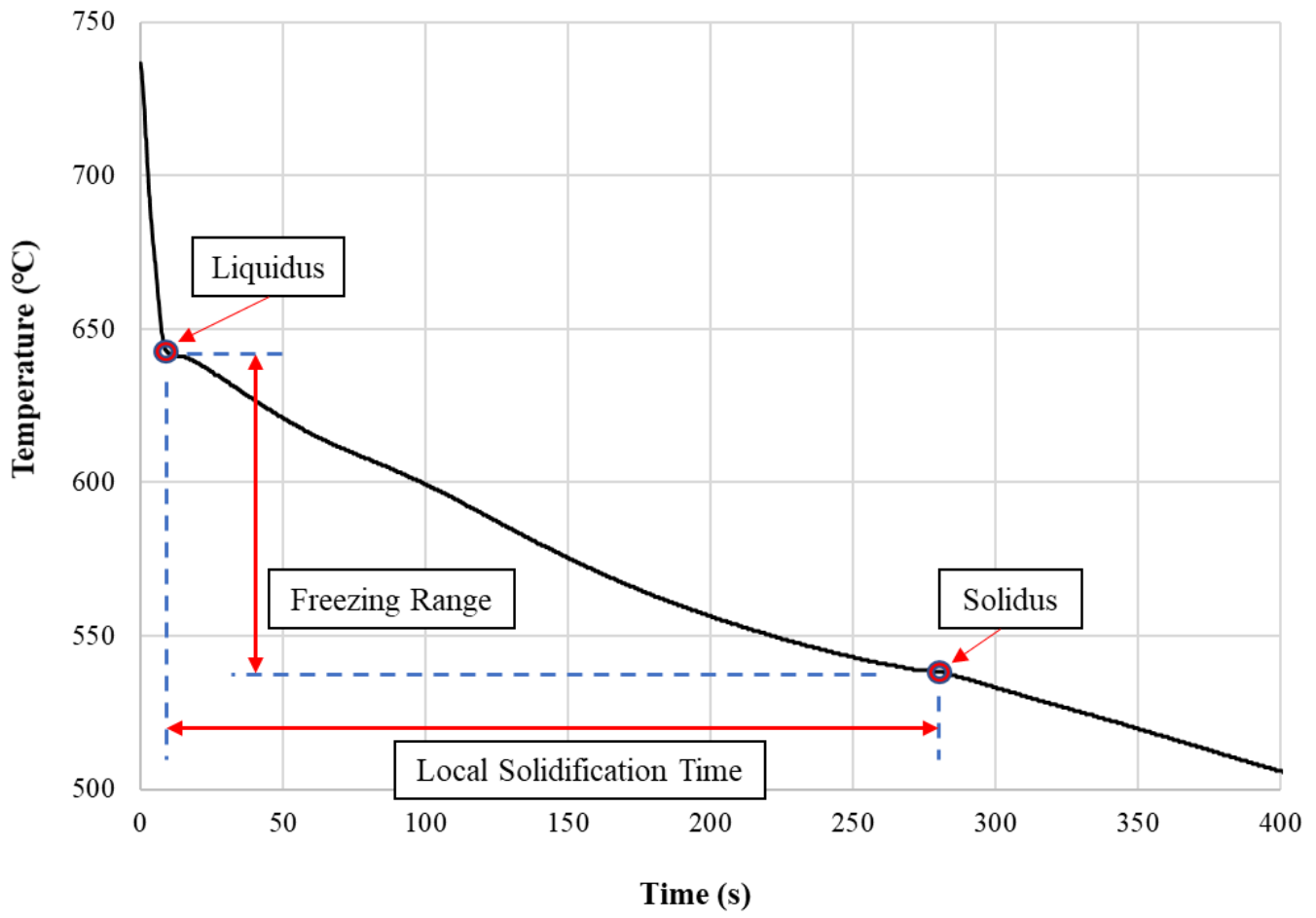

Figure 3-2: Typical HT200 alloy cooling curve

\subsection{Sample preparation}

Samples were extracted from the castings for general analysis of the microstructure (grain structure and secondary phases) using optical microscopy and SEM. Furthermore, separate samples were prepared for solution heat treatment experiments and LSCM analysis. The sample locations are represented in Figure 3-3. This section describes the details of the sample preparation. 


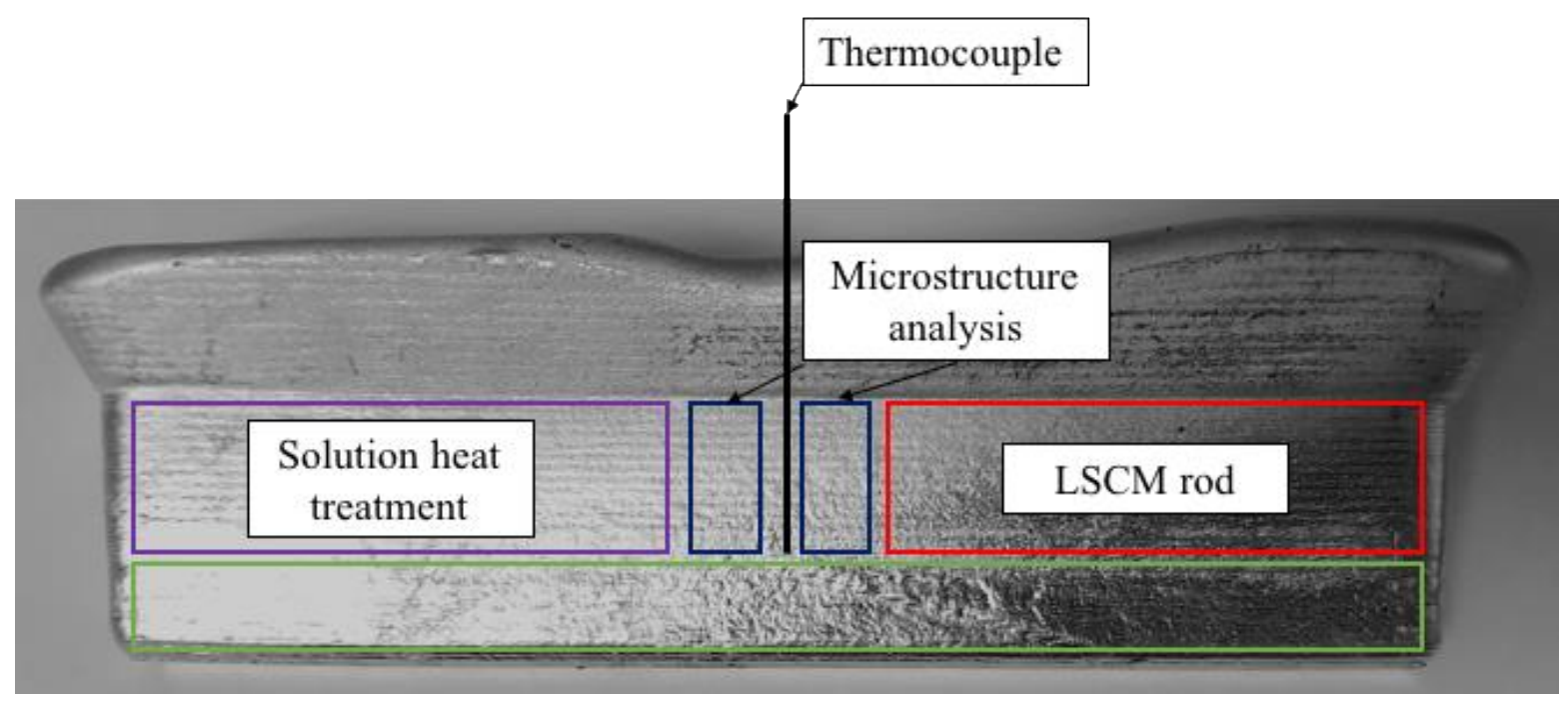

Figure 3-3: Locations of samples for microstructure analysis, thermal analysis, solution heat treatment and LSCM analysis.

\subsubsection{Microscopy samples}

For microstructural analysis, two samples from each casting were extracted using a vertical band saw. These samples were taken primarily for characterization of microstructure (grain structure and secondary phases) under the optical microscope and SEM. The size of the samples was $2 \mathrm{~cm}$ x $1 \mathrm{~cm} \times 0.5 \mathrm{~cm}$. It should be noted that LSCM samples were also characterized under the SEM prior to the LSCM analysis (details provided in section 3.6). For LSCM samples, it was required that the samples were discs with a diameter of $5 \mathrm{~mm}$ and thickness of $1.5 \mathrm{~mm}$. This allowed the samples to fit in a crucible that was then placed inside the heating chamber of the LSCM. Rectangular bars were first cut out of the casting as shown in Figure 3-3. This was followed by machining of the rectangular bars to a rod with a diameter of $5 \mathrm{~mm}$ using a lathe. The rod was then cut into discs using a slow speed cut off wheel.

The metallographic preparation used for optical microscopy, SEM and LSCM samples was the same. The samples were prepared with successive grinding steps using silicon carbide ( $\mathrm{SiC}$ ) grit papers, $5 \mu \mathrm{m}$ alumina and $1 \mu \mathrm{m}$ diamond suspension on a polishing wheel. Abrasive $\mathrm{SiC}$ grinding involved the use of water as a lubricant, and was followed by the drying of samples using compressed air. The polishing steps did not require any use of water. However, after each polishing 
step the samples were placed in an ultrasonic cleaner for 1 min to remove any residuals from the polishing solutions. The metallographic polishing steps are outlined in Table 3-4.

Table 3-4: Polishing procedure for microstructure analysis.

\begin{tabular}{cccc}
\hline Step & Abrasive Grit/ Polishing Cloth & Wheel Speed (RPM) & Time (min) \\
\hline & \multicolumn{2}{c}{ Abrasive Grinding } & \\
\hline $\mathbf{1}$ & $120 \mathrm{Grit} \mathrm{SiC}$ & 300 & Until Plane \\
\hline $\mathbf{2}$ & $320 \mathrm{Grit} \mathrm{SiC}$ & 300 & 1 \\
\hline $\mathbf{3}$ & $600 \mathrm{Grit} \mathrm{SiC}$ & 300 & 1 \\
\hline $\mathbf{4}$ & $1200 \mathrm{Grit} \mathrm{SiC}$ & 300 & 1 \\
\hline & & & $5-8$ \\
\hline $\mathbf{5}$ & Lecloth $+5 \mu \mathrm{m}$ alumina & 120 & $3-5$ \\
\hline $\mathbf{6}$ & Lecloth $+1 \mu \mathrm{m}$ diamond suspension & 120 & \\
\hline
\end{tabular}

\subsubsection{Etching}

Etching was required for both the unrefined HT200 alloy and the HT200 refined with TiBor to reveal the grains. The etchant used was Keller's reagent and consisted of $70 \mathrm{~mL}$ of distilled water, $15 \mathrm{~mL}$ of nitric acid, $10 \mathrm{~mL}$ of hydrochloric acid and $5 \mathrm{~mL}$ of hydrofluoric acid. A sample was immersed in the solution and lightly agitated for a minimum of 25 seconds. Afterwards, the sample was removed, rinsed with water and then dried using compressed air. The sample was then observed under an optical microscope to determine whether extra etching was required.

\subsection{Microstructural Analysis}

Optical and scanning electron microscopy was carried out on the two microscopy samples for each condition (Figure 3-3). Additionally, before and after LSCM analysis the samples were also observed under the optical microscope and the SEM. This was done to show the change in microstructure due to incipient melting of secondary phases. Microstructural characterization 
involved qualitative observation of morphology, quantitative image analysis and microanalysis of secondary phases.

\subsubsection{Quantitative Image Analysis}

Clemex image analysis software was used to measure the volume fraction of $\mathrm{Al}_{2} \mathrm{Cu}$ using at least 30 backscattered electron images for each of the two microscopy samples from each casting condition. The images were taken using a JOEL JSM-6380LV scanning electron microscope at 200x to $400 \mathrm{x}$ magnifications. The software was also used to measure the morphology of $\mathrm{Al}_{2} \mathrm{Cu}$ such as aspect ratio, sphericity and circular diameter.

\subsubsection{Phase Microanalysis}

Energy dispersive X-ray spectroscopy (EDX) was carried out using a JOEL JSM-6380LV scanning electron microscope for a compositional analysis of the secondary phases present in the microstructure. At least 5 particles of each secondary phase were analyzed using EDX. EDX point analysis was used to determine the elements present in each phase. The data was then compared to literature and X-ray diffraction results to determine the stoichiometry. Lastly, EDX elemental mapping was used to observe the distribution of elements in the microstructure. 


\subsection{Laser Scanning Confocal Microscopy (LSCM)}

A High Temperature LSCM (Lasertec VL2000DX) was used for in-situ observation and analysis of incipient melting in the HT200 alloy. The LSCM used at McMaster University's Steel Research Center was equipped with a He-Ne laser and an infrared image furnace. In this study, disc samples of the alloy with a diameter of $5 \mathrm{~mm}$ and thickness of $1.5 \mathrm{~mm}$ were used. The sample was placed inside an alumina $\left(\mathrm{Al}_{2} \mathrm{O}_{3}\right)$ crucible with an inner diameter of $5 \mathrm{~mm}$. Furthermore, the $\mathrm{Al}_{2} \mathrm{O}_{3}$ crucible was then placed at the end of a ceramic cantilever within a gold plated ellipsoidal heating chamber of the LSCM (Figure 3-4). Additionally, an alumina plate was placed beneath the crucible to prevent sticking of the crucible to the cantilever. The location of this crucible is at the focal point of the heating chamber ensuring that the sample is heated efficiently. Prior to heating, the chamber of the LSCM was purged with ultra-high purity Ar (99.9999\%) with a flow of 50 to 60 $\mathrm{mL} / \mathrm{min}$ and then evacuated using a vacuum pump. The process of purging followed by a vacuum was repeated three times to clean the chamber thoroughly spanning a time of approximately 30 minutes. Additionally, the $\mathrm{Al}_{2} \mathrm{O}_{3}$ crucible was wrapped with a strip of Ti foil $(99.6 \%)$ having a thickness of $0.0127 \mathrm{~mm}$ to prevent oxidation of the sample surface.

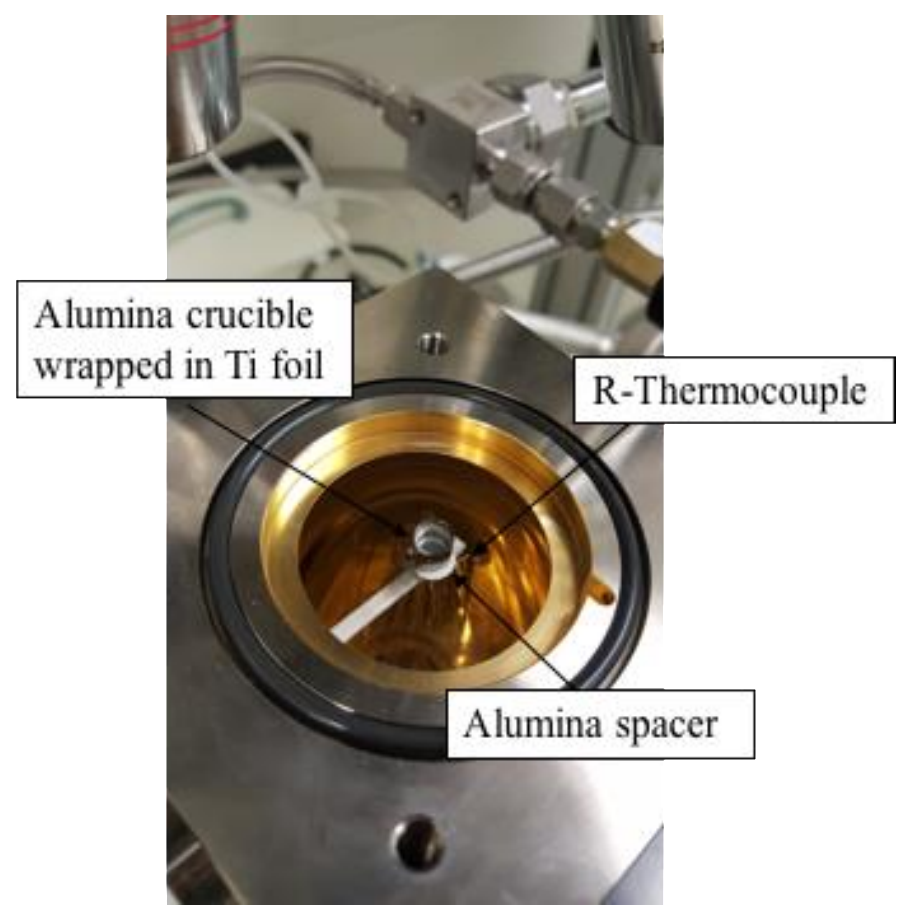

Figure 3-4: Experimental setup of LSCM heating chamber. 
Prior to performing experiments, a pure $\mathrm{Fe}(>99.9 \%)$ sample was used to calibrate the sample surface temperature observed with the LSCM. The temperature was measured using an R-type thermocouple $\left( \pm 0.6{ }^{\circ} \mathrm{C}\right.$ or $0.1 \%$ ANSI special limit of error), attached beneath the $\mathrm{Al}_{2} \mathrm{O}_{3}$ crucible and plate. The temperature of the thermocouple was calibrated using the theoretical $\alpha$-Fe to $\gamma$-Fe phase transformation temperature $\left(910^{\circ} \mathrm{C}\right)$ of the Fe sample placed in the LSCM. It was found that the sample surface temperature was $50{ }^{\circ} \mathrm{C}$ higher than the thermocouple temperature when the phase transformation was observed under the LSCM. The temperature difference found is due to the thickness of the $\mathrm{Al}_{2} \mathrm{O}_{3}$ plate and crucible in between the thermocouple and sample. This temperature difference was accounted for in the experiments carried out for analysis of incipient melting using the LSCM. Furthermore, the small size of the samples, slow heating rate used and the heating mechanism of the heating chamber allows the samples to quickly reach equilibrium temperature. This calibration method is commonly used with LSCM and provides a simple and efficient method for accurately measuring the temperature of the sample surface [34]. In this study, DSC analysis and solution heat treatment experiments were carried out to verify the temperatures obtained from the calibration method.

In the series of experiments, the heating profile (Figure 3-5) for the analysis of HT200 samples was set to $580^{\circ} \mathrm{C}$ at a heating rate of $10^{\circ} \mathrm{C} / \mathrm{min}$. The high temperature set point allows for sufficient time to manually control and hold at a specific temperature when incipient melting is observed; this provides an isothermal analysis of incipient melting. Initially, the samples were heated to 150 ${ }^{\circ} \mathrm{C}$ at a heating rate of $40{ }^{\circ} \mathrm{C} / \mathrm{min}$ to avoid overshoot when continuing to high temperatures, thus preventing any damage to the lamp chamber (i.e. initially the chamber was allowed to reach equilibrium). Afterwards, the heating profile continues to $450{ }^{\circ} \mathrm{C}$ at $100{ }^{\circ} \mathrm{C} / \mathrm{min}$ before slow heating to the set point temperature of $580^{\circ} \mathrm{C}$. Upon heating to the set point temperature, real time video analysis allows for observation of phase transitions such as incipient melting. The temperature was then manually controlled and held at the observance of incipient melting $\left(\mathrm{T}_{\mathrm{IM}}\right)$ until there were no further changes in microstructure. The observation of incipient melting at the sample surface was video recorded with a frame rate of 30 frames per second. From the video, images were extracted frame by frame to create temperature-time series micrographs to analyze incipient melting. 


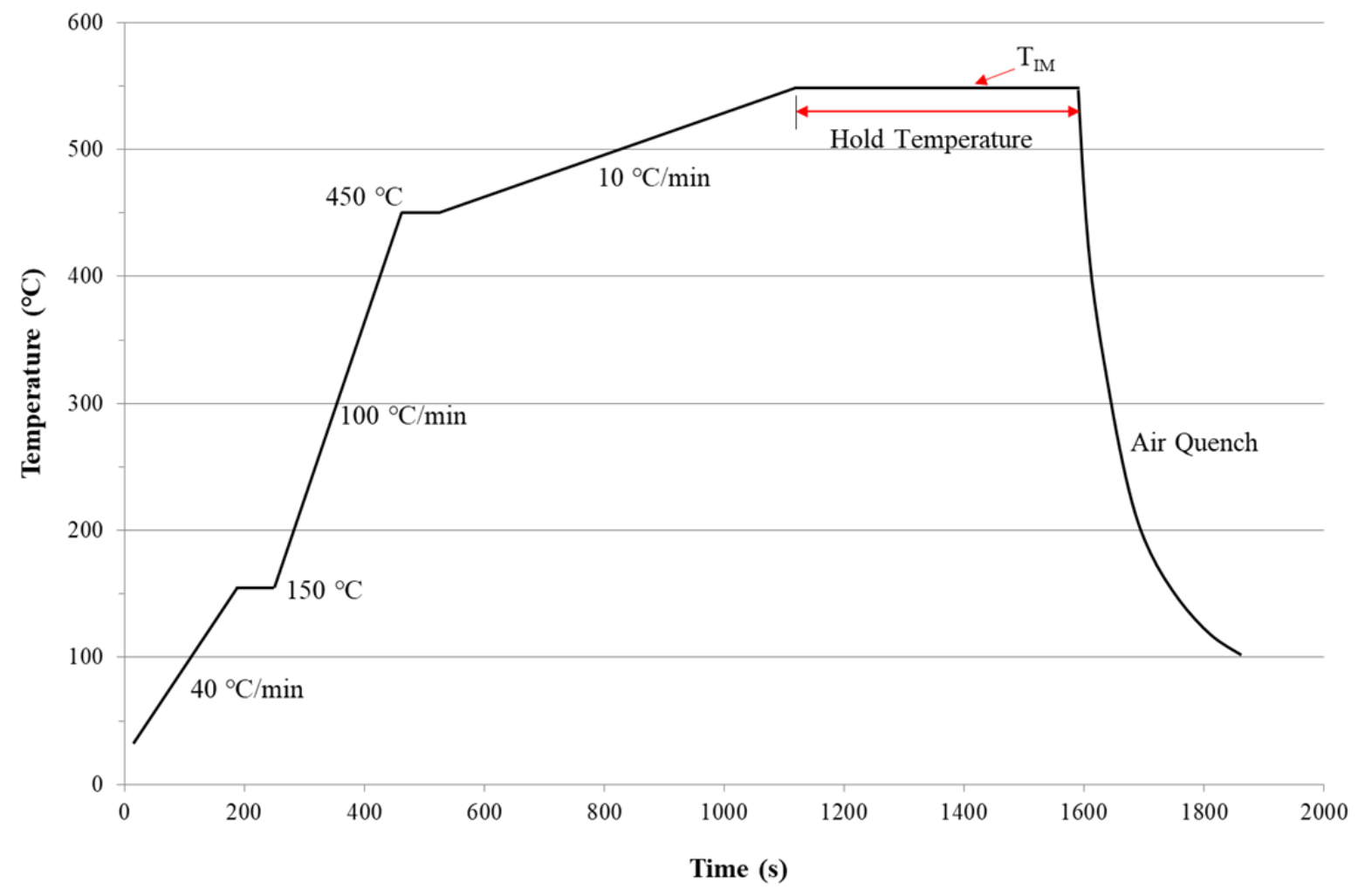

Figure 3-5: LSCM heating profile for analysis of incipient melting in HT200 alloy.

\subsection{Differential Scanning Calorimetry (DSC)}

A Thermogravimetric (TG) and Differential Scanning Calorimetric (DSC) analysis was carried out using a NETZSCH STA 449 F3 Jupiter Simultaneous Analyzer. A disc sample of 5 mm diameter and $1.5 \mathrm{~mm}$ thickness with a weight of approximately $17.4 \mathrm{mg}$ was used. The sample was placed in an alumina $\left(\mathrm{Al}_{2} \mathrm{O}_{3}\right)$ crucible during the analysis. Furthermore, an inert atmosphere was produced using argon (Ar) at a flow rate of $50 \mathrm{~mL} / \mathrm{min}$. During the investigation, the sample was heated from ambient to $700{ }^{\circ} \mathrm{C}$ at a heating rate of $10{ }^{\circ} \mathrm{C} / \mathrm{min}$ for an analysis of incipient melting. Additionally, a solidification analysis of the HT200 alloy was also carried out using DSC where a sample was melted in the DSC apparatus and then cooled at a rate of $10^{\circ} \mathrm{C} / \mathrm{min}$ until room temperature. Quantitative measurements of enthalpy and temperature were extracted from the DSC data using NETZSCH Proteus Software. 


\subsection{Solution Heat Treatment of HT200 alloy}

Solution heat treatment experiments were carried out using an STT-1600C High Temperature Tube Furnace. The heat treatments were carried out at temperatures of 530, 540, 550 and $560{ }^{\circ} \mathrm{C}$ for a time of $4 \mathrm{hrs}$. The size of the samples was $2 \mathrm{~cm} \times 1 \mathrm{~cm} \times 0.5 \mathrm{~cm}$. The sample temperature was determined by inserting a K-type thermocouple within the sample. This was done by drilling a hole to the center of the sample and ensured that the correct solution heat treatment temperature was used. Hence the furnace controller temperature was calibrated with the sample thermocouple. Two samples were used for each heat treatment. Prior to placing the samples inside the tube furnace, the temperature was raised to $500{ }^{\circ} \mathrm{C}$ and left for an hour to allow the furnace chamber to reach equilibrium. Following this, the samples were placed in the furnace, where a soaking time of approximately 20 minutes was used. This ensured that the sample reaches the desired temperature, prior to starting the solution heat treatment for $4 \mathrm{hrs}$. Afterwards, each of the samples were quenched in iced water (temperature of approximately $10{ }^{\circ} \mathrm{C}$ ). Immediately afterwards, Rockwell E (HRE) hardness tests and density measurements were carried out.

\subsubsection{Hardness Measurements}

Hardness measurements were taken on as-cast and solution heat treated samples using a Leco LR300 Rockwell-type hardness tester. Measurements were taken on the Rockwell E (HRE) scale, using a $1 / 8$ " indenter and a load of $100 \mathrm{~kg}$. The average hardness was found using at least $9 \mathrm{HRE}$ readings per sample.

\subsubsection{Density Measurements}

Density was measured using the hydrostatic displacement technique. This method uses Archimedes' Principle, where the weight of the sample is compared to the measured weight of the sample that is suspended in a beaker of water. After measuring the sample weight in both conditions, the density $(\rho)$ can be evaluated by the following equation: 


$$
\rho=\frac{m_{s} \rho_{w}}{m_{s w}-m_{w}}
$$

Where,

$m_{s}=$ Mass of the sample in air

$\rho_{w}=$ Density of water

$m_{s w}=$ Apparent mass of the sample in a container of water

$m_{w}=$ Mass of water in a container

The density of water was taken to be $0.9978 \mathrm{~g} / \mathrm{cm}^{3}$ for the calculations. 


\section{Chapter 4 Results and Discussion}

In this chapter, the results from the casting experiments, DSC thermal analysis, high temperature laser scanning confocal microscopy, and solution heat treatment are presented and interpreted. Solidification analysis of the casting cooling curves of the HT200 alloy is first discussed. From the cooling curves, solidification parameters were measured and calculated. These results are followed by microstructural analysis of the different solidification conditions. Then, the characterization of the alloy grain structure and secondary phases is discussed. Furthermore, results from the in-situ observation of incipient melting using laser scanning confocal microscope (LSCM) are presented. Lastly, the effect of solution heat treatment on hardness, density and $\mathrm{Al}_{2} \mathrm{Cu}$ vol. $\%$ is analyzed.

\subsection{Thermal Analysis}

The experimental cooling curves for the $500{ }^{\circ} \mathrm{C}$ and $200{ }^{\circ} \mathrm{C}$ mould castings are plotted in Figure 4-1 and Figure 4-2 respectively. Each mould temperature includes a casting of the base HT200 alloy, without alloying additions, and HT200 alloy with addition the of TiBor (0.8 wt.\% Al-5TiB) grain refiner. Regardless of mould temperature, the casting thermal data showed that the alloy liquidus for the HT200 alloy and HT200 alloy with TiBor addition was found to be approximately 643 and $645{ }^{\circ} \mathrm{C}$ respectively. While mould temperature did not have an effect on the liquidus temperature, the addition of TiBor shifted the liquidus slightly by $2{ }^{\circ} \mathrm{C}$. Furthermore, the shape of the cooling curves for all conditions remained relatively the same. The unrefined HT200 alloy had inflection points at approximately $607{ }^{\circ} \mathrm{C}$ and $538{ }^{\circ} \mathrm{C}$, which likely corresponded to the precipitation of the Al-Cu-Fe-Mn and Al-Cu phases respectively (discussed in section 4.2). This was more identifiable in the $500{ }^{\circ} \mathrm{C}$ mould cooling curves, whereas the inflection points were more

difficult to identify in the cooling curves of the $200{ }^{\circ} \mathrm{C}$ mould castings; this was likely because the resolution of the K-type thermocouple was inadequate for the fast cooling. The local solidification time, freezing range, and solidification rate were extracted from the cooling curves and are summarized in Table 4-1. 
Table 4-1: Experimental solidification parameters.

\begin{tabular}{ccccc}
\hline $\begin{array}{c}\text { Mould } \\
\text { Temperature } \\
\left({ }^{\circ} \mathbf{C}\right)\end{array}$ & Alloy & $\begin{array}{c}\text { Local } \\
\text { Solidification } \\
\text { Time }(\mathbf{s})\end{array}$ & $\begin{array}{c}\text { Freezing } \\
\text { Range }\left({ }^{\circ} \mathbf{C}\right)\end{array}$ & $\begin{array}{c}\text { Solidification } \\
\text { Rate }\left({ }^{\circ} \mathbf{C} / \mathbf{s}\right)\end{array}$ \\
\hline $\mathbf{5 0 0}$ & HT200 & 269 & 104.4 & 0.39 \\
\cline { 2 - 5 } & HT200+ TiBor & 225.6 & 106.1 & 0.46 \\
\hline $\mathbf{2 0 0}$ & HT200 & 20 & 106.1 & 5.3 \\
\cline { 2 - 5 } & HT200 + TiBor & 10.4 & 108.9 & 10.5 \\
\end{tabular}

\subsubsection{0 ${ }^{\circ} \mathrm{C}$ Mould Castings}

The base HT200 alloy was found to have a liquidus at approximately $643{ }^{\circ} \mathrm{C}$. The local solidification time (LST) of the alloy was measured to be approximately $269 \mathrm{~s}$, which corresponded to a solidification rate $(\mathrm{SR})$ of $0.39{ }^{\circ} \mathrm{C} / \mathrm{s}$. The slow solidification rate was expected, because of the high mould temperature used. Additionally, the freezing range (FR) for the HT200 alloy in this condition was found to be approximately $104.4^{\circ} \mathrm{C}$. According to the cooling curve, the formation of $\mathrm{Al}_{2} \mathrm{Cu}$ occurred at $540{ }^{\circ} \mathrm{C}$ in the unrefined HT200 alloy. This corresponds well to a study by D'Elia et al. [39] on the solidification analysis of an Al-5Cu alloy. In the study, neutron diffraction experiments showed that $\mathrm{Al}_{2} \mathrm{Cu}$ phases precipitated at $540{ }^{\circ} \mathrm{C}$. The addition of TiBor $(0.8 \mathrm{wt} \% \mathrm{Al}-5 \mathrm{Ti}-\mathrm{B})$ resulted in a shift in the alloy liquidus to $645^{\circ} \mathrm{C}$. This also led to a decrease in local solidification time to $225.6 \mathrm{~s}$ and an increase in freezing range to $106.1^{\circ} \mathrm{C}$. As a result, the TiBor addition increased the solidification rate to $0.46{ }^{\circ} \mathrm{C} / \mathrm{s}$. This was approximately a $15 \%$ increase in solidification rate compared to the unrefined alloy. The faster solidification rate is likely a result of an increased presence of $\mathrm{Ti}$ inoculants, thereby reducing the time for nucleation of grains. The change in solidification rate is also indicative of the refinement of grain size and morphology, as seen in section 4.2.1.1. The solidification parameters were also analyzed for castings in a $200{ }^{\circ} \mathrm{C}$ mould temperature. 


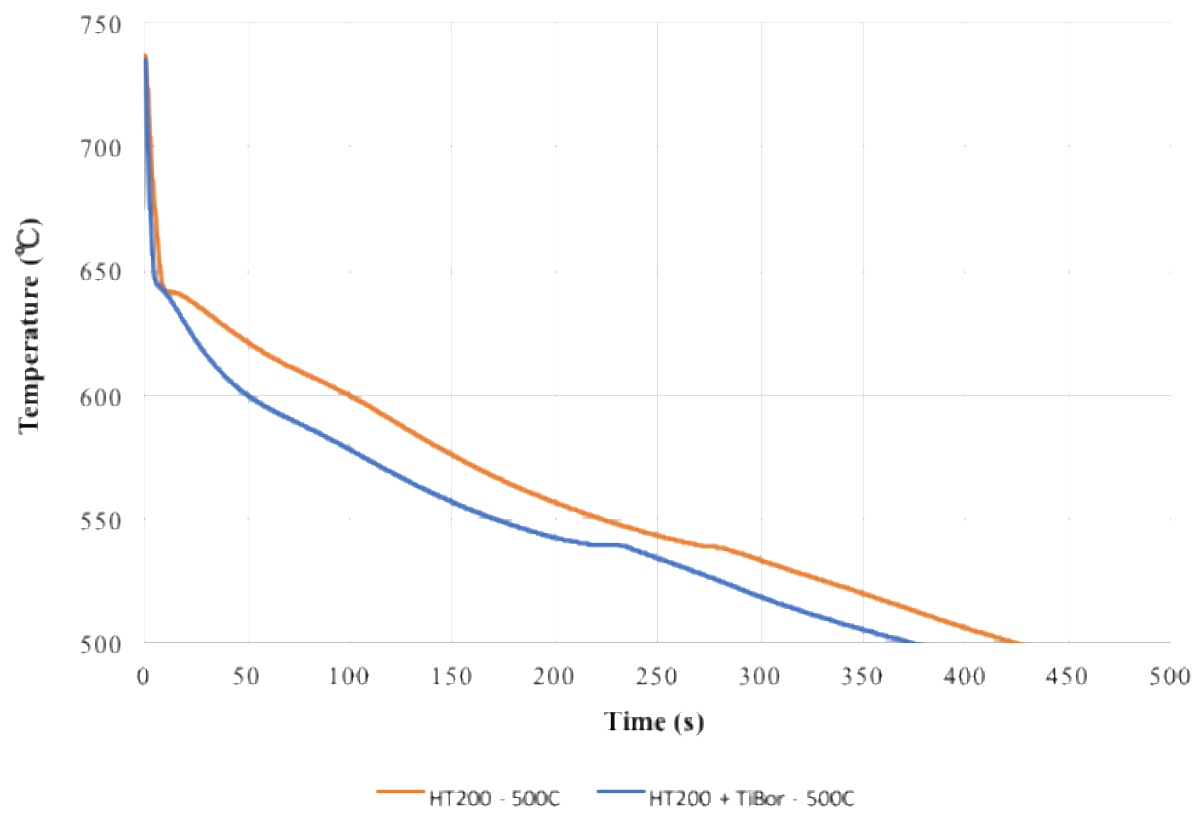

Figure 4-1: Experimental cooling curves for HT200 and HT200 with 0.8 wt\% TiBor at $500{ }^{\circ} \mathrm{C}$ mould temperature.

\subsubsection{0 ${ }^{\circ} \mathrm{C}$ Mould Castings}

Similar results were found in the $200{ }^{\circ} \mathrm{C}$ mould castings of the HT200 alloy. In this case, the alloy liquidus for the base alloy was also found to be approximately $643{ }^{\circ} \mathrm{C}$. The addition of TiBor was found to increase the liquidus to $646^{\circ} \mathrm{C}$; this was also observed in the $500{ }^{\circ} \mathrm{C}$ mould castings. The low mould temperature promoted fast solidification rates measured at 5.3 and $10.5{ }^{\circ} \mathrm{C} / \mathrm{s}$ for the base HT200 alloy and HT200 with TiBor addition respectively. Thus, it was evident that at lower mould temperatures the solidification rate was found to significantly increase with the addition of TiBor (approximately 49\% increase). The faster solidification rate for the casting with TiBor addition was primarily due to decreased local solidification time and slightly higher freezing range. The base HT200 alloy was found to have a local solidification time of $20 \mathrm{~s}$ and a freezing range of $106.1^{\circ} \mathrm{C}$. However, with TiBor addition there was a significant reduction in local solidification time of $10.4 \mathrm{~s}$ and a freezing range of $108.9^{\circ} \mathrm{C}$. Thus, it can be said that at lower mould temperatures the addition of TiBor promotes a more rapid solidification due to additional effect of the large temperature gradient between the molten metal and mould. This suggests that the TiBor addition and lower mold temperature have a synergistic effect in accelerating solidification rate. 
This difference is well observed in Figure 4-2, where the addition of TiBor results in faster solidification. The microstructural observations presented in section 4.2.1.2 also correlate well to the thermal data discussed in this section.

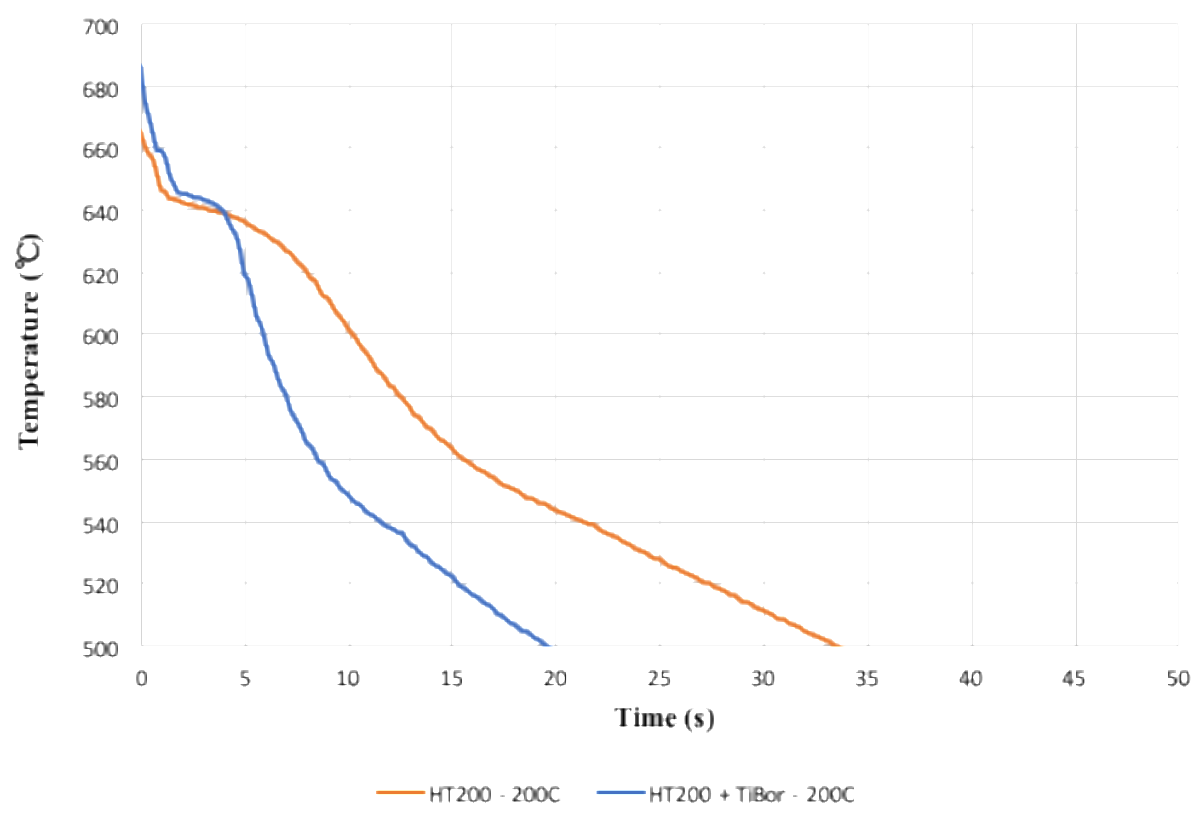

Figure 4-2: Experimental cooling curves for HT200 and HT200 with 0.8 wt\% TiBor at $200{ }^{\circ} \mathrm{C}$ mould temperature.

\subsubsection{Differential Scanning Calorimetry (DSC) - Solidification Analysis}

Thermal analysis with DSC was also carried out for a phase transformation analysis during solidification of the HT200 alloy at a cooling rate of $10^{\circ} \mathrm{C} / \mathrm{min}$. The DSC cooling curve presented in Figure 4-3 shows that the onset of exothermic reactions occurs at 640,582 , and $540{ }^{\circ} \mathrm{C}$. The reaction temperatures approximately correspond to the formation of $\alpha$ - $\mathrm{Al}$ dendrites, $\mathrm{Al}-\mathrm{Cu}-\mathrm{Fe}-\mathrm{Mn}$ intermetallic and $\mathrm{Al}_{2} \mathrm{Cu}$ [14]. The DSC results correspond well to the thermal data gathered from the castings. However, the formation of Al-Fe-Mn-Cu was initially determined to occur at $607{ }^{\circ} \mathrm{C}$ according to the thermal data gathered from the thermocouple inserted in the casting. The discrepancy could be a result of a difference in cooling rate or because of the accuracy of the Ktype thermocouple. 


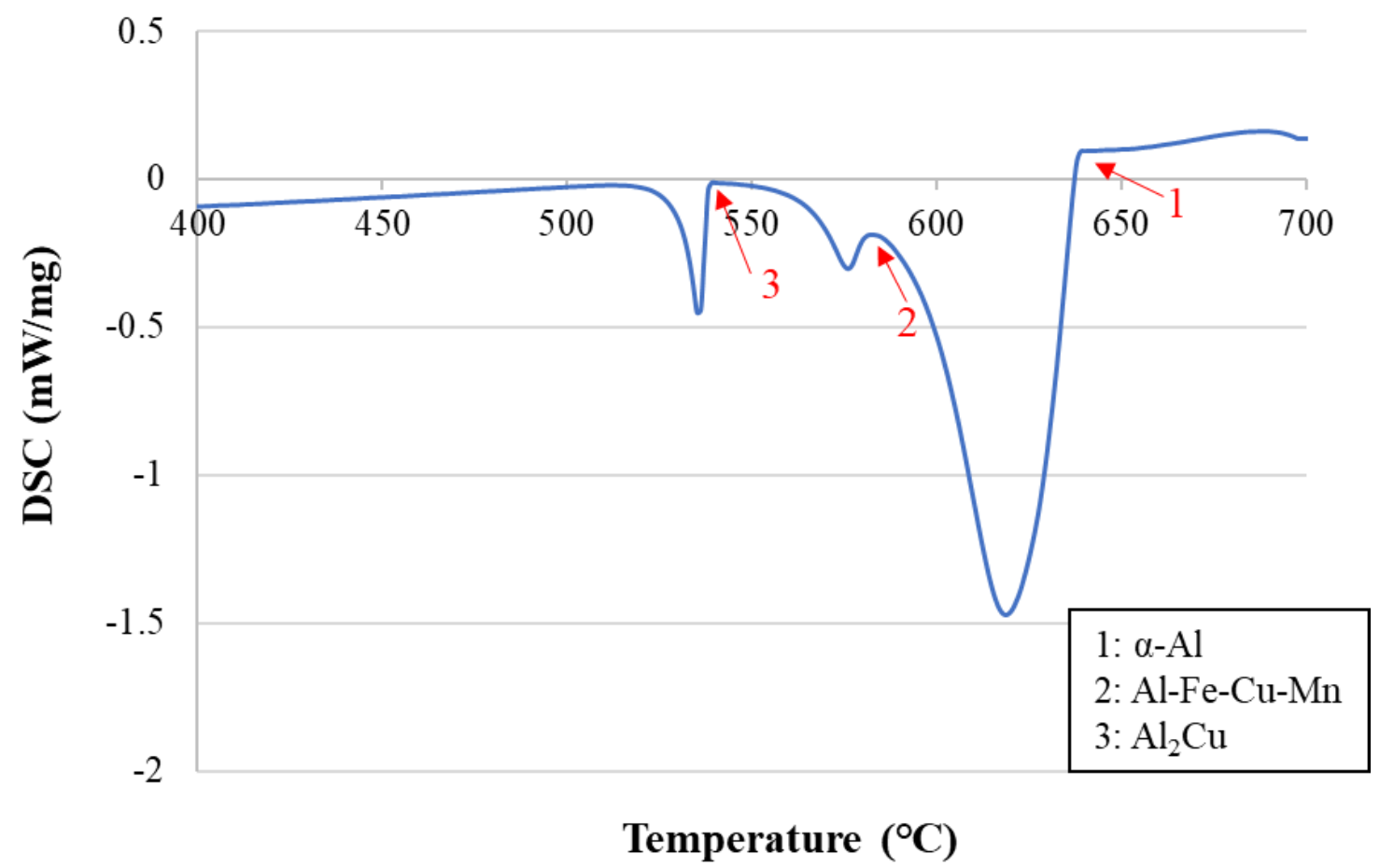

Figure 4-3: DSC cooling curve of $\mathrm{HT} 200$ alloy for a cooling rate of $10{ }^{\circ} \mathrm{C} / \mathrm{min}$.

\subsubsection{Section Summary}

Thermal analysis was carried out to determine the solidification characteristics of the HT200 alloy. This was done for castings at 500 and $200{ }^{\circ} \mathrm{C}$ mould temperatures. The effect of the addition of TiBor grain refiner on the solidification of the HT200 alloy was also analyzed. For each condition, the local solidification time, freezing range, and solidification rate were measured from the thermal data. For $500{ }^{\circ} \mathrm{C}$ mould castings, the addition of TiBor to the HT200 alloy increased the solidification rate by $15 \%$. A lower mould temperature of $200{ }^{\circ} \mathrm{C}$ resulted in a $49 \%$ increase in solidification rate with the addition of TiBor. This was a result of an increased presence of of $\mathrm{Ti}$ inoculants, thereby reducing the time for nucleation of grains. The results also showed that grain refinement with TiBor and a lower mould temperature have a synergistic effect in accelerating solidification of the alloy. Furthermore, the thermal data showed critical points relating to the formation of secondary phases. Additional study of phase transformation during solidification of the HT200 alloy was carried out using DSC. The results were then related to the microstructural analysis and in-situ study of incipient melting using LSCM. 


\subsection{Microstructural Analysis}

The microstructure of HT200 alloy was examined using optical microscopy and scanning electron microscopy. Microstructural analysis was carried out to correlate alloy grain structure and secondary phase morphology to the mechanisms of incipient melting. The results are presented in the following subsections.

\subsubsection{Grain Structure}

The following section presents the characterization of the grain structure of unrefined HT200 alloy and HT200 alloy refined with TiBor. This section shows the changes in grain structure as a function of mould temperature (i.e. solidification rate), as well as the effect of TiBor grain refiner on the grains. The results were used to explain the potential mechanisms of incipient melting in the alloy, as discussed in later sections.

\subsubsection{500 ${ }^{\circ} \mathrm{C}$ Mould Castings}

Micrographs of the base HT200 alloy from the $500{ }^{\circ} \mathrm{C}$ mould castings can be seen in Figure 4-4 at 50x and 100x magnification. Without the addition of TiBor, the HT200 alloy was found to have very coarse grains with a fully dendritic structure. The dendritic morphology likely results in the precipitation of secondary phases within the interdendritic channels, thus incipient melting is more likely occur in these regions as opposed to along the grain boundaries. Additionally, TiBor grain refiner in the form of Al-5Ti-B was added to HT200 alloy to form finer grains and subsequently change the secondary phase distribution. This was done to determine whether the mechanisms of incipient melting are affected by grain refinement. The addition of TiBor was held constant at $0.8 \mathrm{wt} \%$ Al-5Ti-B to simplify the study, while conforming to a current industry practice. The addition of $0.8 \mathrm{wt} \% \mathrm{Al}-5 \mathrm{Ti}-\mathrm{B}$ resulted in a change in the grain structure of the HT200 alloy from a coarse dendritic structure to an equiaxed dendritic structure as presented in Figure 4-5. The grains are relatively finer compared to the unrefined base HT200 alloy. The presence of more grain boundaries promotes the precipitation of secondary phases along the boundaries as opposed to 
within interdendritic channels. Thus, it can be expected that incipient melting occurs along the grain boundaries.
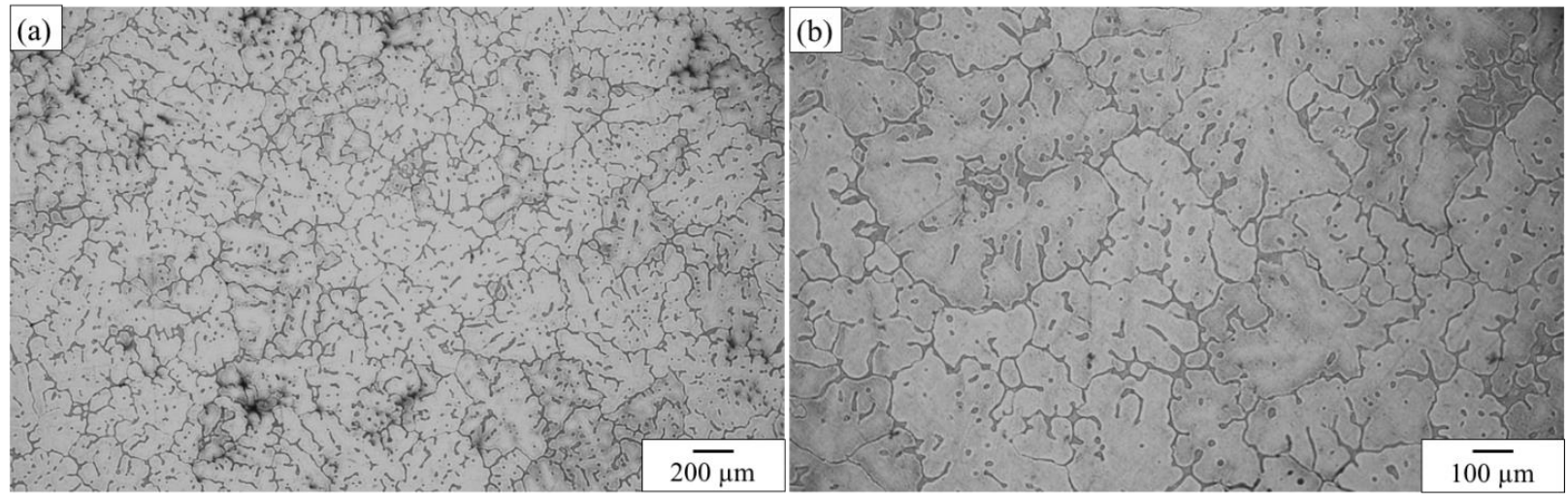

Figure 4-4: Optical micrographs of base HT200 alloy from $500{ }^{\circ} \mathrm{C}$ mould castings at (a) 50x magnification and (b) 100x magnification.
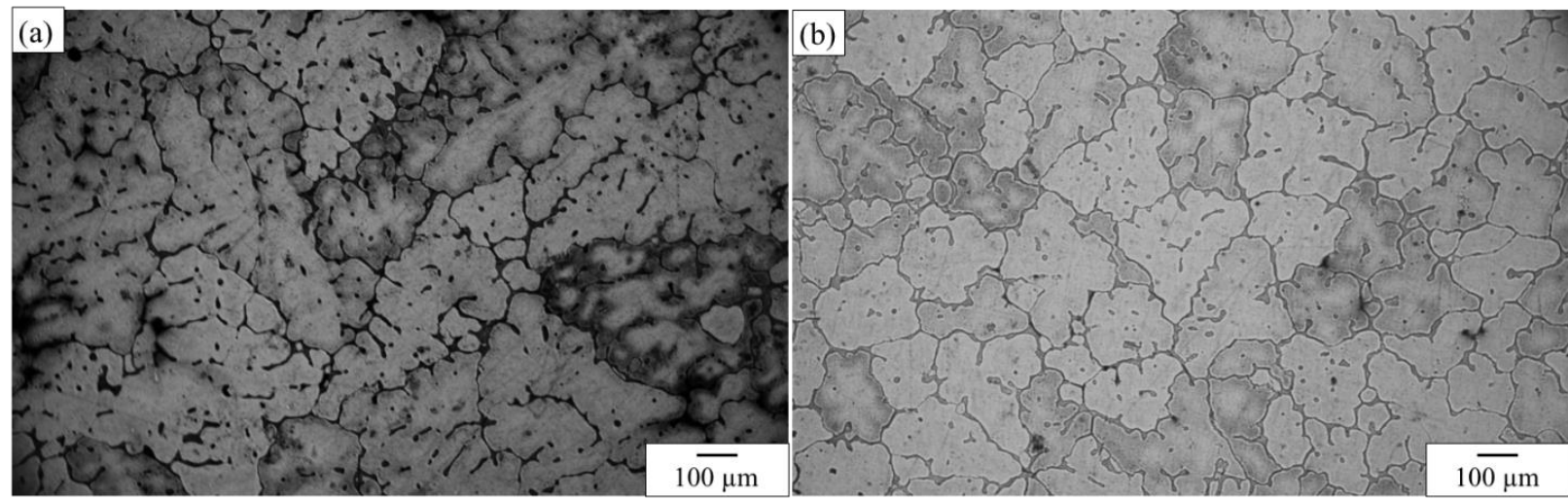

Figure 4-5:Optical micrographs showing grain structure of (a) base HT200 alloy and (b) HT200 with TiBor at $100 x$ magnification from $500{ }^{\circ} \mathrm{C}$ mould castings.

\subsubsection{200 ${ }^{\circ} \mathrm{C}$ Mould Castings}

Analysis of $200{ }^{\circ} \mathrm{C}$ mould castings of unrefined HT200 and HT200 refined with TiBor was also carried out in this work to show the change in microstructure with faster solidification rate. The grain structure of these castings is depicted in Figure 4-6 and Figure 4-7 for 50x and 100x magnifications respectively. The results show a finer grain structure compared to the $500{ }^{\circ} \mathrm{C}$ mould castings for both unrefined and refined HT200 alloys. 
It was found that the resulting grain structure due to fast cooling still appeared to be dendritic. This is well observed in the higher magnification (100x) micrograph, Figure 4-7(a), where the grains have a coarse and fully dendritic morphology. However, compared to the grain morphology from the $500{ }^{\circ} \mathrm{C}$ mould casting (Figure 4-5(a)), the fast solidification rate promoted a significantly finer dendrites and grain size. The addition of TiBor at this mould temperature also resulted in a slight change in morphology to finer and more globular grains (Figure 4-7(b)). At slower solidification rate, the refined HT200 alloy was found to have a more equiaxed morphology (Figure 4-5(b)) with a more defined grain boundary network and less dendrites. However, the results found at faster solidification rates suggest that the same addition of TiBor (0.8 wt.\% Al-5Ti-B) does not have the same effect when compared to the slow cooling condition. While finer grain structure is produced, the morphology is still more dendritic compared to the grain refinement results found with the 500 ${ }^{\circ} \mathrm{C}$ mould castings. Hence, grain refinement addition levels should be adjusted for varying solidification rates. In this case, the difference in solidification rate is large and thus there is a greater influence on the effectiveness of the TiBor refinement on the microstructure $\left(10.5^{\circ} \mathrm{C} / \mathrm{s}\right.$ compared to $0.46^{\circ} \mathrm{C} / \mathrm{s}$. as seen in Table 4-1). The work done in this study provides preliminary analysis on the solidification characteristics of this alloy; future work is required to determine optimal grain refiner addition for the HT200 alloy. Furthermore, in-situ analysis of incipient melting was carried out only for the $500{ }^{\circ} \mathrm{C}$ mould castings because the relatively larger microstructure provides better detail in observing microstructural changes.
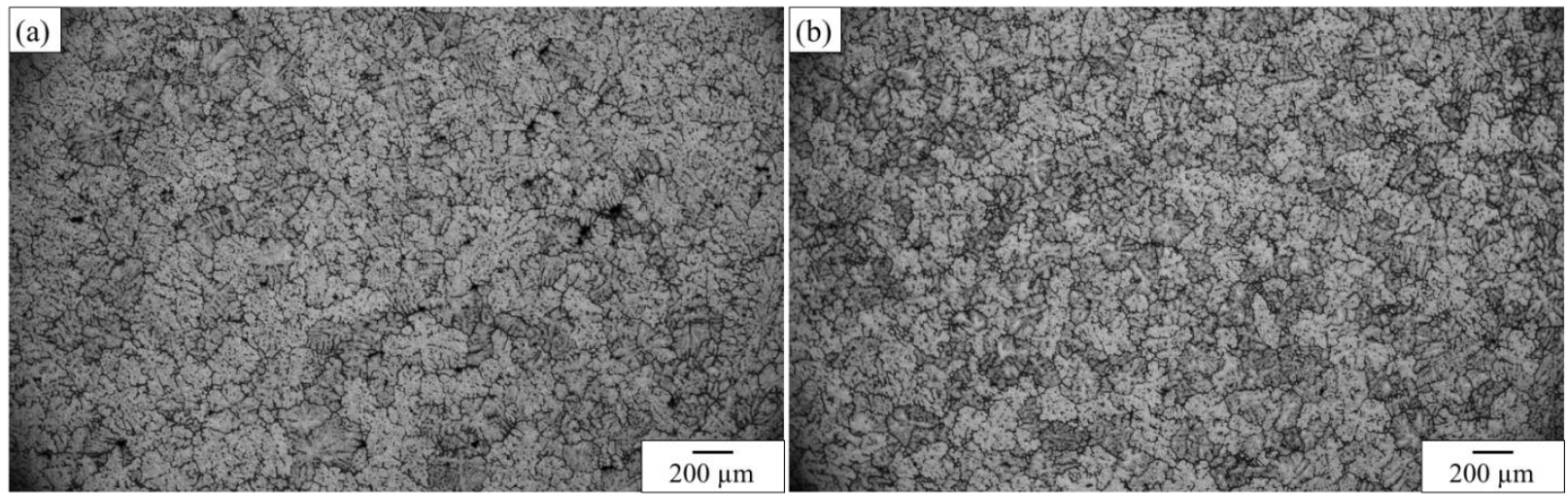

Figure 4-6: Optical micrographs showing grain structure of (a) base HT200 alloy and (b) HT200 with TiBor at 50x magnification from $200{ }^{\circ} \mathrm{C}$ mould castings. 

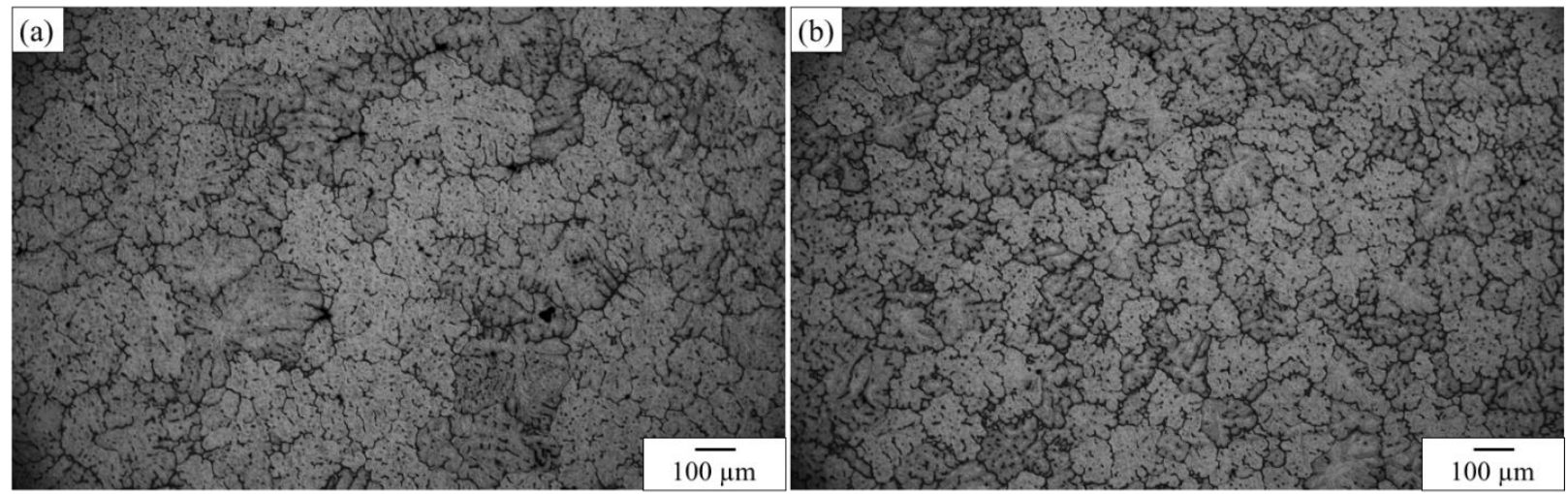

Figure 4-7: Optical micrographs showing grain structure of (a) base HT200 alloy and (b) HT200 with TiBor at $100 x$ magnification from $200{ }^{\circ} \mathrm{C}$ mould castings.

\subsubsection{Secondary Phases}

The secondary phases of the HT200 alloy were examined using SEM. This was done for both 500 and $200{ }^{\circ} \mathrm{C}$ mould temperatures and subsequently for the base HT200 alloy and HT200 refined with TiBor. Thus, the effect of both solidification rate and alloying addition on the microstructure was investigated. Finally, energy dispersive X-ray spectroscopy (EDX) was used to analyze the composition of the secondary phases.

The SEM results show that the predominant phase of the HT200 alloy was $\mathrm{Al}_{2} \mathrm{Cu}$ as seen in Figure 4-8. The $\mathrm{Al}_{2} \mathrm{Cu}$ phase was also identified and confirmed using X-ray diffraction analysis as seen in Figure C-1. The microstructural refinement achieved by faster solidification rates is also observed in Figure 4-9, which correspond well to the grain morphology results discussed in the previous section. The microstructure resulting from the $200{ }^{\circ} \mathrm{C}$ mould casting (Figure 4-9) is finer compared to the microstructure of the $500{ }^{\circ} \mathrm{C}$ mould casting (Figure 4-8) for both unrefined and refined conditions. The addition of TiBor was also only found to be effective at slower solidification rates. It can be seen in Figure 4-8, that the secondary phases were more distributed along the grain boundaries after refinement. This observation corresponds well to the grain structure observed in Figure 4-5. Furthermore, the $\mathrm{Al}_{2} \mathrm{Cu}$ intermetallic compound was found to be present in two forms, as eutectic $\mathrm{Al}_{2} \mathrm{Cu}$ and blocky $\mathrm{Al}_{2} \mathrm{Cu}$. The morphology of the eutectic form has an internal structure of alternating layers of $\mathrm{Al}+\mathrm{Al}_{2} \mathrm{Cu}$, known to be partially departed or lamellar. However, the blocky form was homogeneous and did not have an internal structure. A 
more detailed image of the morphology of the eutectic $\mathrm{Al}_{2} \mathrm{Cu}$ is shown in Figure 4-10. The two different morphologies of $\mathrm{Al}_{2} \mathrm{Cu}$ may contribute to the mechanisms of incipient melting due to their difference in interfacial energies. This will be further discussed in the following section presenting the in-situ observation of incipient melting. Additionally, the other secondary phases identified with EDX were Al-Cu-Fe-Mn and Al-Zr intermetallic. According to the findings in literature the $\mathrm{Al}-\mathrm{Cu}-\mathrm{Fe}-\mathrm{Mn}$ intermetallic is likely to be $\mathrm{Al}_{6}(\mathrm{MnFeCu})$ and not the Chinese script $\alpha$-Fe or the platelet $\beta$-Fe phase [40].

The Al-Zr intermetallic was also identified under the SEM, although the precipitation of this phase was not observed by thermal analysis due to low addition levels $(0.22 \mathrm{wt}$.\%). The Al-Zridentified by $\mathrm{EDX}$ is likely the $\mathrm{Al}_{3} \mathrm{Zr}$ phase and not observed by thermal analysis because most of the phase is in solution; $\mathrm{Zr}$ has a maximum solubility of approximately $0.11 \%$ in aluminum [41]. In literature, $\mathrm{Al}_{3} \mathrm{Zr}$ was observed in $\mathrm{Al}-\mathrm{Cu}$ alloys containing $\mathrm{Zr}$ and is known to enhance high temperature deformation behaviour $[4,42]$. It was evident that these phases were present in very low amounts as they could only be observed at high magnifications (at least 1000x magnification) and at limited number of locations across a sample. The $\mathrm{Al}-\mathrm{Cu}-\mathrm{Fe}-\mathrm{Mn}$ phase was found to have a darker grey contrast compared to $\mathrm{Al}_{2} \mathrm{Cu}$, while $\mathrm{Al}-\mathrm{Zr}$ appeared to be lighter compared to $\mathrm{Al}-\mathrm{Cu}-$ $\mathrm{Fe}-\mathrm{Mn}$ and $\mathrm{Al}_{2} \mathrm{Cu}$ (Figure 4-11). Both phases were also found to be embedded in the $\mathrm{Al}_{2} \mathrm{Cu}$ phase and were not present as separate entities. The corresponding EDX data of the identified secondary phases shown in Figure 4-11 is presented in Figure 4-12.

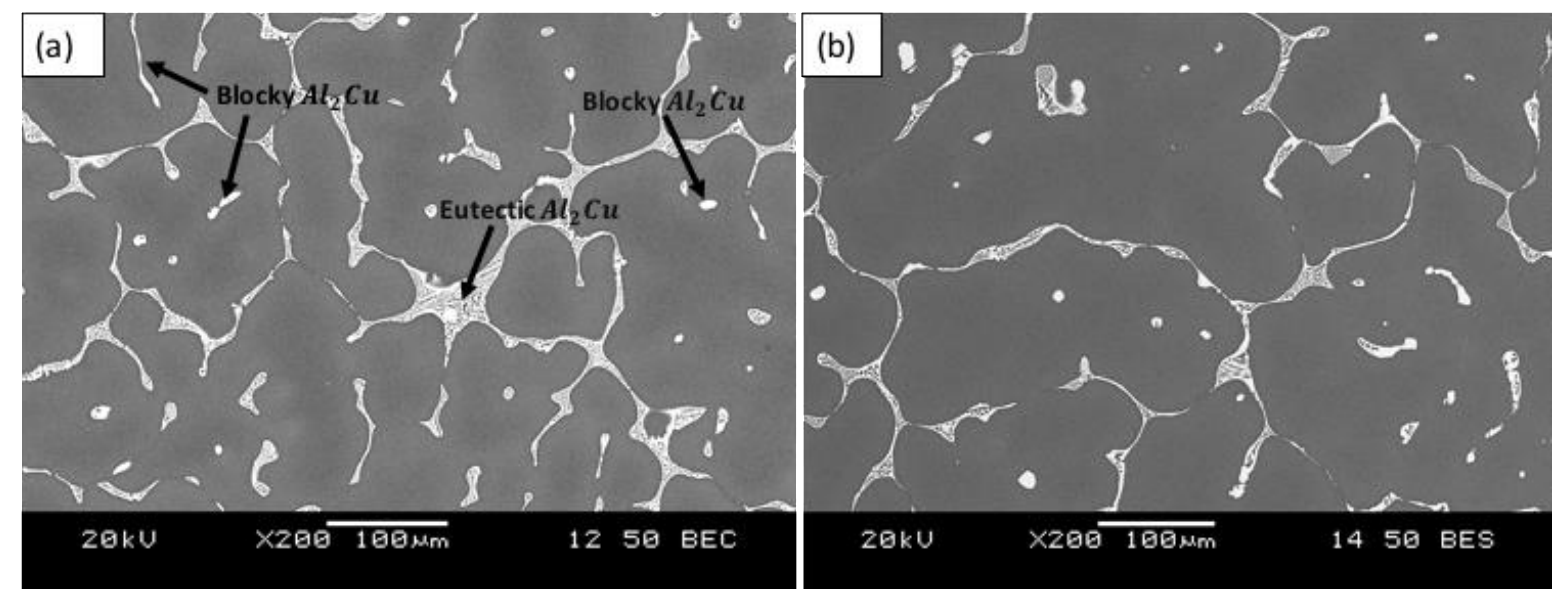

Figure 4-8: Backscattered electron images of intermetallic compounds for $500{ }^{\circ} \mathrm{C}$ castings of (a) base HT200 alloy and (b) HT200 alloy with TiBor at 200x magnification. 

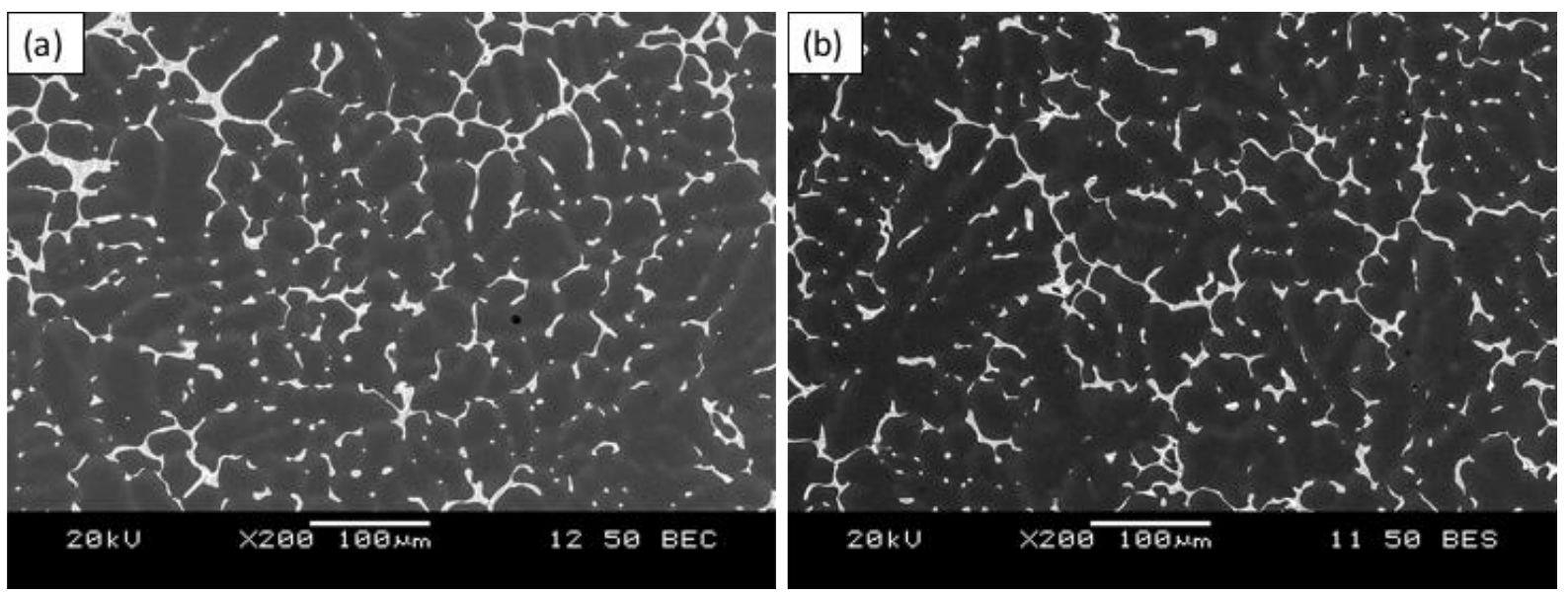

Figure 4-9: Backscattered electron images of intermetallic compounds for $200{ }^{\circ} \mathrm{C}$ castings of (a) base HT200 alloy and (b) HT200 alloy with TiBor at 200x magnification.

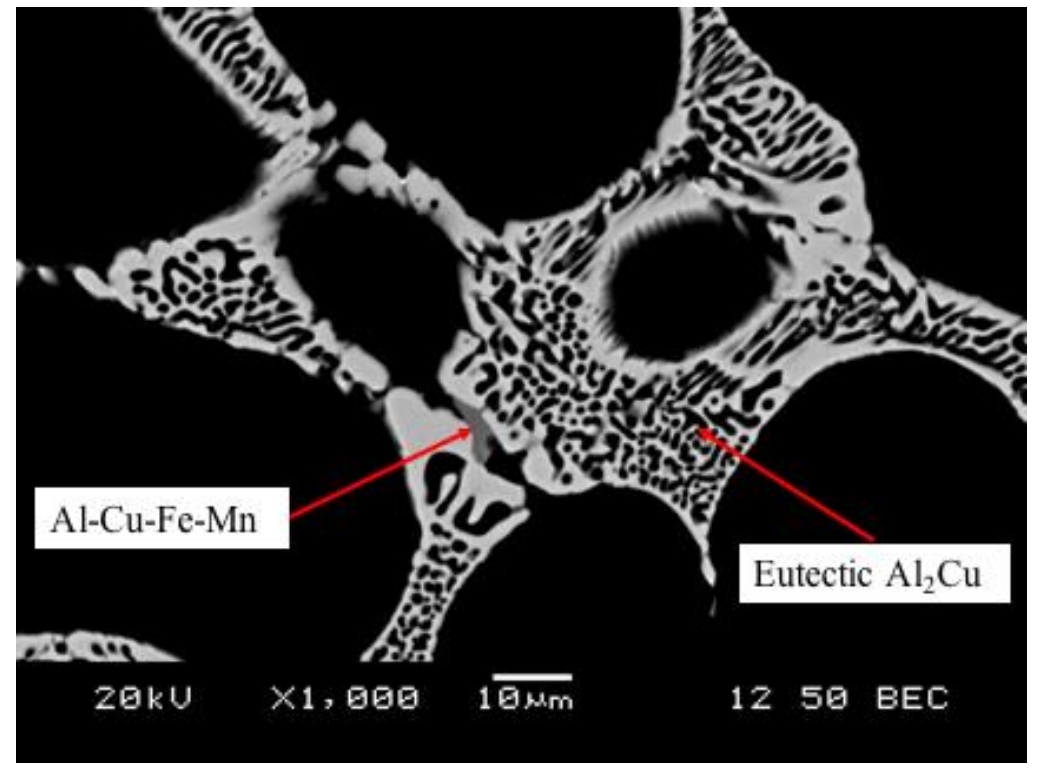

Figure 4-10: Higher magnification backscattered electron image showing the internal structure of eutectic $\mathrm{Al}_{2} \mathrm{Cu}$. 


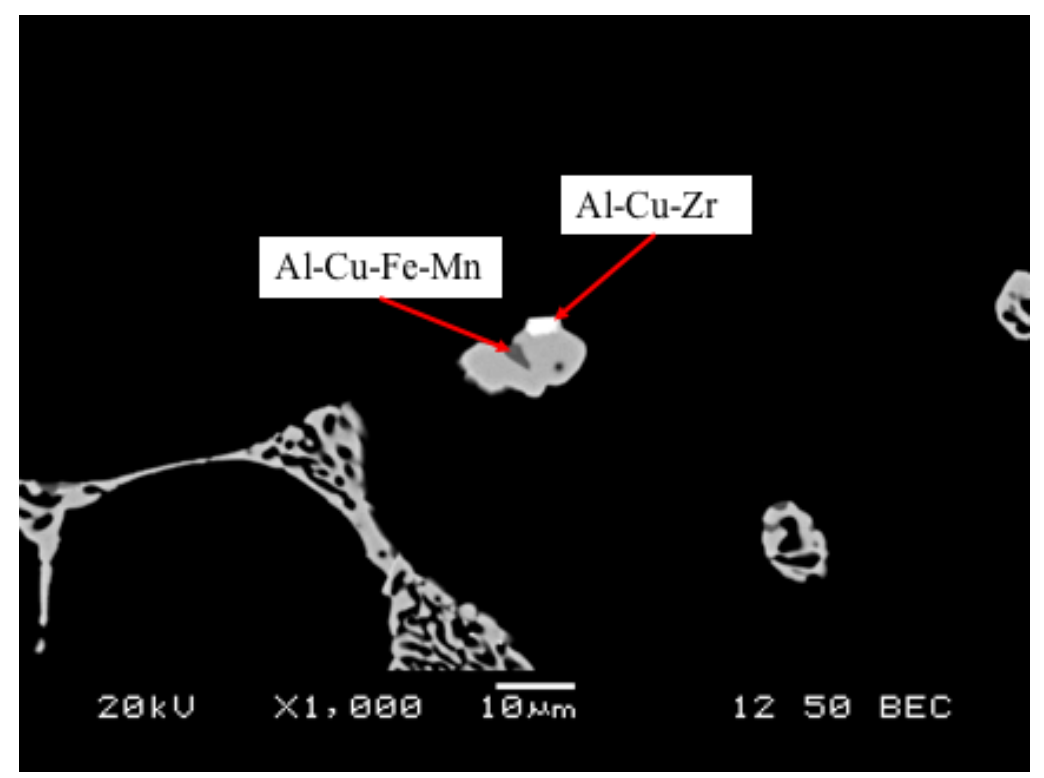

Figure 4-11: Backscattered electron image showing Al-Fe-Mn and Al-Zr intermetallic compounds embedded in $\mathrm{Al}_{2} \mathrm{Cu}$.
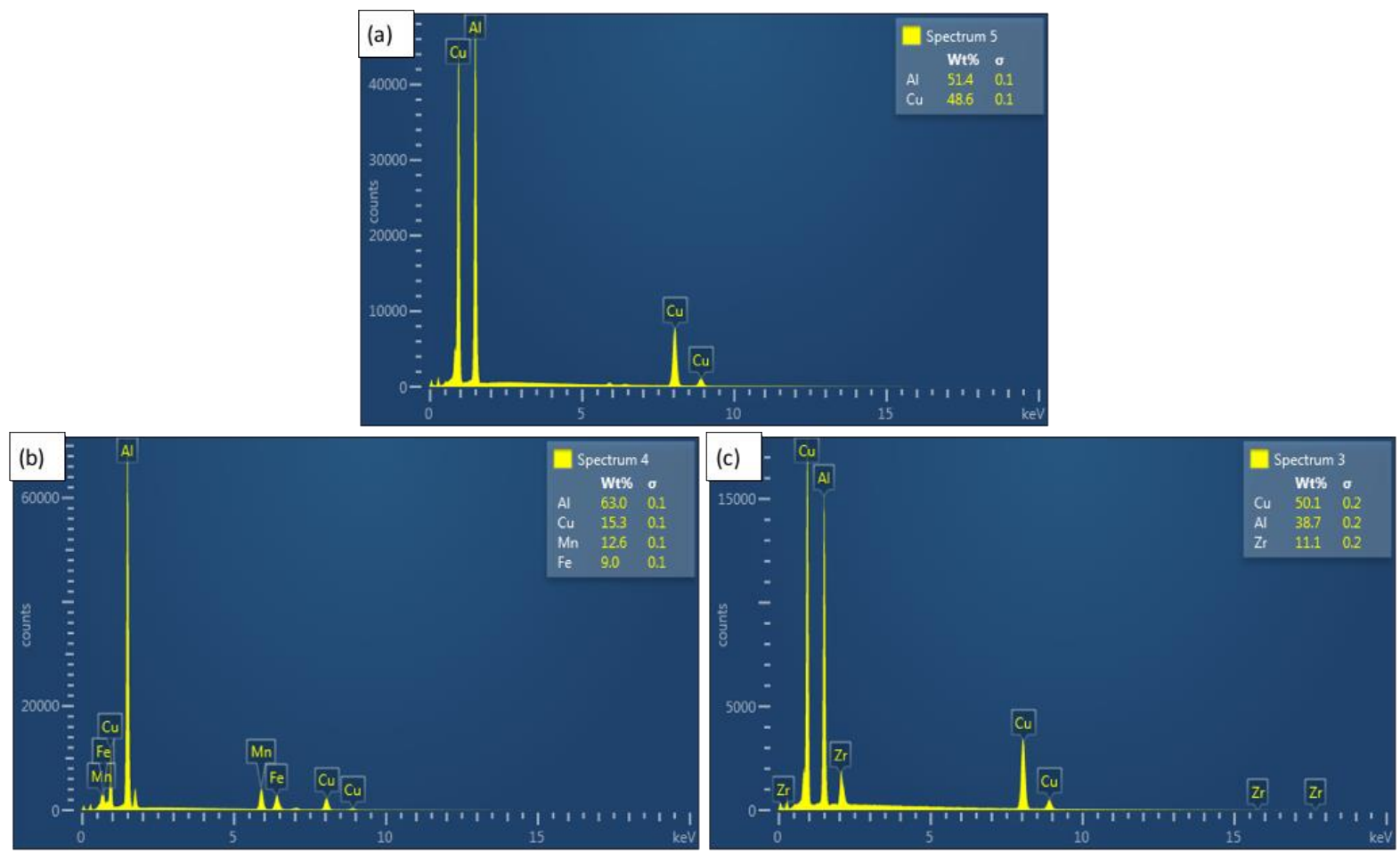

Figure 4-12: EDX analysis of (a) $\mathrm{Al}_{2} \mathrm{Cu}$, (b) $\mathrm{Al}-\mathrm{Cu}-\mathrm{Fe}-\mathrm{Mn}$, and (c) $\mathrm{Al}-\mathrm{Zr}$ secondary phases. 


\subsubsection{Section Summary}

Microstructural analysis was carried out using SEM and optical microscopy. The grain structures obtained with mold temperatures of 500 and $200{ }^{\circ} \mathrm{C}$ were characterized for HT200 alloy with and without TiBor addition. Similarly, the secondary phases for the same set of conditions were analyzed for its morphology and composition. Using EDX, it was determined that $\mathrm{Al}-\mathrm{Cu}, \mathrm{Al}-\mathrm{Cu}-$ $\mathrm{Fe}-\mathrm{Mn}$ and $\mathrm{Al}-\mathrm{Zr}$ were the intermetallic compounds present in the alloy. From X-ray diffraction and existing literature, the stoichiometry of the intermetallic compounds was found to be $\mathrm{Al}_{2} \mathrm{Cu}$, $\mathrm{Al}_{6}(\mathrm{MnFeCu})$ and $\mathrm{Al}_{3} \mathrm{Zr}$. However, $\mathrm{Al}_{2} \mathrm{Cu}$ was evidently the predominant phase in the alloy. This suggests that the majority of incipient melting occur from $\mathrm{Al}_{2} \mathrm{Cu}$ secondary phases. Microstructural analysis was done prior to a study of incipient melting carried out with LSCM. This enabled correlation the mechanisms of incipient melting with microstructural features. 


\subsection{In-situ Analysis of Incipient Melting}

Incipient melting of secondary phases was analyzed using a high temperature laser scanning confocal microscope (LSCM). This section presents temperature-time series micrographs that show detailed transition from the solid to liquid phase. The analysis with LSCM was carried out for $500{ }^{\circ} \mathrm{C}$ mould castings because the relatively larger microstructure provided a more detailed observation of incipient melting. Furthermore, samples of HT200 with TiBor addition were also analyzed under the LSCM. The microstructure after heat treatment in the LSCM was then analyzed using SEM and EDX. Theory on the mechanisms of incipient melting are also discussed.

\subsubsection{Laser Scanning Confocal Microscopy (LSCM)}

In this investigation, LSCM was used to observe incipient melting of $\mathrm{Al}_{2} \mathrm{Cu}$ and accurately determine the melting temperature. This was done by heating the sample at $10{ }^{\circ} \mathrm{C} / \mathrm{min}$ until the phase transformation occurred. At the onset of incipient melting, where there was a coarsening at the interface between the $\mathrm{Al}$ matrix and $\mathrm{Al}_{2} \mathrm{Cu}$ phase, the temperature was held constant to provide an isothermal analysis of incipient melting. The transition of $\mathrm{Al}_{2} \mathrm{Cu}$ to liquid phase was then observed at a constant temperature with increasing time. LSCM micrographs (100x magnification) showing the melting of $\mathrm{Al}_{2} \mathrm{Cu}$ in unrefined HT200 and refined HT200 alloy are illustrated in Figure 4-13 and Figure 4-14 respectively. As seen in Figure 4-13(a), the onset of incipient melting was observed at $548{ }^{\circ} \mathrm{C}$. Isothermal analysis at $549{ }^{\circ} \mathrm{C}$ (the start of the phase transformation) was then carried out to analyze incipient melting of $\mathrm{Al}_{2} \mathrm{Cu}$. The increase in temperature to $549{ }^{\circ} \mathrm{C}$ resulted in the formation of liquid phase and clusters of liquid droplets around the $\mathrm{Al}_{2} \mathrm{Cu}$ along the grain boundary (Figure 4-13(b) and (c)). It is believed that the formation of these liquid droplets may be due to diffusion aided clustering of $\mathrm{Cu}$ atoms. Microstructural analysis on the samples after LSCM suggests that this process may have occurred; this is discussed later in this section. Furthermore, due to the dendritic morphology of the unrefined alloy, the liquid phase was found to expand and propagate into the interdendritic regions. With increasing time, it was observed that the liquid phase and droplets rapidly spread across the surface of the sample away from the grain boundary region and into the interdendritic regions (Figure 4-13(d) and (e)). Furthermore, with increasing time (temperature held at $549{ }^{\circ} \mathrm{C}$ ) the microstructure appears to expand in volume as a 
result of the solid to liquid phase transition. Approximately $146 \mathrm{~s}$ since holding the temperature at $549{ }^{\circ} \mathrm{C}$ no further changes in microstructure were observed. Subsequently, the complete melting of $\mathrm{Al}_{2} \mathrm{Cu}$ resulted in a formation of cavities along the grain boundaries as seen in Figure 4-13(f).

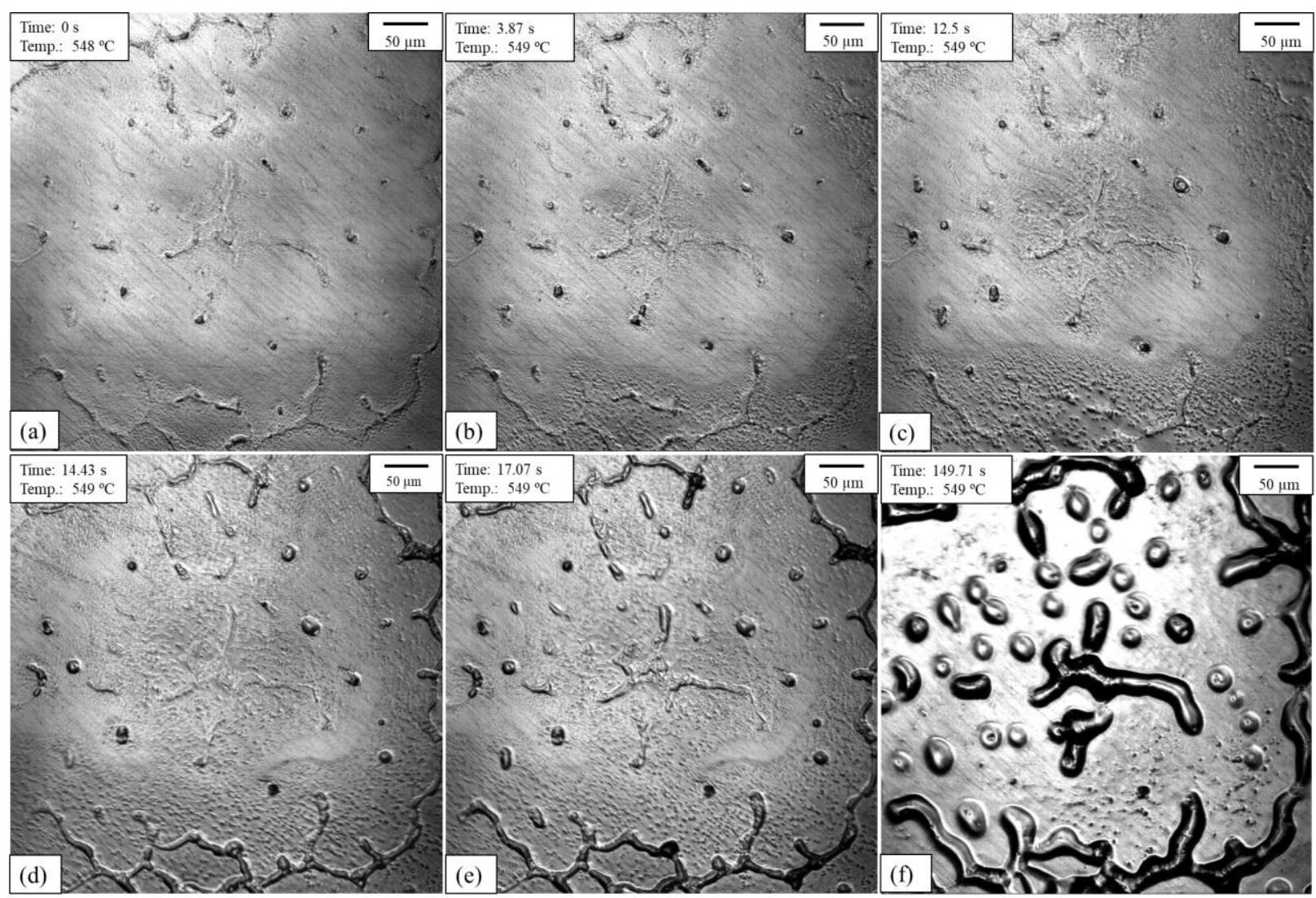

Figure 4-13: $\mathrm{LSCM}$ micrographs showing the sequence of incipient melting of $\mathrm{Al}_{2} \mathrm{Cu}$ in the $\mathrm{HT200}$ alloy at 100x magnification: (a-c) onset of incipient melting and formation of liquid droplets, (d-f) spreading of liquid phase, increase in size of microstructure and formation of cavities.

Similarly, the refined HT200 alloy follows the previously described process of melting. However, it can be seen in Figure 4-14 that the microstructure is less dendritic as evidenced by the presence of more grain boundaries at the same magnification. As a result, localized melting was found to occur at the grain boundaries and expand towards the center of the grain rather than expanding into the interdendritic regions. This was expected when optical microscopy and SEM analysis showed that the addition of TiBor resulted in a more equiaxed grain morphology and a distribution of $\mathrm{Al}_{2} \mathrm{Cu}$ phases along the grain boundaries. Nonetheless, the formation of liquid phase and clusters of liquid droplets (Figure 4-14(c)) due to diffusion of $\mathrm{Cu}$ atoms was observed. In this case, 
the complete melting of $\mathrm{Al}_{2} \mathrm{Cu}$ also led to the formation of cavities (Figure 4-14(d) to Figure 4-14(f)) along the grain boundaries.

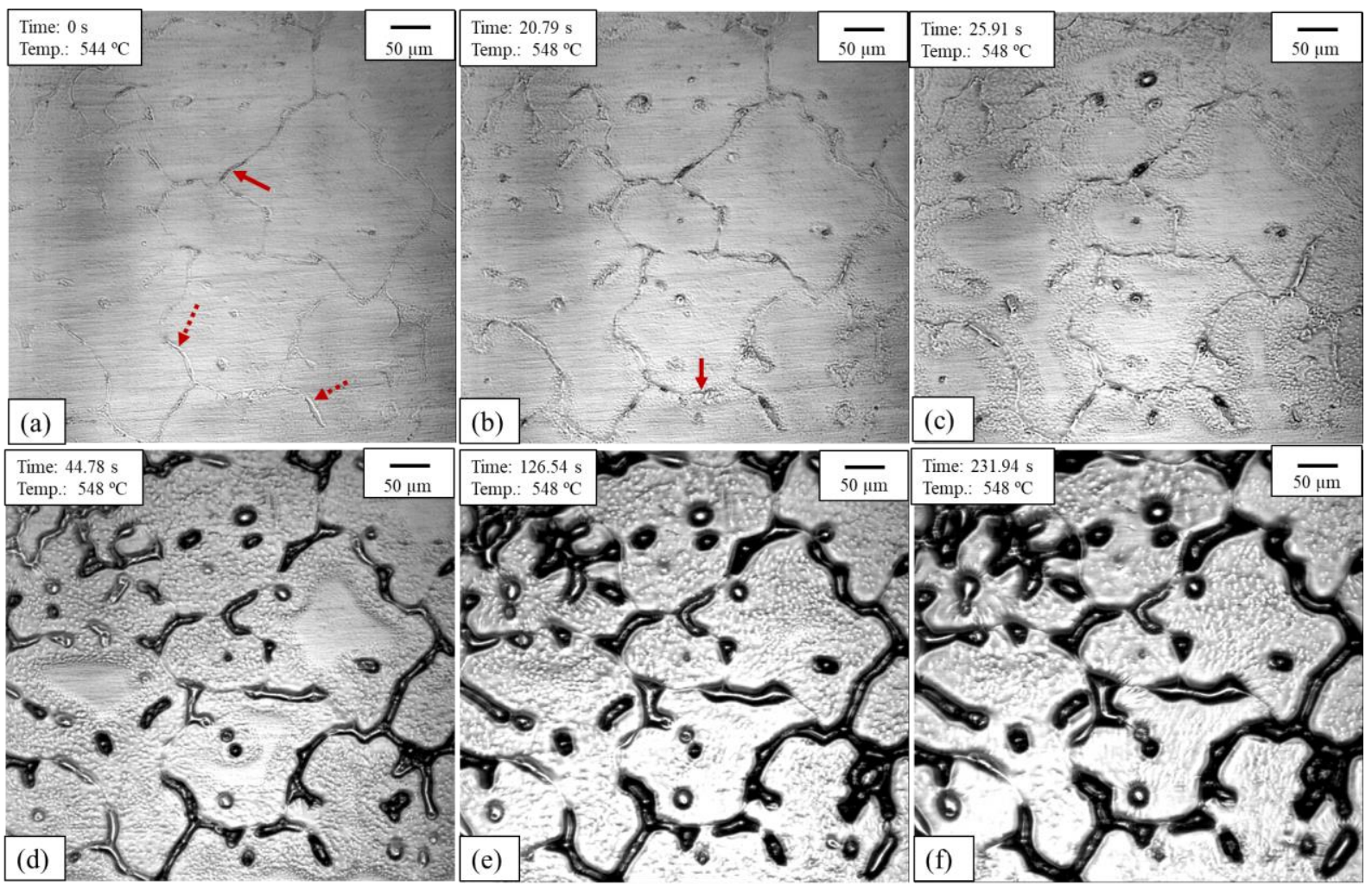

Figure 4-14: LSCM micrographs showing the sequence of incipient melting of $\mathrm{Al}_{2} \mathrm{Cu}$ in the $\mathrm{HT200}$ alloy refined with TiBor at 100x magnification: (a-c) onset of incipient melting and formation of liquid droplets, (d-f) spreading of liquid phase, increase in size of microstructure and formation of cavities.

Higher magnification analysis was also carried out for a more detailed observation of incipient melting. This is illustrated in the LSCM micrographs in Figures 4-15 and 4-16. Figure 4-15 presents the analysis for the unrefined HT200 alloy, whereas LSCM analysis of the refined HT200 alloy is shown in Figure 4-16. In this analysis, the onset of incipient melting of $\mathrm{Al}_{2} \mathrm{Cu}$ was at $554{ }^{\circ} \mathrm{C}$. It is important to note that increasing magnification likely results in missing the overall start of the phase transformation, which may occur at a different location on the surface. Although, the analysis begins at $554{ }^{\circ} \mathrm{C}$ in this case, the critical temperature is still believed to be $548{ }^{\circ} \mathrm{C}$. It was also found that at the onset of melting, there was a coarsening of the phases at the $\mathrm{Al}$ and $\mathrm{Al}_{2} \mathrm{Cu}$ interface. An increase in temperature to $555{ }^{\circ} \mathrm{C}$ resulted in the formation of liquid phase and droplets as previously observed from the lower magnification results. However, it was clearly observed that this phase transition initially occurred for the eutectic (solid red arrow) $\mathrm{Al}_{2} \mathrm{Cu}$ phase 
as seen in Figure 4-15(b), where a rapid propagation of liquid resulted in a pool of Al surrounding the eutectic $\mathrm{Al}_{2} \mathrm{Cu}$. Conversely, the surrounding round blocky (dashed red arrow) $\mathrm{Al}_{2} \mathrm{Cu}$ phases have not yet reached complete melting with increasing time at a constant temperature of $555{ }^{\circ} \mathrm{C}$. This suggests that the eutectic type $\mathrm{Al}_{2} \mathrm{Cu}$ melts prior to the blocky type $\mathrm{Al}_{2} \mathrm{Cu}$ particles. This was followed by the propagation of the liquid phase across the sample surface (Figure 4-15(b) to (c)). Similarly, the high magnification analysis for the refined alloy followed the same sequence of melting. As seen in Figure 4-16(a), the eutectic particle is seen to coarsen at the $\mathrm{Al}_{\text {and }} \mathrm{Al}_{2} \mathrm{Cu}$ interface when reaching $547^{\circ} \mathrm{C}$. In this case, it was also observed that the eutectic phase was found to melt prior to the blocky phase with increasing time (Figure 4-16(b) to (c)). As previously discussed, for both analyses (Figure 4-15 and Figure 4-16), the complete melting of $\mathrm{Al}_{2} \mathrm{Cu}$ resulted in the expansion of microstructure which led to the formation of cavities along the grain boundaries. In this investigation, the critical temperature for complete melting of $\mathrm{Al}_{2} \mathrm{Cu}$ was found to occur at $548{ }^{\circ} \mathrm{C}$ and higher.
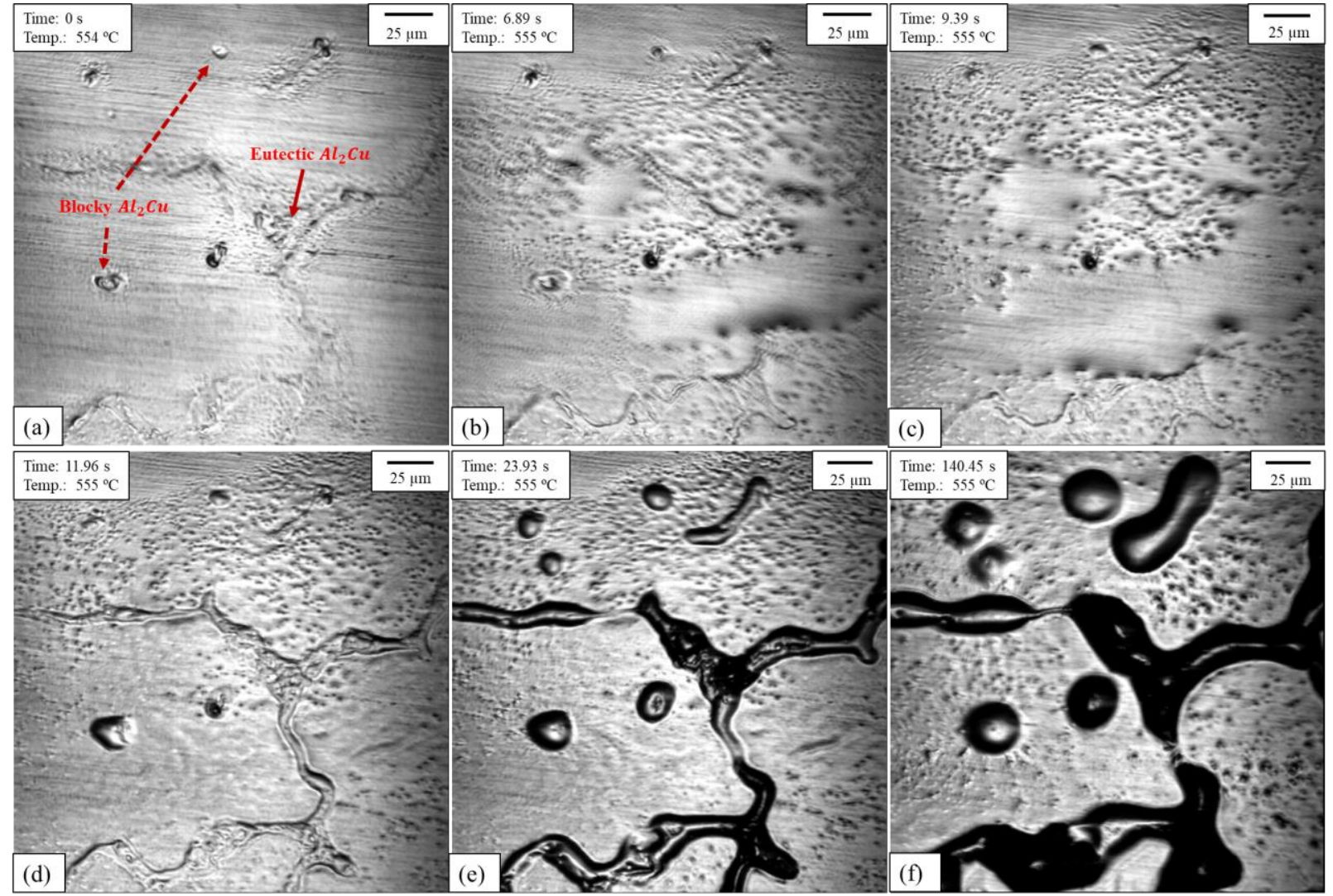

Figure 4-15: LSCM micrographs showing the sequence of incipient melting of $\mathrm{Al}_{2} \mathrm{Cu}$ in the $\mathrm{HT200}$ alloy at 200x magnification: (a-c) melting at $\mathrm{Al}+\mathrm{Al}_{2} \mathrm{Cu}$ interface and formation of liquid phase, (d-f) increase in size of microstructure and formation of cavities. 


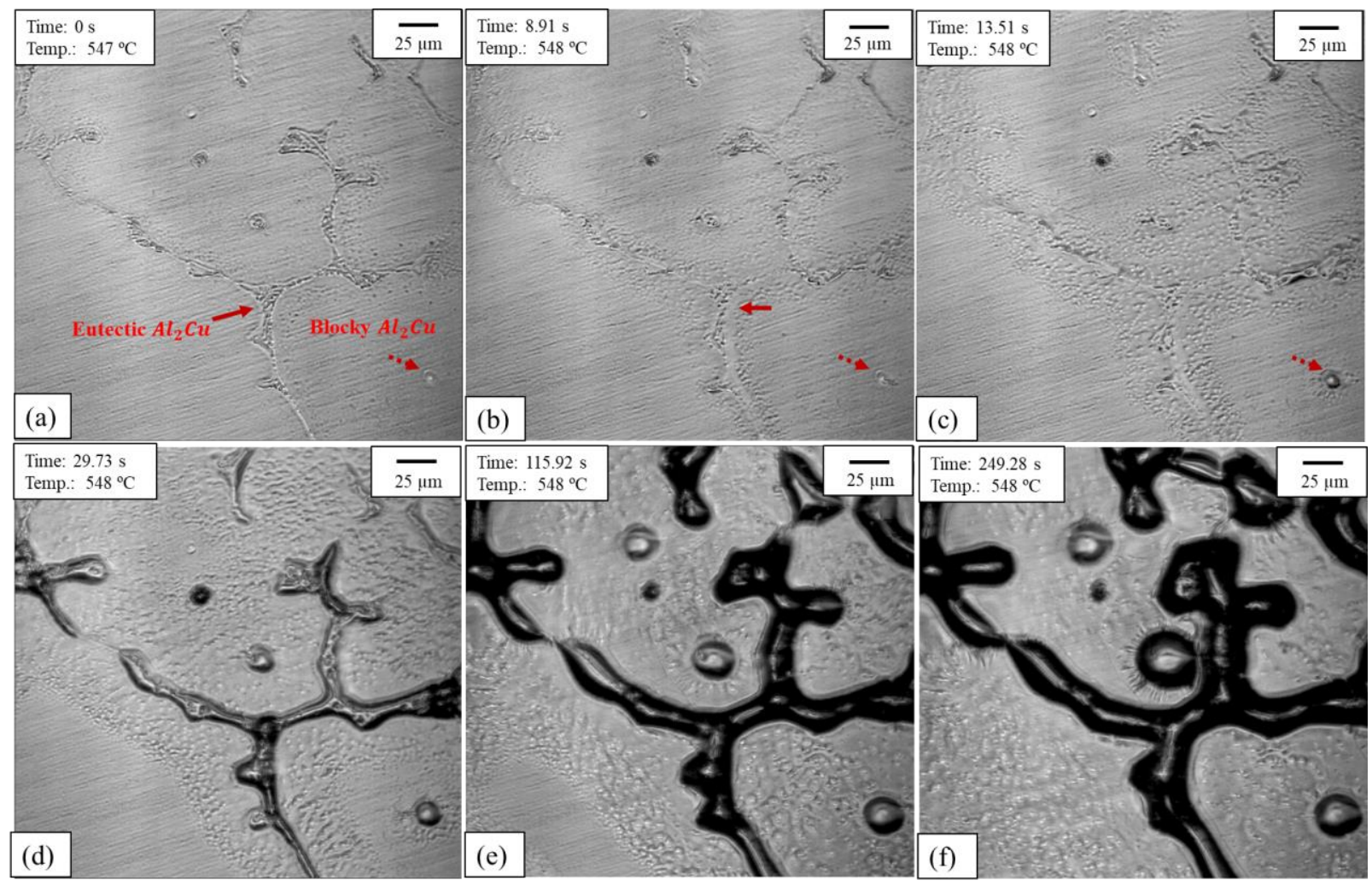

Figure 4-16: LSCM micrographs showing the sequence of incipient melting of $\mathrm{Al}_{2} \mathrm{Cu}$ in the $\mathrm{HT200}$ alloy refined with TiBor at 200x magnification: (a-c) melting at $\mathrm{Al}+\mathrm{Al}_{2} \mathrm{Cu}$ interface and formation of liquid phase, (d-f) increase in size of microstructure and formation of cavities.

\subsubsection{Differential Scanning Calorimetry (DSC)}

The results found using LSCM corresponded well to the results obtained from DSC analysis as seen in Figure 4-17. The DSC curve obtained when heating the sample to $700{ }^{\circ} \mathrm{C}$ at a heating rate of $10{ }^{\circ} \mathrm{C} / \mathrm{min}$ resulted in two endothermic peaks. The first peak occurred at $549.6{ }^{\circ} \mathrm{C}$ with an enthalpy of $27.83 \mathrm{~J} / \mathrm{g}$, followed by a second peak at $648.4^{\circ} \mathrm{C}$ having an enthalpy of $284.8 \mathrm{~J} / \mathrm{g}$. These results entail that incipient melting of $\mathrm{Al}_{2} \mathrm{Cu}$ occurred at $549.6{ }^{\circ} \mathrm{C}$. Although two other phases (Al-Cu-Zr and $\mathrm{Al}-\mathrm{Cu}-\mathrm{Fe}-\mathrm{Mn})$ were identified, no energy peaks were found indicating the melting of these phases. This is likely because $\mathrm{Al}_{2} \mathrm{Cu}$ is the predominant phase, while the $\mathrm{Zr}$ and Fe bearing phases are present in small amounts. This was also observed under the LSCM where the primary source of incipient melting is $\mathrm{Al}_{2} \mathrm{Cu}$. The second peak corresponds to the melting of $\alpha$-Al dendrites (liquidus temperature). The DSC experiment was repeated for HT200 samples with the addition of TiBor. The results showed that the addition of TiBor did not have an effect on the 
incipient melting temperature of $\mathrm{Al}_{2} \mathrm{Cu}\left(\sim 549.6^{\circ} \mathrm{C}\right)$. However, the enthalpy measured for the $\mathrm{Al}_{2} \mathrm{Cu}$ peak was determined to be less than in the unrefined alloy. The enthalpy measured in the refined alloy was $25.7 \mathrm{~J} / \mathrm{g}$. This was a result of the refinement of the microstructure, where the $\mathrm{Al}_{2} \mathrm{Cu}$ secondary phases were finer and redistributed along the grain boundaries. Hence, there is a lower surface area and volume fraction of $\mathrm{Al}_{2} \mathrm{Cu}$, which would subsequently require less energy to cause melting of the particles.

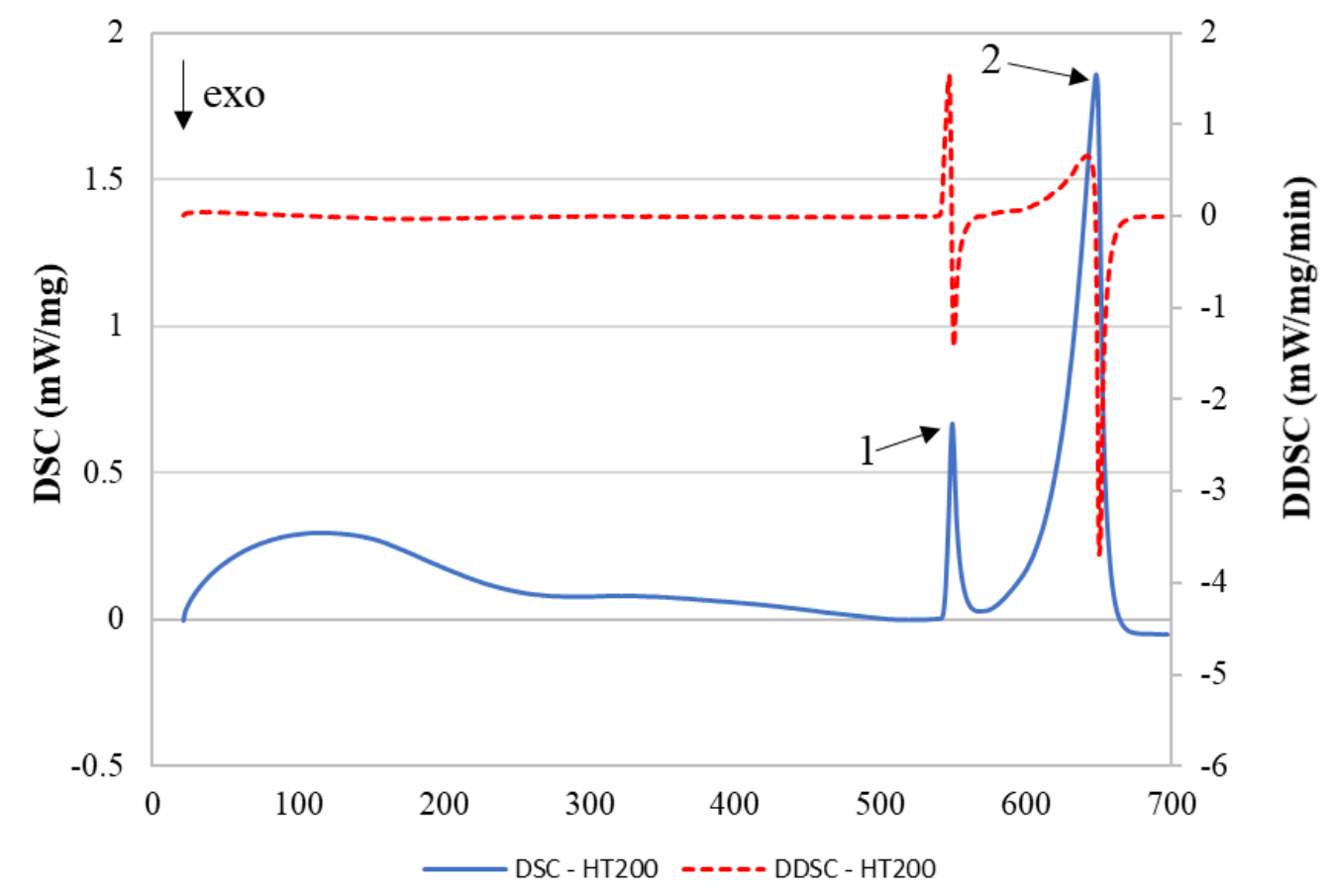

Temperature $\left({ }^{\circ} \mathrm{C}\right)$

Figure 4-17: DSC analysis of $\mathrm{HT200}$ alloy heated to $700{ }^{\circ} \mathrm{C}$ at a heating rate of $10{ }^{\circ} \mathrm{C} / \mathrm{min}$.

\subsubsection{Analysis of Microstructure Post-LSCM}

Microstructural analysis was also carried on samples after heat treatment under the LSCM. SEM and EDX were used to analyze the microstructure that developed resulting from incipient melting. Figure 4-18 illustrates the difference in microstructure of the HT200 alloy before and after LSCM, while Figure 4-19 presents SEM micrographs at higher magnification for detailed observation of the microstructure after incipient melting. It was found that the microstructure had a significant presence of cavities (i.e. porosity), a rough surface topography and glassy ultra-fine eutectic (UFE) 
clusters. Incipient melting has been well documented to be deleterious to mechanical properties [21]. This is in large part, due to the formation of defects such as porosity and UFE clusters as seen in Figure 4-19. In this case, glassy eutectic clusters are brittle in nature and are sites for crack initiation, thereby having a negative effect on mechanical properties. The results were found to be the same for both the unrefined and refined HT200 alloy.
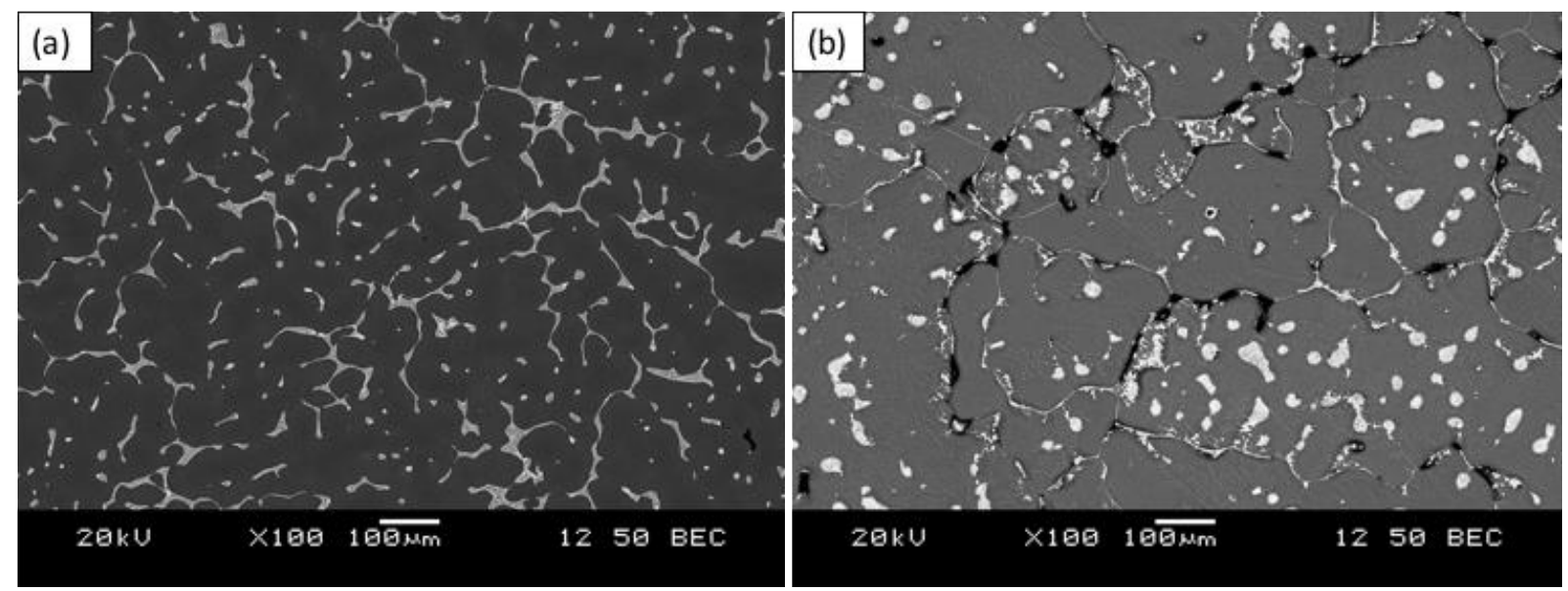

Figure 4-18: SEM images showing microstructure of HT200 alloy (a) before incipient melting and (b) after incipient melting at 100x magnification.
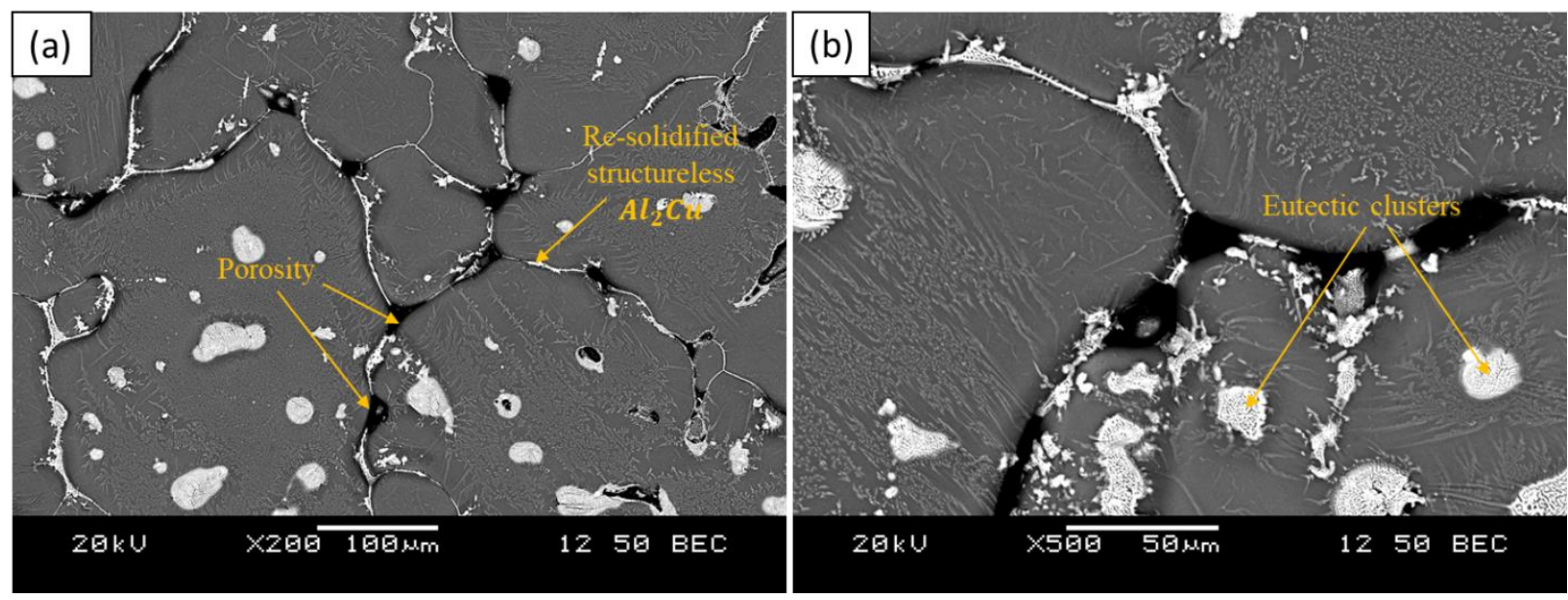

Figure 4-19: Microstructure of LSCM HT200 alloy sample after incipient melting at (a) 200x and (b) 500x magnification.

Additionally, the SEM images show a rough surface topography on the samples after incipient melting, which may also attribute to poor mechanical properties. As seen in Figure 4-19(b), the surface contained fine spherical particles that were accumulated around the grain boundary and 
UFE clusters. Furthermore, these fine particles appear to have solidified directionally away from the grain boundary or UFE clusters. In the previous section, it was discussed that observation under the LSCM showed the formation of liquid droplets during incipient melting that were likely clusters of diffused $\mathrm{Cu}$ atoms from the $\mathrm{Al}_{2} \mathrm{Cu}$ particles. EDX analysis, shown in Figure 4-20, indicates that the surface of the Al sample that contained these fine spherical particles are rich in $\mathrm{Cu}$. The distribution of elements in the microstructure was also analyzed and illustrated in the EDX elemental maps in Figure 4-21. The EDX elemental mapping results also show a greater distribution of $\mathrm{Cu}$ in the $\mathrm{Al}$ matrix, as previously stated. This suggests, that the liquid droplets observed under the LSCM during incipient melting was a clustering of $\mathrm{Cu}$ diffusing into the $\mathrm{Al}$ matrix. Additionally, the Fe and Mn phases were also well dispersed across the sample surface as seen in Figure 4-21(e) and (f), which show how the other intermetallic compounds were affected by the complete melting of $\mathrm{Al}_{2} \mathrm{Cu}$. Furthermore, the UFE has a composition close to the eutectic composition, according to the binary Al-Cu phase diagram. This analysis was also carried out to determine whether any oxides were present on the surface of the sample. However, no evidence of oxidation was found, likely because of the inert atmosphere used in the LSCM heating chamber.
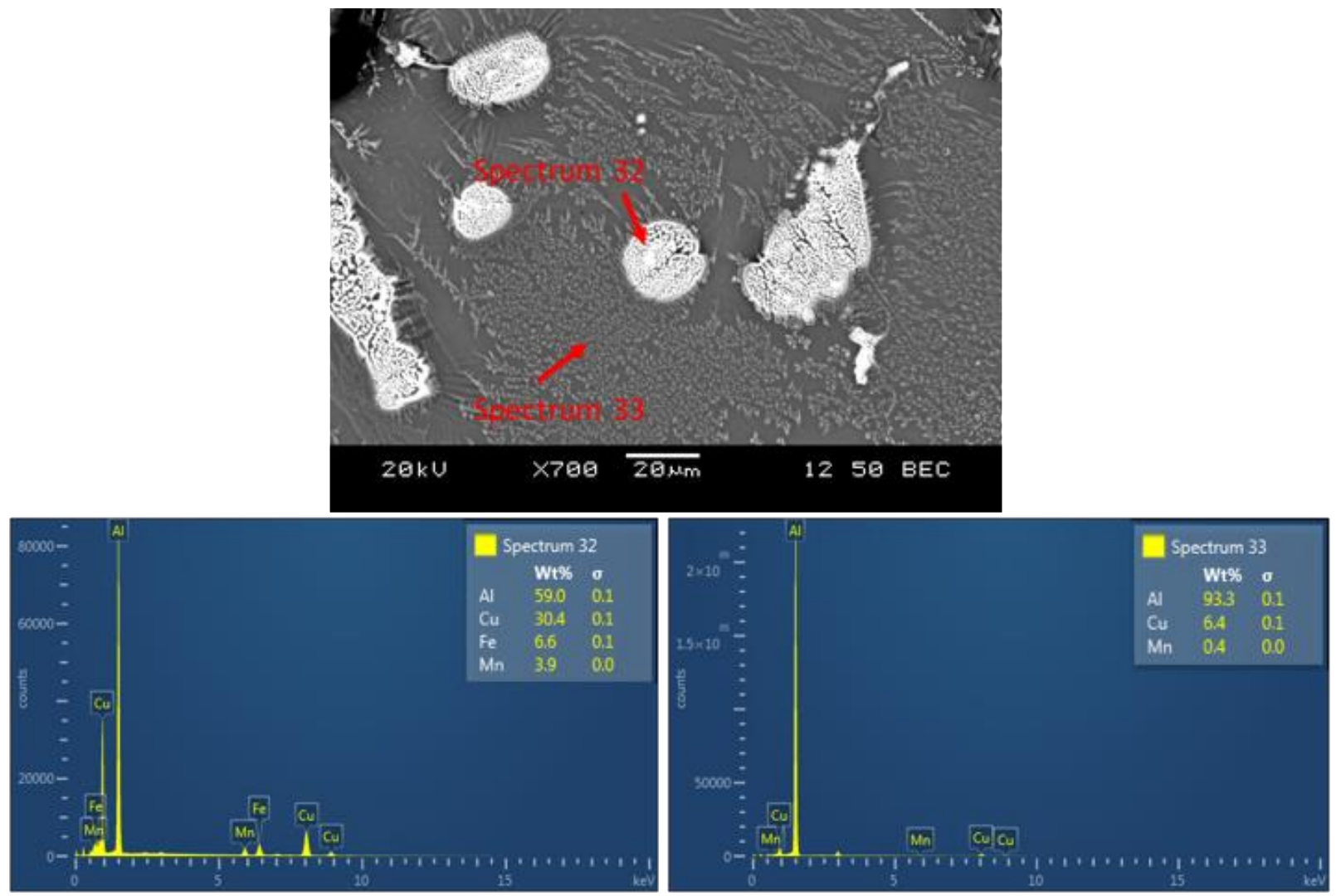

Figure 4-20: EDX analysis of ultra-fine eutectic cluster and surrounding Al matrix. 


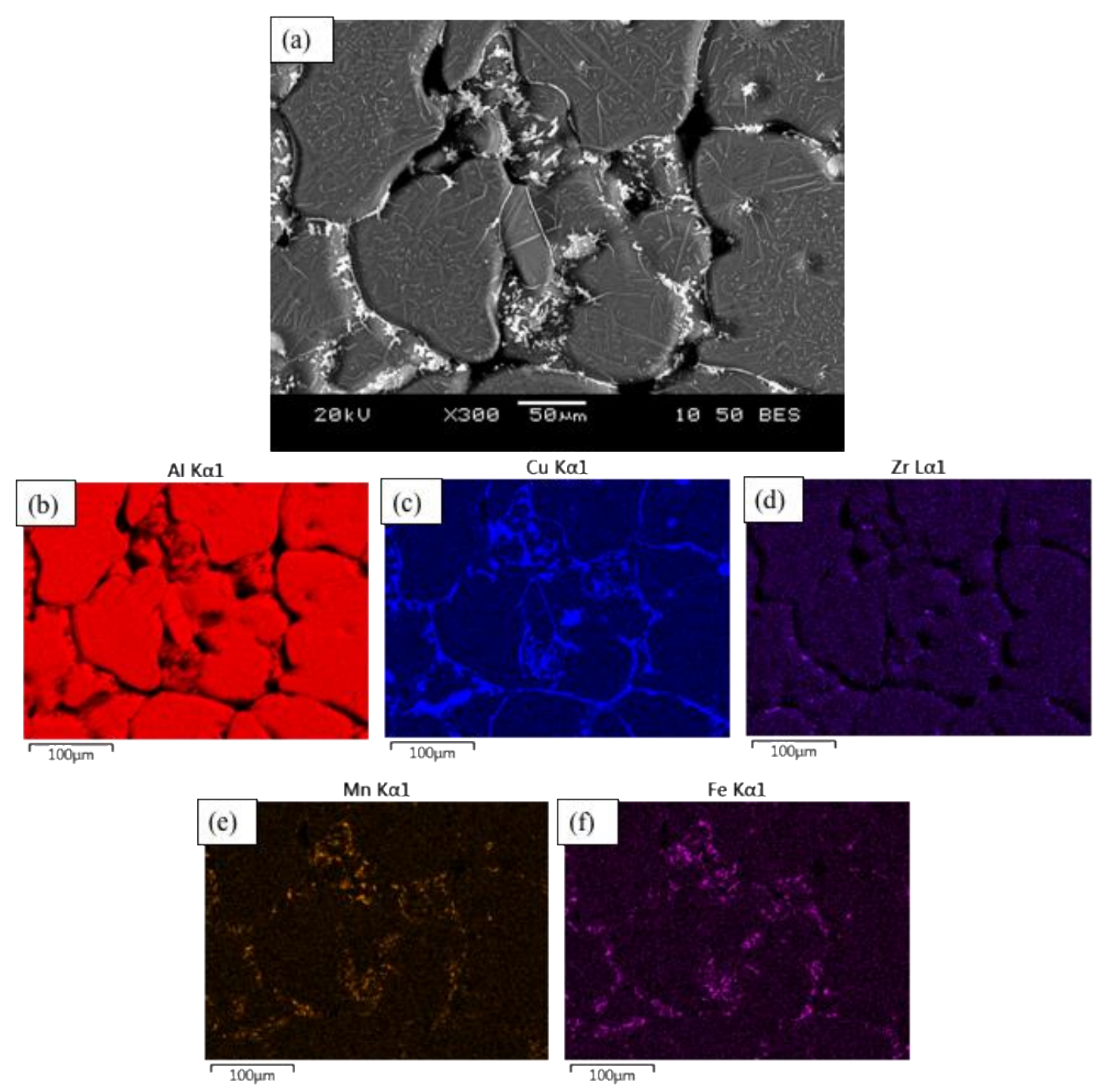

Figure 4-21: Backscattered SEM image of HT200 alloy showing (a) surface microstructure and EDX elemental maps for (b) Al, (c) $\mathrm{Cu}$, (d) $\mathrm{Zr}$, (e) Mn and (f) Fe after incipient melting.

\subsubsection{Mechanisms of Incipient Melting}

The results found from the LSCM analysis were used to explain a possible theory for the mechanisms of incipient melting. The mechanisms of incipient melting were found to consist of a combination of 2 phenomena: (1) interfacial energy of the $\mathrm{Al}_{2} \mathrm{Cu}$ intermetallic phases and (2) diffusion of $\mathrm{Cu}$ atoms. As previously discussed, the results showed that blocky $\mathrm{Al}_{2} \mathrm{Cu}$ was found to melt after eutectic $\mathrm{Al}_{2} \mathrm{Cu}$ as the temperature was increased to the incipient melting temperature $\left(\sim 548^{\circ} \mathrm{C}\right)$. Additionally, an isothermal analysis was also done where the temperature was held constant at the instant that the phases began to melt. While at constant temperature, it was observed 
that with increasing time the eutectic phase first melt and was then followed by the melting of the blocky phase. The observed phenomena may be a result of the difference in interfacial energies between the blocky and eutectic type $\mathrm{Al}_{2} \mathrm{Cu}$. Although, the interfacial energy $\Delta \mathrm{H}$ (eV/atom) of $\mathrm{Al}_{2} \mathrm{Cu}$ have been reported variously as 0.18 [43] and 0.14-0.25 [44]. The morphology of the eutectic phase consists of an internal structure with alternating layers of $\mathrm{Al}$ and $\mathrm{Al}_{2} \mathrm{Cu}$, whereas the blocky phase is homogenous. As a result, the eutectic phases have higher interfacial area per unit volume compared to the blocky phase. Additionally, for both types of $\mathrm{Al}_{2} \mathrm{Cu}$ it was found that initial melting earlier occurred at the interface of the $\mathrm{Al}$ and $\mathrm{Al}_{2} \mathrm{Cu}$. This is because the interfacial energy is higher at the interface of the particle relative to the internal face. Melting also primarily occurred at the grain boundaries, which correspond well to the results found in previous studies $[21,23]$. It is generally accepted that grain boundary regions are at a high energy state, thus enabling faster atomic motion and consequently melting at high temperatures [45]. In this study, the secondary phases were found to precipitate along the grain boundaries, thus rendering these phases more susceptible to incipient melting.

Additionally, in this study it was also observed that random and localized melting occurred at different regions within a eutectic phase. Hence, another potential variable may contribute to localized melting of secondary phases in addition to interfacial energy. EDX point analyses were taken across eutectic $\mathrm{Al}_{2} \mathrm{Cu}$ secondary phases, and it was found that the $\mathrm{Cu}$ content varied from 34 to 48 wt.\% (Figure 4-22). The amount of Cu likely attributes to the random and localized melting of $\mathrm{Al}_{2} \mathrm{Cu}$. In the analysis, the blocky phases were found to have a more constant value of approximately $48 \mathrm{wt}$.\% $\mathrm{Cu}$. This observation also remains consistent with the previous discussion as to why blocky phases melt after the eutectic type $\mathrm{Al}_{2} \mathrm{Cu}$. It should be noted that EDX has limitations with accuracy in composition analysis depending on the size of the microstructure; hence error may result from EDX accuracy. Thus, additional work was done where the $\mathrm{Al}_{2} \mathrm{Cu}$ particles were extracted and isolated from the Al matrix to carry out a composition analysis with EDX (Figure 4-23). This would eliminate noise picked up from the Al matrix and focus solely on the $\mathrm{Al}_{2} \mathrm{Cu}$ particles. The results were found to be consistent with the previous observation and showed a variation in $\mathrm{Cu}$ content across different particles. A variation in $\mathrm{Cu}$ content from 40 to 58 wt.\% was observed. Hence, it is possible that the localized melting of secondary phases is also affected by the amount of $\mathrm{Cu}$ in $\mathrm{Al}_{2} \mathrm{Cu}$, where particles containing higher amounts of $\mathrm{Cu}$ will melt 
at higher temperature or require more time to melt. The inhomogeneity of $\mathrm{Cu}$ in $\mathrm{Al}_{2} \mathrm{Cu}$ would also result in a higher diffusion rate at different regions across a sample. This was evident in the LSCM results found in this study, where melting of various $\mathrm{Al}_{2} \mathrm{Cu}$ particles on the surface did not melt simultaneously, but rather at different instances of temperature or time.

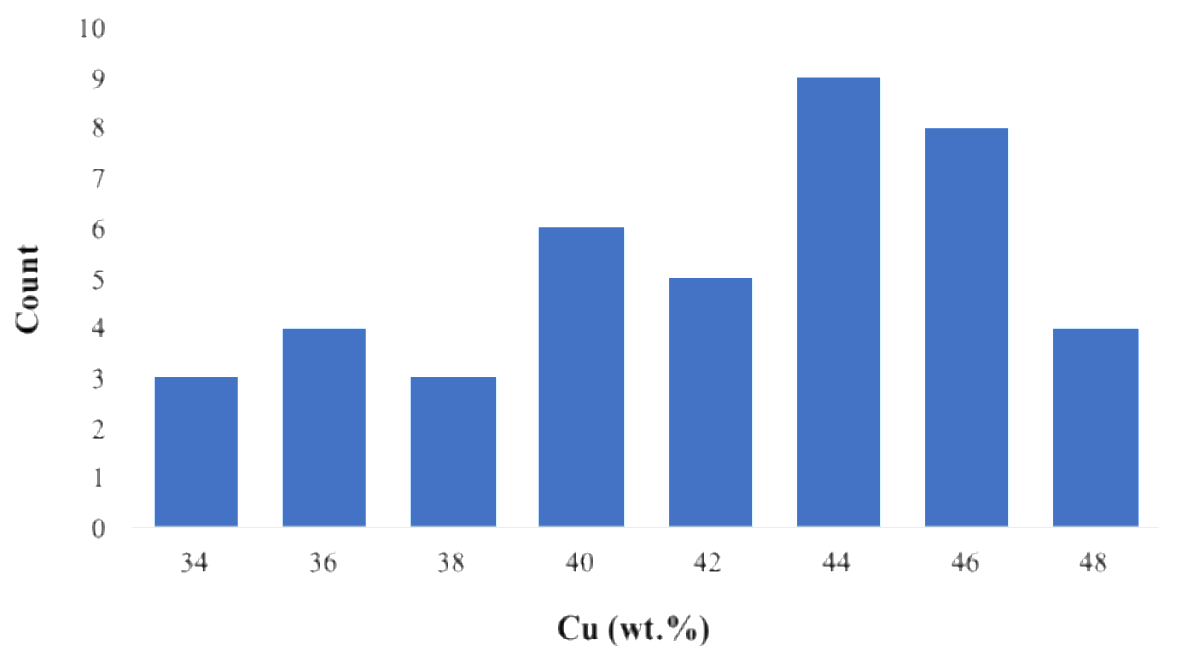

Figure 4-22: Variation in $\mathrm{Cu}$ content in eutectic $\mathrm{Al}_{2} \mathrm{Cu}$ measured from $\mathrm{EDX}$.

This study, using LSCM enabled direct observation of the proposed mechanism, which was then confirmed using SEM on samples after incipient melting. The findings on variation of $\mathrm{Cu}$ content in eutectic $\mathrm{Al}_{2} \mathrm{Cu}$ were also observed in a study by Reiso et. al [46] on the dissolution and melting of $\mathrm{Al}_{2} \mathrm{Cu}$ in an $\mathrm{Al}-\mathrm{Cu}$ alloy. However, the variation in $\mathrm{Cu}$ content was not related by these authors to the random and localized melting of $\mathrm{Al}_{2} \mathrm{Cu}$, due to limitations with SEM. In-situ analysis with high temperature LSCM in this study allowed for evidence of this mechanism for incipient melting. This was evident when a formation of liquid droplets during the melting process, believed to be a diffusion aided clustering of $\mathrm{Cu}$ atoms was observed using the LSCM. $\mathrm{Cu}$ in $\mathrm{Al}_{2} \mathrm{Cu}$ diffuses in order to reduce the free energy, which is the largest for the liquid phase. Thus, this reduction in free energy drives the melting process and enables the system to reach equilibrium. The analysis of microstructure after LCSM revealed a higher concentration of $\mathrm{Cu}$ in the $\mathrm{Al}$ matrix (section 4.3.3). This phenomenon was also observed by Reiso et. al [46], where melted $\mathrm{Al}_{2} \mathrm{Cu}$ particles were surrounded by regions with increased $\mathrm{Cu}$ concentration. The results found in this study on incipient melting will be valuable in the computer modeling of the heat treatment processes of $\mathrm{Al}$ alloys to optimize conditions prior to experimental evaluation. 


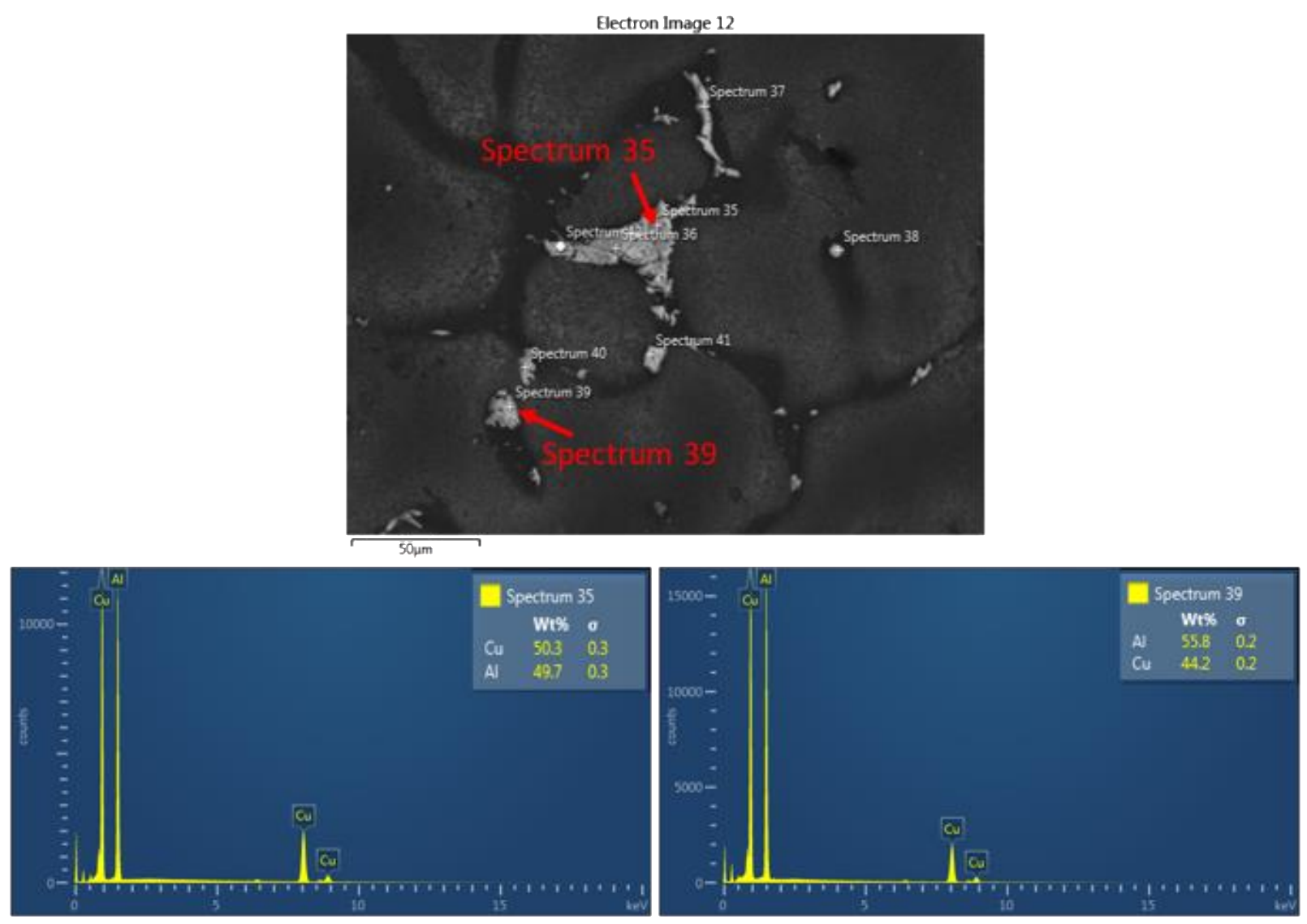

Figure 4-23: Backscattered $\mathrm{SEM}$ image showing extracted $\mathrm{Al}_{2} \mathrm{Cu}$ particles on carbon tape and EDX analysis.

\subsubsection{Section Summary}

In-situ observation of the incipient melting of $\mathrm{Al}_{2} \mathrm{Cu}$ was carried out using a high temperature LSCM. The analysis was done for both the unrefined HT200 alloy and HT200 refined with TiBor. It was found that the incipient melting temperature of $\mathrm{Al}_{2} \mathrm{Cu}$ occurs at approximately $548{ }^{\circ} \mathrm{C}$. At higher temperatures, complete melting is observed. It was also found that TiBor does not affect the incipient melting temperature of $\mathrm{Al}_{2} \mathrm{Cu}$. The $\mathrm{LSCM}$ results correlates well with the DSC data, however the DSC results revealed that the addition of TiBor reduces the enthalpy measured for $\mathrm{Al}_{2} \mathrm{Cu}$ during melting. Additionally, eutectic $\mathrm{Al}_{2} \mathrm{Cu}$ was found to melt prior to the blocky type $\mathrm{Al}_{2} \mathrm{Cu}$ as a result of the difference in their interfacial energies. The melting of $\mathrm{Al}_{2} \mathrm{Cu}$ was accompanied by a formation of liquid droplets prior to spreading across the surface. This was confirmed using SEM/EDX to be a diffusion aided clustering of $\mathrm{Cu}$ atoms. Incipient melting 
resulted in the formation of defects such as UFE clusters and cavities along the grain boundaries. Possible mechanisms for incipient melting were discussed and proposed.

\subsection{Solution Heat Treatment (SHT) of HT200 Alloy}

This section will discuss the results from solution heat treatment experiments on the HT200 alloy. The solution heat treatment temperature was varied in a high temperature tube furnace. Hardness, density and $\mathrm{Al}_{2} \mathrm{Cu}$ vol.\% were measured after SHT and quenching to determine the effect of SHT temperature on these properties.

\subsubsection{Effect of SHT Temperature on Density and Hardness}

Solution heat treatment experiments were carried out to confirm LSCM and DSC results. This was done considering that industrial furnaces do not typically have the same level control of temperature and atmosphere as the LSCM or DSC. From LSCM, it was determined that the critical temperature was found to be approximately $548{ }^{\circ} \mathrm{C}$, where incipient melting of $\mathrm{Al}_{2} \mathrm{Cu}$ was observed. Solution heat treatment was carried out at temperatures ranging from Nemak's current standard of $530{ }^{\circ} \mathrm{C}$ to a maximum of $560{ }^{\circ} \mathrm{C}$. Density and Rockwell E hardness (HRE) measurements were used to observe any changes with increasing SHT temperature and determine when incipient melting occurs. The results illustrated in Figure 4-24 show that the density remained constant at approximately $2.81 \mathrm{~g} / \mathrm{cm}^{3}$ from the as-cast state to $540{ }^{\circ} \mathrm{C}$ SHT temperature. However, at $550{ }^{\circ} \mathrm{C}$ there was a significant increase in density to approximately $2.84 \mathrm{~g} / \mathrm{cm}^{3}$; the same result was measured at $560{ }^{\circ} \mathrm{C}$. The increase in density was found to be a result of incipient melting which led to the formation of oxides on the sample surface. This was evident on the post microstructural analysis under the SEM discussed in the next section. Subsequently, it is also likely that existing pores from the as-cast state were filled during incipient melting, therefore also contributing to the significant increase in density.

A similar trend was observed with hardness measurements (Figure 4-25). It was found that with increasing SHT temperature, there was a steady increase in hardness measured. From the as-cast 
state, the hardness was found to be approximately $57 \mathrm{HRE}$, which further increased to $69 \mathrm{HRE}$ at $530{ }^{\circ} \mathrm{C} \mathrm{SHT}$. Moreover, the hardness continued to increase further at $540{ }^{\circ} \mathrm{C} \mathrm{SHT}$ to approximately 74 HRE. Although there was an increase in hardness at 530 and $540{ }^{\circ} \mathrm{C} \mathrm{SHT}$ the samples did not show any evidence of incipient melting from analysis of the surface and microstructure under the SEM (Figure 4-27 and Figure 4-29). Therefore, the increase in hardness was a result of solid solution strengthening at 530 and $540{ }^{\circ} \mathrm{C}$. However, it was also found that the hardness at 550 and $560{ }^{\circ} \mathrm{C}$ SHT temperatures significantly increased, and then remain relatively constant at approximately 76 HRE. In this case, the increase in hardness was likely due to the presence of hard and brittle microstructure that formed after incipient melting. This is evident in the microstructure, which is discussed in the following section.

Quantitative image analysis of microstructure in the as-cast condition and for each SHT temperature showed that volume fraction measurements correspond well to the hardness measurements. As shown in Figure 4-26, with increasing solution heat treatment temperature there was a decrease in volume fraction of $\mathrm{Al}_{2} \mathrm{Cu}$. The decrease in volume fraction indicates increase in dissolution of $\mathrm{Al}_{2} \mathrm{Cu}$, and thus a higher hardness due to a greater effect from solid solution strengthening. Because the dissolution kinetics of $\mathrm{Al}_{2} \mathrm{Cu}$ are dependent on temperature and time, it is expected that more $\mathrm{Al}_{2} \mathrm{Cu}$ is dissolved with increasing temperature. However, it should be noted that at SHT temperatures of 550 and $560{ }^{\circ} \mathrm{C}$ the occurrence of incipient melting resulted in the presence of re-solidified $\mathrm{Al}_{2} \mathrm{Cu}$ and UFE clusters. Hence, volume fraction measurements were of UFE clusters and re-solidified $\mathrm{Al}_{2} \mathrm{Cu}$ (Figure 4-29). This may contribute to error, as evident by the increase in $\mathrm{Al}_{2} \mathrm{Cu}$ vol.\% at $560{ }^{\circ} \mathrm{C}$. This may also suggest that at $560{ }^{\circ} \mathrm{C}$, all undissolved secondary phases melt immediately, then re-solidify upon quenching.

The results found suggests that the solution heat treatment temperature can be increased to a maximum of $540{ }^{\circ} \mathrm{C}$ without causing incipient melting. This enhances the dissolution kinetics and further increases the strength of the alloy with subsequent heat treatment (i.e. age hardening). The current practice is at a SHT temperature of $530{ }^{\circ} \mathrm{C}$ for 4 hours; further investigations can be done to vary time at $540{ }^{\circ} \mathrm{C}$ and determine whether the operating time can be reduced. Conversely, as shown in the results found in this study, overheating results in incipient melting of $\mathrm{Al}_{2} \mathrm{Cu}$ and the 
formation of harmful and deleterious microstructure, which will be further discussed in the following section.

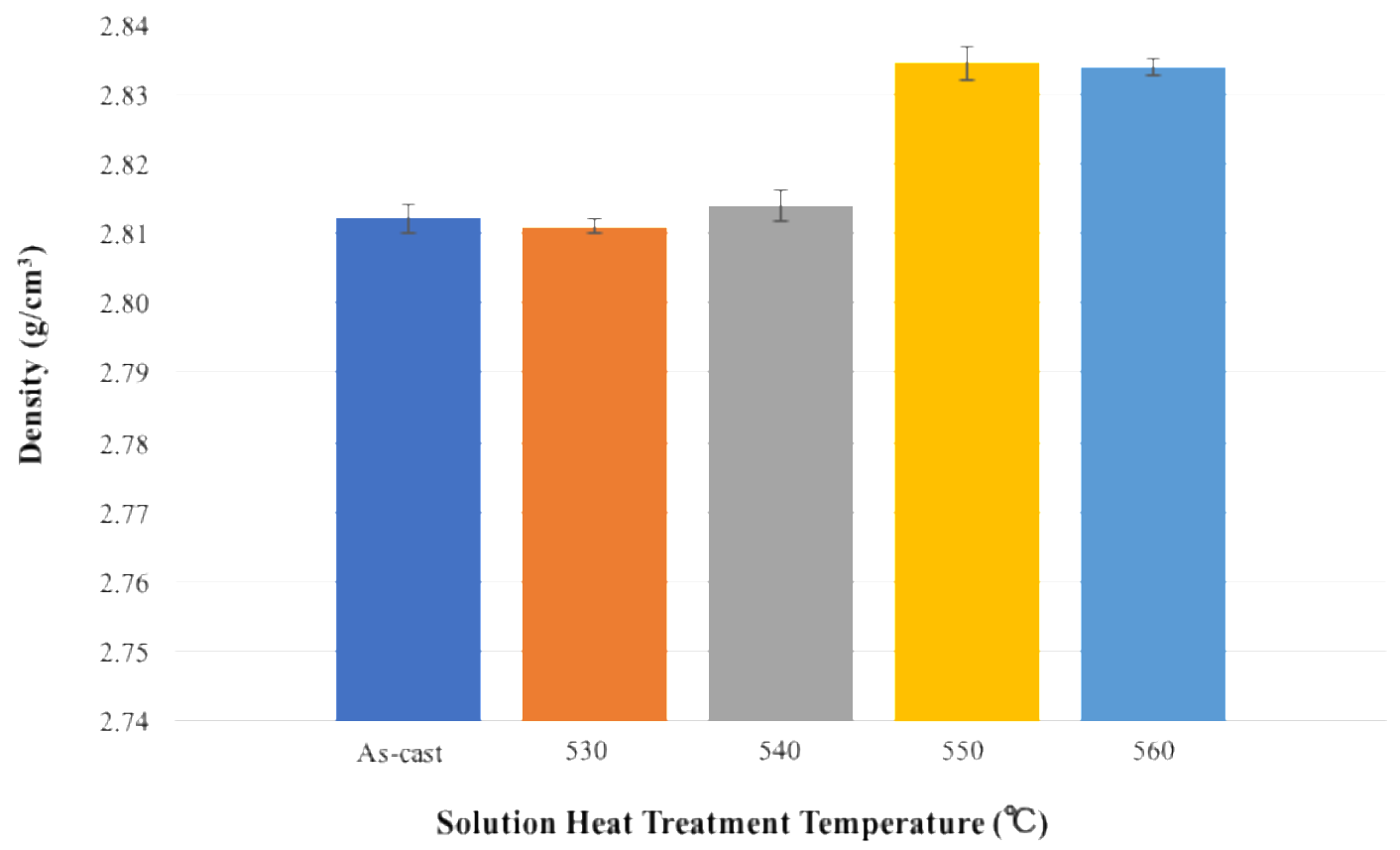

Figure 4-24: Variation in density of HT200 alloy as a function of solution heat treatment temperature.

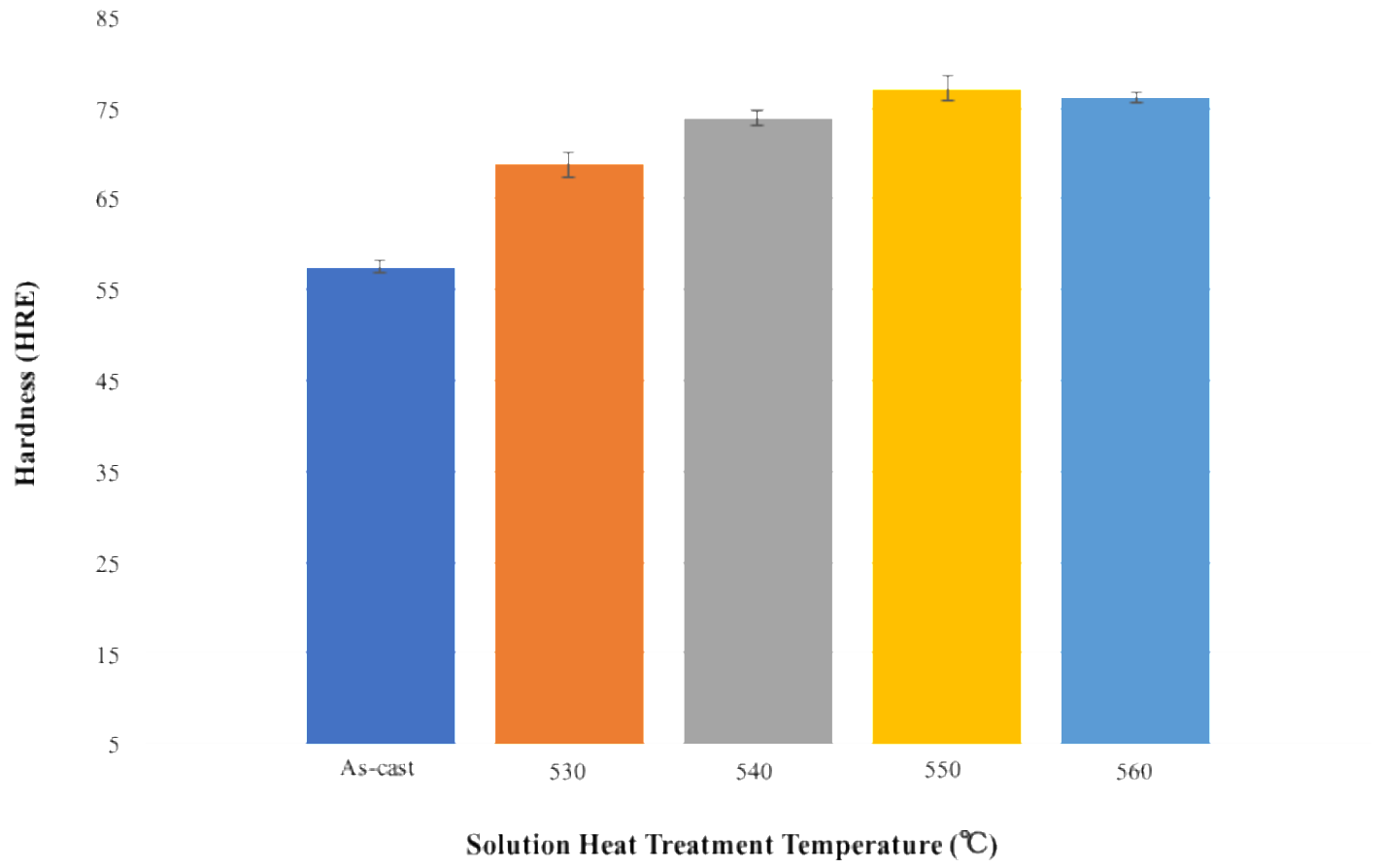

Figure 4-25: Variation in Rockwell hardness (HRE) of HT200 alloy as a function of solution heat treatment temperature. 


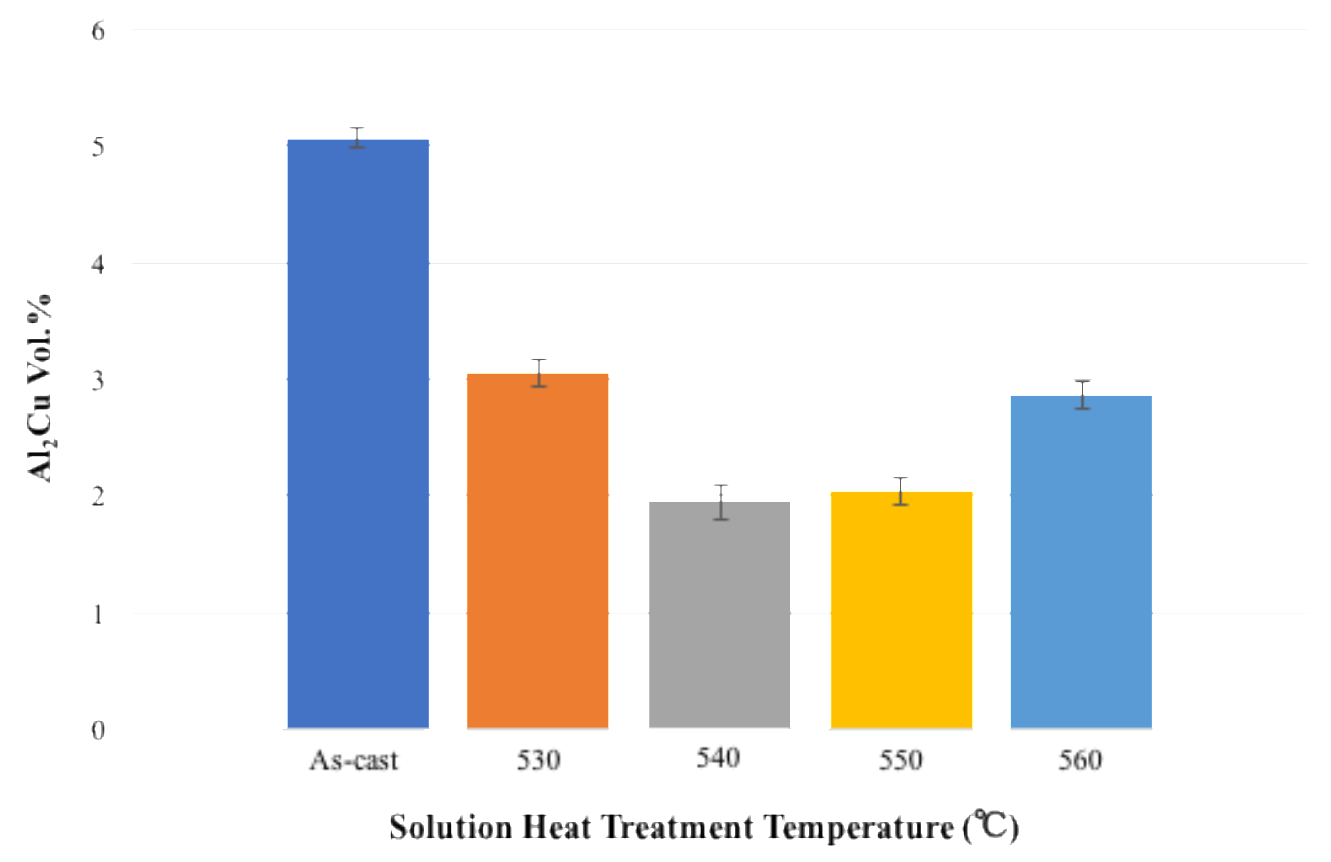

Figure 4-26: Variation in $\mathrm{Al}_{2} \mathrm{Cu}$ vol.\% as a function of solution heat treatment temperature.

\subsubsection{Post-Solution Heat Treatment Analysis}

Macro images of the HT200 samples after solution heat treatment can be seen in Figure 4-27. Incipient melting was evident on the surface of the samples that underwent SHT at 550 and 560 ${ }^{\circ} \mathrm{C}$. The surface was found to have a rough texture, likely from the re-solidified $\mathrm{Al}_{2} \mathrm{Cu}$ after melting. Furthermore, surface oxidation is also present thus explaining the increase in density and hardness at the corresponding SHT temperatures. SEM analysis was carried out on the heat-treated samples prior to grinding off the surface oxidation and polishing. It was evident from the results, presented in Figure 4-28, that incipient melting lead to oxidation on the surface of the samples. EDX elemental mapping revealed that there was a high presence of oxygen distributed around the $\mathrm{Al}_{2} \mathrm{Cu}$ (Figure 4-28(d)). While no other elements were present that are reactive at high temperatures, it is evident that the oxide formed is aluminum oxide. This is in contrast with the results found in the post-heat treatment analysis under the LSCM, where no oxidation was present due to the inert environment used. Therefore, when heat treating the alloy in industry application, overheating will also lead to oxidation. In addition to porosity and detrimental glassy UFE clusters, the combined influence of these defects would negatively impact the alloy integrity and mechanical properties. 
Conversely, the samples that underwent SHT at 530 and $540{ }^{\circ} \mathrm{C}$ did not show evidence of incipient melting or oxidation on the surface, while still showing an increase in hardness relative to the ascast condition. Microstructural analysis under the SEM revealed that the samples where incipient melting did not occur, had a presence of fragmented undissolved $\mathrm{Al}_{2} \mathrm{Cu}$ particles that were spheroidal in morphology (Figure 4-29(a)). Because the $\mathrm{Cu}$ content in the alloy is greater than the solubility limit of $\mathrm{Cu}$ in $\mathrm{Al}$, it is expected that not all $\mathrm{Al}_{2} \mathrm{Cu}$ particles will dissolve. However, the overheated samples were in contrast showing the presence of glassy and brittle ultra-fine eutectic UFE clusters (Figure 4-29(b)). This corresponds well to the higher hardness values measured for the SHT samples at 550 and $560{ }^{\circ} \mathrm{C}$ that was discussed in the previous section (see Figure 4-25). Additionally, the morphology of the $\mathrm{Al}_{2} \mathrm{Cu}$ particles after incipient melting was found to have a sharp and needle-like morphology. This may also contribute to increased sites of high stress concentration. Interestingly, the SEM analysis carried out on the SHT samples was after grinding and polishing the samples, resulting in sufficient removal of material from the surface. Thus this suggests that incipient melting is not only a surface phenomenon, but this also occurs in the subsurface microstructure as well. In section 4.3.3, the post-LSCM analysis was carried out to observe the change in microstructure due to incipient melting on the surface of the samples. Therefore, the results from microstructural analysis corresponds well to the density and hardness results (Figure 4-24 and Figure 4-25) discussed in section 4.4.1.

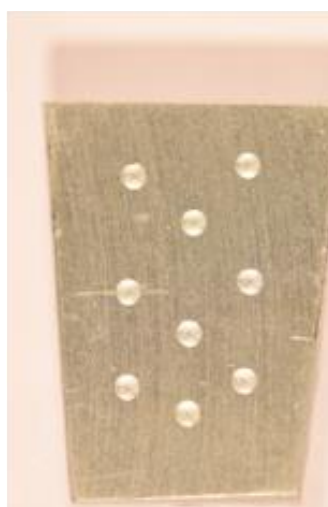

(a)

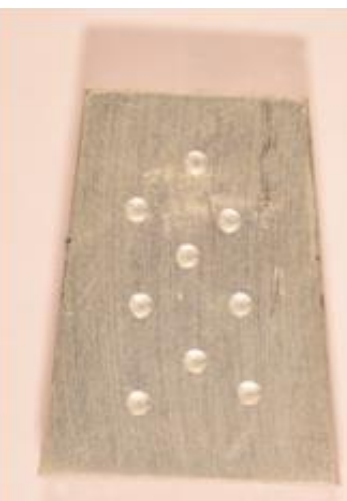

(b)

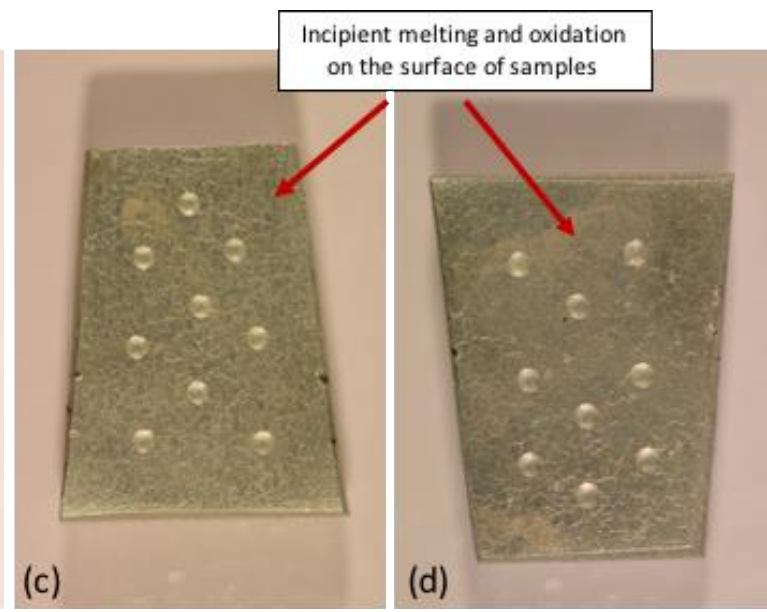

Figure 4-27: Macro images of HT200 alloy after solution heat treatment at a) 530, b) 540, c) 550 and d) $560{ }^{\circ} \mathrm{C}$. 


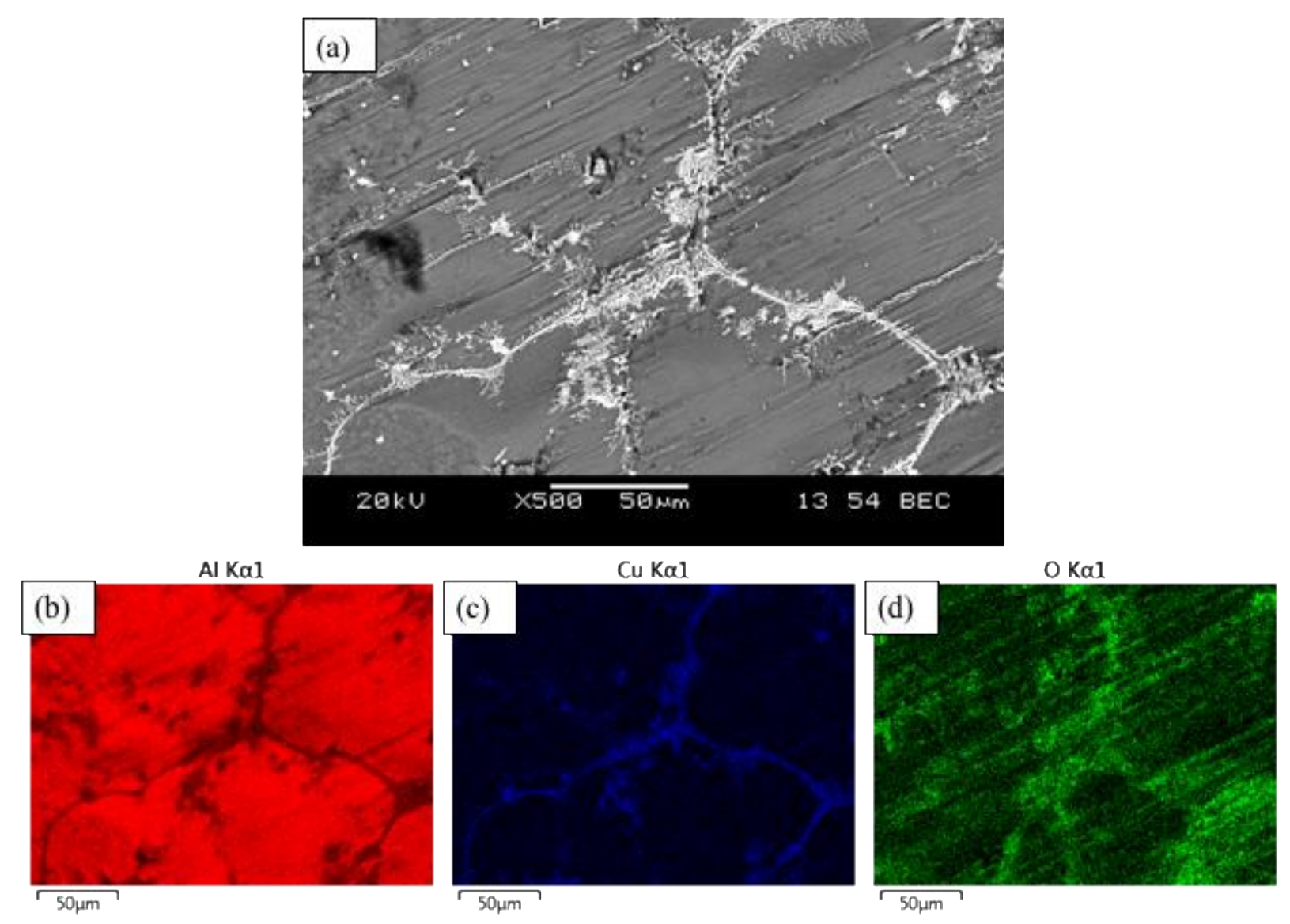

Figure 4-28: Backscattered electron image of solution heat treated HT200 sample before repolishing showing: (a) surface microstructure and EDX elemental maps of (b) Al, (c) Cu and (d) $\mathrm{O}$.
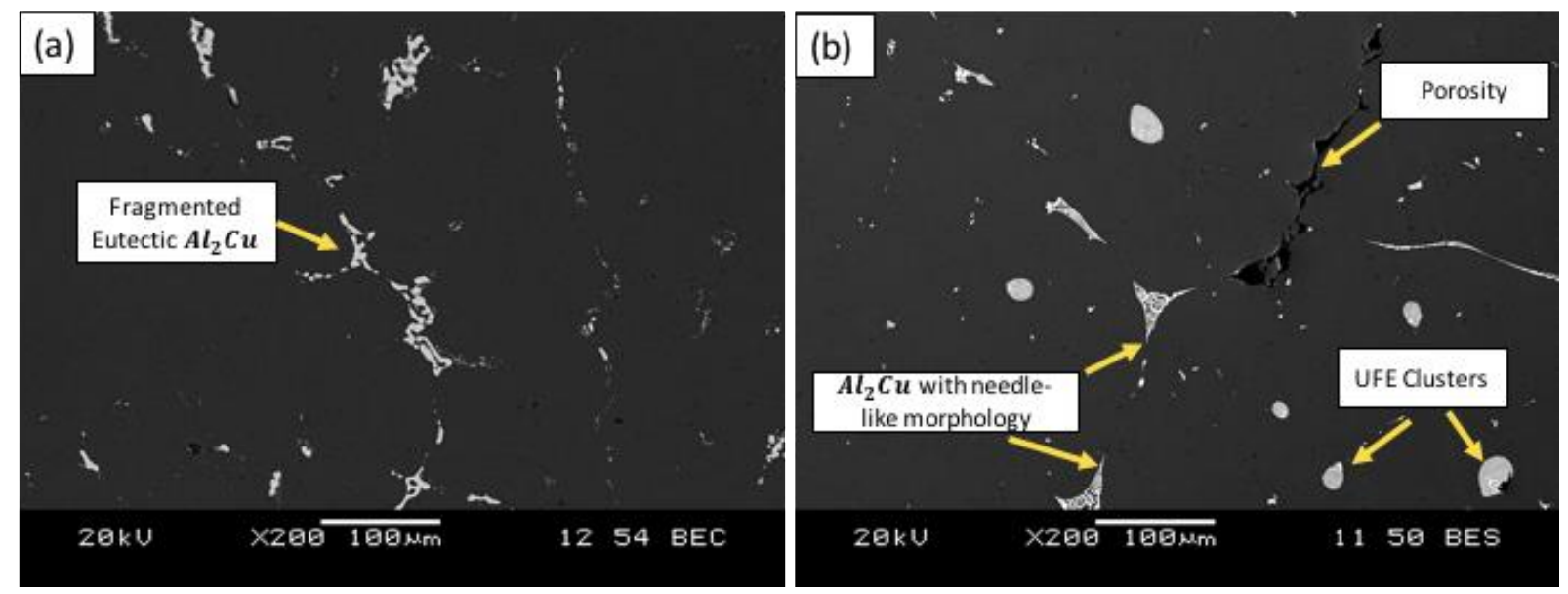

Figure 4-29: Backscattered electron images of HT200 alloy after solution heat treatment at (a) 540 and (b) $550{ }^{\circ} \mathrm{C}$. 


\subsubsection{Section Summary}

HT200 samples were solution heat treated at temperatures ranging from 530 to $560{ }^{\circ} \mathrm{C}$. The results showed that SHT at temperatures of 550 and $560{ }^{\circ} \mathrm{C}$ resulted in incipient melting and oxidation. Excessively high SHT temperatures resulted in an increase in density and hardness, due to the filling of existing pores in the as-cast sample, an aluminum-oxide layer formed and the presence of brittle re-solidified $\mathrm{Al}_{2} \mathrm{Cu}$ phases. Furthermore, the HT200 alloy can undergo solution heat treatment at $540{ }^{\circ} \mathrm{C}$ without causing incipient melting of $\mathrm{Al}_{2} \mathrm{Cu}$. The hardness at $540{ }^{\circ} \mathrm{C}$ was found to increase to $74 \mathrm{HRE}$ compared to 69 and $57 \mathrm{HRE}$ at $530{ }^{\circ} \mathrm{C}$ SHT and the as-cast state, respectively. No incipient melting was observed at these conditions; therefore, the hardness increase was primarily due to solid solution strengthening. This suggests that the operating temperature can be increased to a maximum of $540{ }^{\circ} \mathrm{C}$, an observation of significance to the industry. 


\section{Chapter 5 Conclusions}

This study investigated the microstructural and solidification characteristics of a novel $\mathrm{Al}-\mathrm{Cu}$

alloy, HT200. These features were analyzed at slow and fast solidification rates. Furthermore, correlations between the microstructural aspects of the alloy and its behaviour at elevated temperatures during heat treatment were made. To achieve this, advanced microscopic analysis was performed for in-situ observation of the incipient melting of $\mathrm{Al}_{2} \mathrm{Cu}$ secondary phases in the HT200 alloy using a high temperature LSCM. The significance and observations of impact include the following: The characterization of microstructure and solidification behaviour of a novel alloy. Also, the analysis contributed to the development of mechanisms for incipient melting, using quantitative data and direct in-situ observations with LSCM. This study also enabled the determination of an optimal solution heat treatment temperature for this alloy. DSC thermal analysis and solution heat treatment experiments were carried out to verify the LSCM results found. In doing so, increased mechanical properties can be achieved by increasing the operating temperature of heat treatment furnaces and simultaneously reducing time, a significant result for the industry. This research also provides extensive insight into the use of novel real time in-situ analysis using LSCM.

The main conclusions of this study are:

1. For $500{ }^{\circ} \mathrm{C}$ mould castings, the addition of TiBor to the HT200 alloy increased solidification rate by $15 \%$. A lower mould temperature of $200{ }^{\circ} \mathrm{C}$ resulted in a $49 \%$ increase in solidification rate with the addition of TiBor. Grain refinement with TiBor and a lower mould temperature have a synergistic effect in accelerating solidification rate.

2. As a grain refiner, TiBor was more effective at relatively slow solidification rate. At slow cooling using the $500{ }^{\circ} \mathrm{C}$ mould castings, the TiBor grain refiner was effective in changing the HT200 alloy's grain structure from coarse and fully dendritic to a finer and equiaxed dendritic structure. However, at fast solidification rates using the $200{ }^{\circ} \mathrm{C}$ mould castings, the addition of TiBor was not effective in changing the coarse and fully dendritic structure of the HT200 alloy to an equiaxed structure. 
The dendrites appeared to be finer due to the increased solidification rate $\left(200{ }^{\circ} \mathrm{C}\right.$ mould).

3. SEM revealed that $\mathrm{Al}_{2} \mathrm{Cu}$ is the predominant phase and present as both eutectic and blocky type morphology. Other secondary phases such as $\mathrm{Al}_{3} \mathrm{Zr}$ and $\mathrm{Al}_{6}(\mathrm{MnFeCu})$ were identified using EDX and data from literature.

4. LSCM results showed that the incipient melting temperature of $\mathrm{Al}_{2} \mathrm{Cu}$ occurs at approximately $548{ }^{\circ} \mathrm{C}$. At higher temperatures, complete melting is observed. It was also found that TiBor does not affect the incipient melting temperature of $\mathrm{Al}_{2} \mathrm{Cu}$. Additionally, eutectic $\mathrm{Al}_{2} \mathrm{Cu}$ was found to melt prior to the blocky type $\mathrm{Al}_{2} \mathrm{Cu}$ as a result of the difference in their interfacial energies. The melting of $\mathrm{Al}_{2} \mathrm{Cu}$ was accompanied by a formation of liquid droplets prior to spreading across the surface.

5. DSC results corresponded well to the results found from LSCM. The analysis showed two endothermic peaks at 549.6 and $648.4{ }^{\circ} \mathrm{C}$ with enthalpies of 27.83 and $284.8 \mathrm{~J} / \mathrm{g}$ respectively. The first peak was found to correspond to the incipient melting of $\mathrm{Al}_{2} \mathrm{Cu}$, while the second peak was found to be the melting of $\alpha-\mathrm{Al}$ dendrites.

6. The addition of TiBor did not have an effect on the incipient melting temperature of $\mathrm{Al}_{2} \mathrm{Cu}$. This was observed in both LSCM and DSC results. However, the DSC data showed that the measured enthalpy of the melting of $\mathrm{Al}_{2} \mathrm{Cu}$ decreased to $25.7 \mathrm{~J} / \mathrm{g}$ as a result of the refinement of $\mathrm{Al}_{2} \mathrm{Cu}$ microstructure.

7. Post-LSCM analysis of microstructure using SEM revealed the presence of glassy and brittle ultra-fine eutectic (UFE) clusters, porosity and a rough surface texture. These defects are known to be deleterious to the alloy integrity and its mechanical properties.

8. The results showed that SHT at temperatures of 550 and $560{ }^{\circ} \mathrm{C}$ resulted in incipient melting and oxidation. Excessively high SHT temperatures resulted in an increase in density and hardness, due to the filling of existing pores of the as-cast sample, an aluminum-oxide layer formed and the presence of brittle re-solidified $\mathrm{Al}_{2} \mathrm{Cu}$ phases. Furthermore, the HT200 alloy can undergo solution heat treatment at $540{ }^{\circ} \mathrm{C}$ without causing incipient melting of $\mathrm{Al}_{2} \mathrm{Cu}$. 


\subsection{Future Work}

1. Carry out age hardening experiments from 200 to $250{ }^{\circ} \mathrm{C}$ for unrefined and refined HT200 alloy.

2. Vary age hardening time at different age hardening temperatures.

3. Perform transmission electron microscopy (TEM) on age hardened samples to characterize precipitates.

4. Tensile test samples following solution heat treatment at $540{ }^{\circ} \mathrm{C}$ and varied age hardening temperatures. Compare with standard at solution heat treatment of 530 ${ }^{\circ} \mathrm{C}$.

5. Tensile test samples that have been solution heat treated above incipient melting temperature to confirm the deleterious effect of incipient melting on strength.

6. Fractography of tensile tested samples under the SEM to characterize fracture mechanisms.

7. Tensile tests of optimal heat treatment at elevated temperatures to determine performance during in-service conditions. 


\section{Appendices}

\section{A. Phase Diagrams}

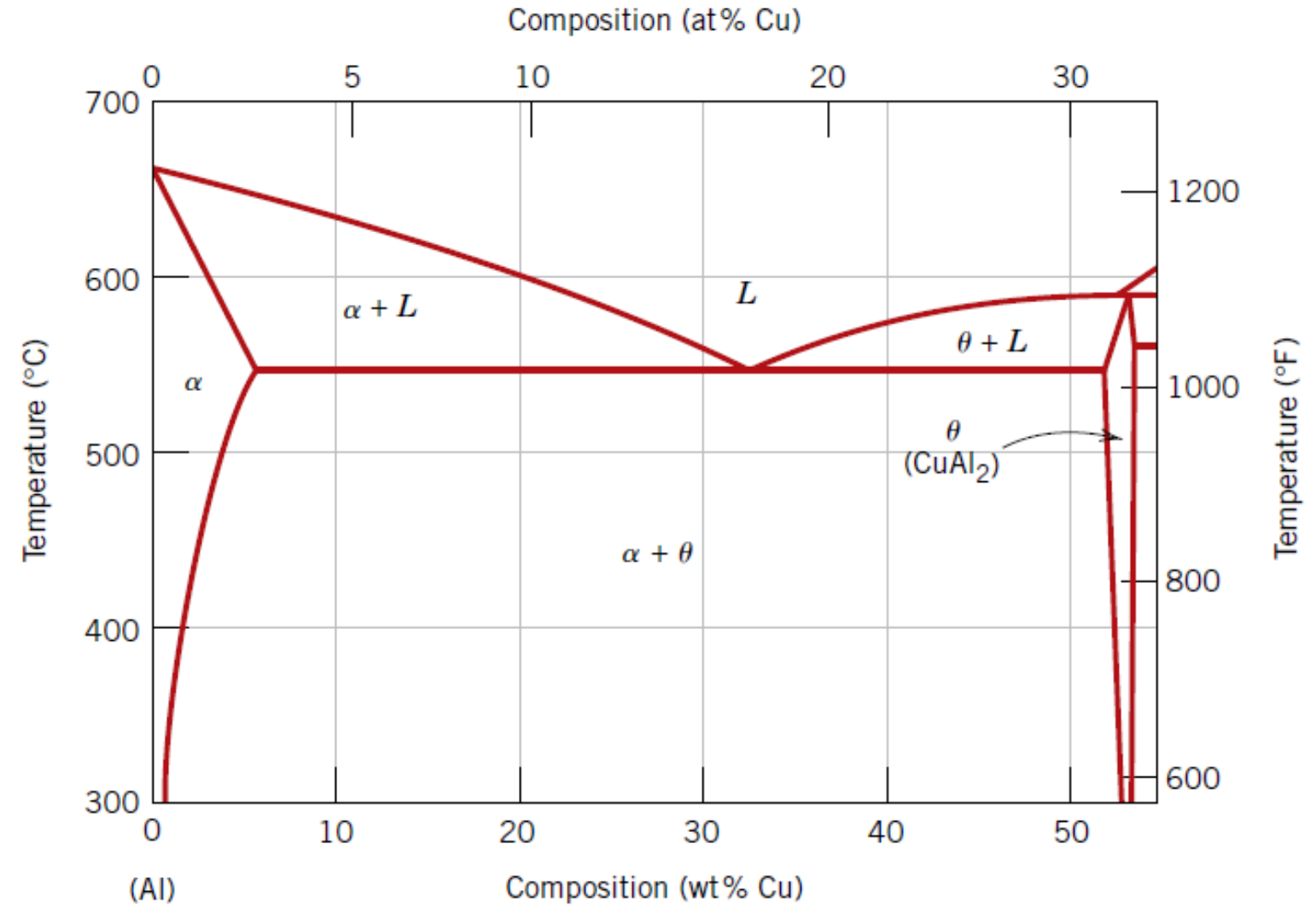

Figure A-1: Aluminum-rich side of aluminum-copper (Al-Cu) phase diagram. 


\section{B. Cooling Curves}

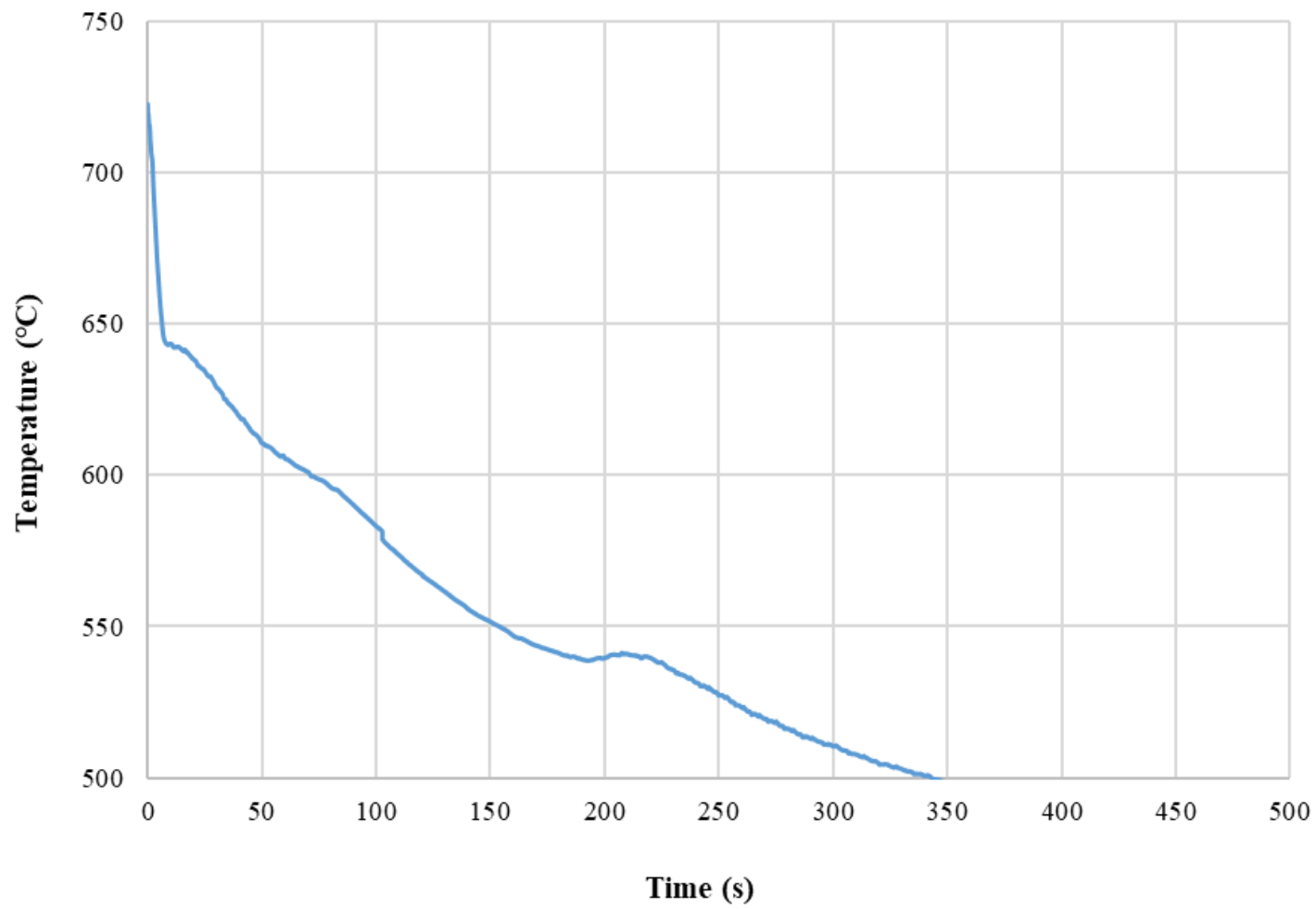

Figure B-1: HT200 500 ${ }^{\circ} \mathrm{C}$ mould cooling curve. 


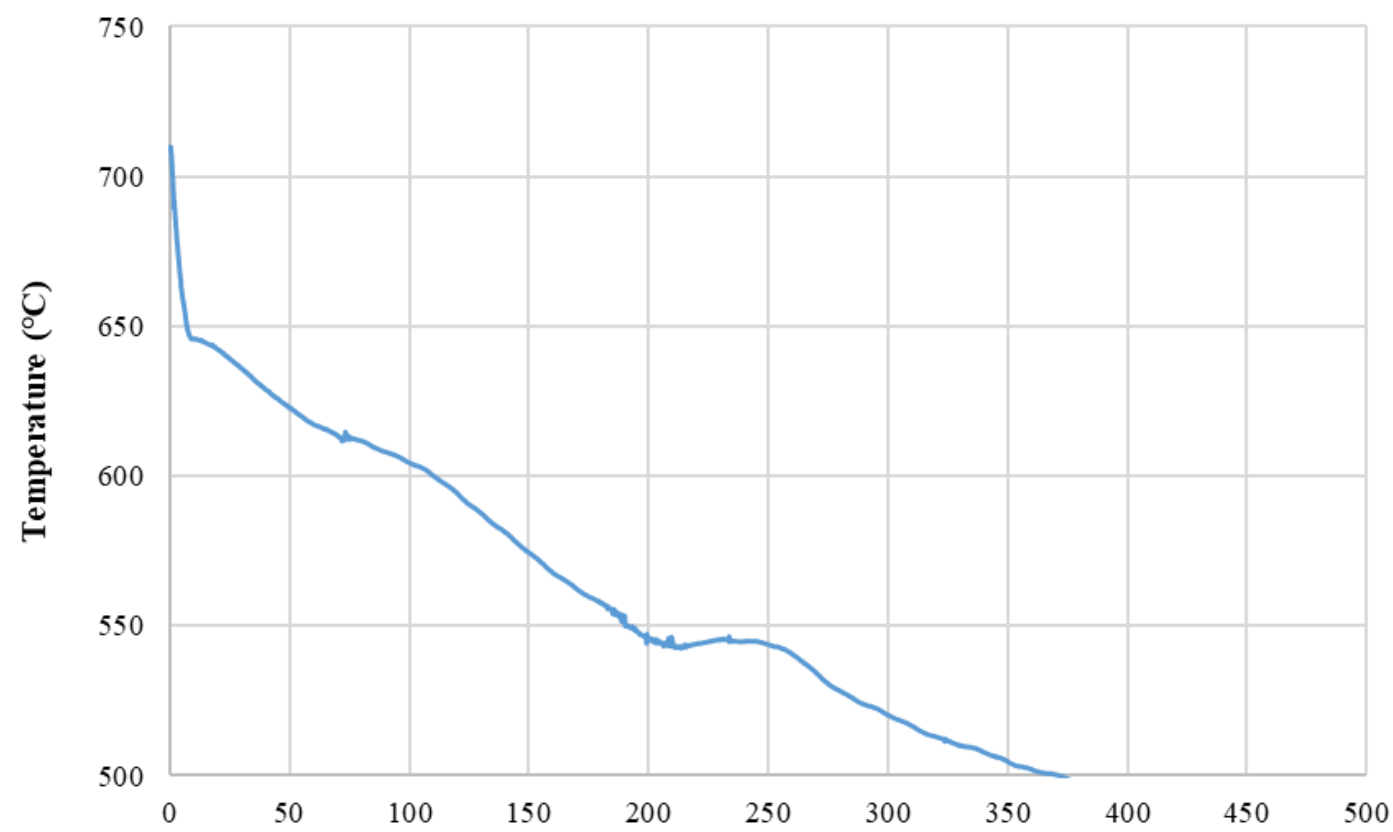

Time (s)

Figure B-2: HT200 $500{ }^{\circ} \mathrm{C}$ mould cooling curve.

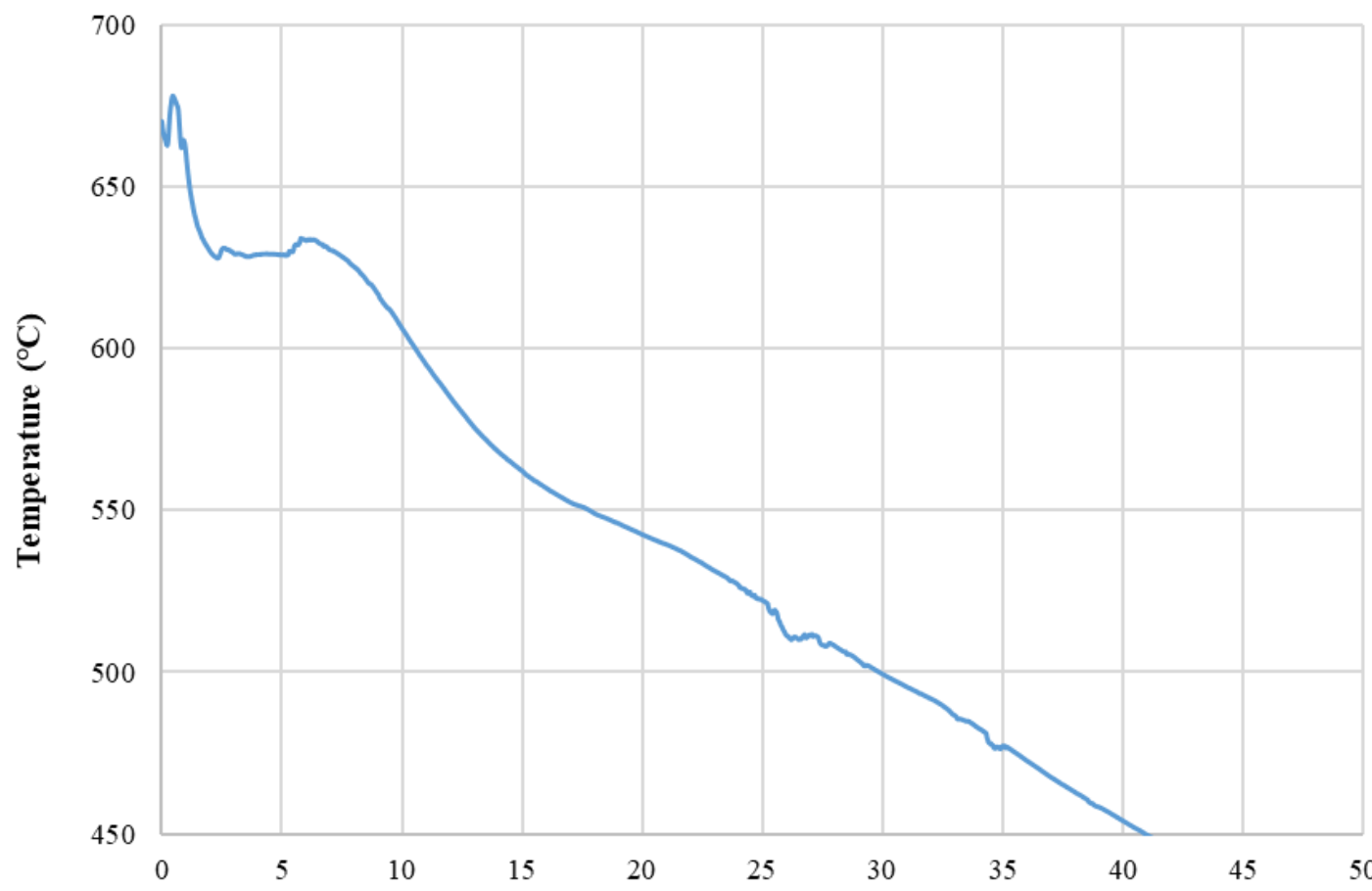

Time (s)

Figure B-3: HT200 $200{ }^{\circ} \mathrm{C}$ mould cooling curve. 


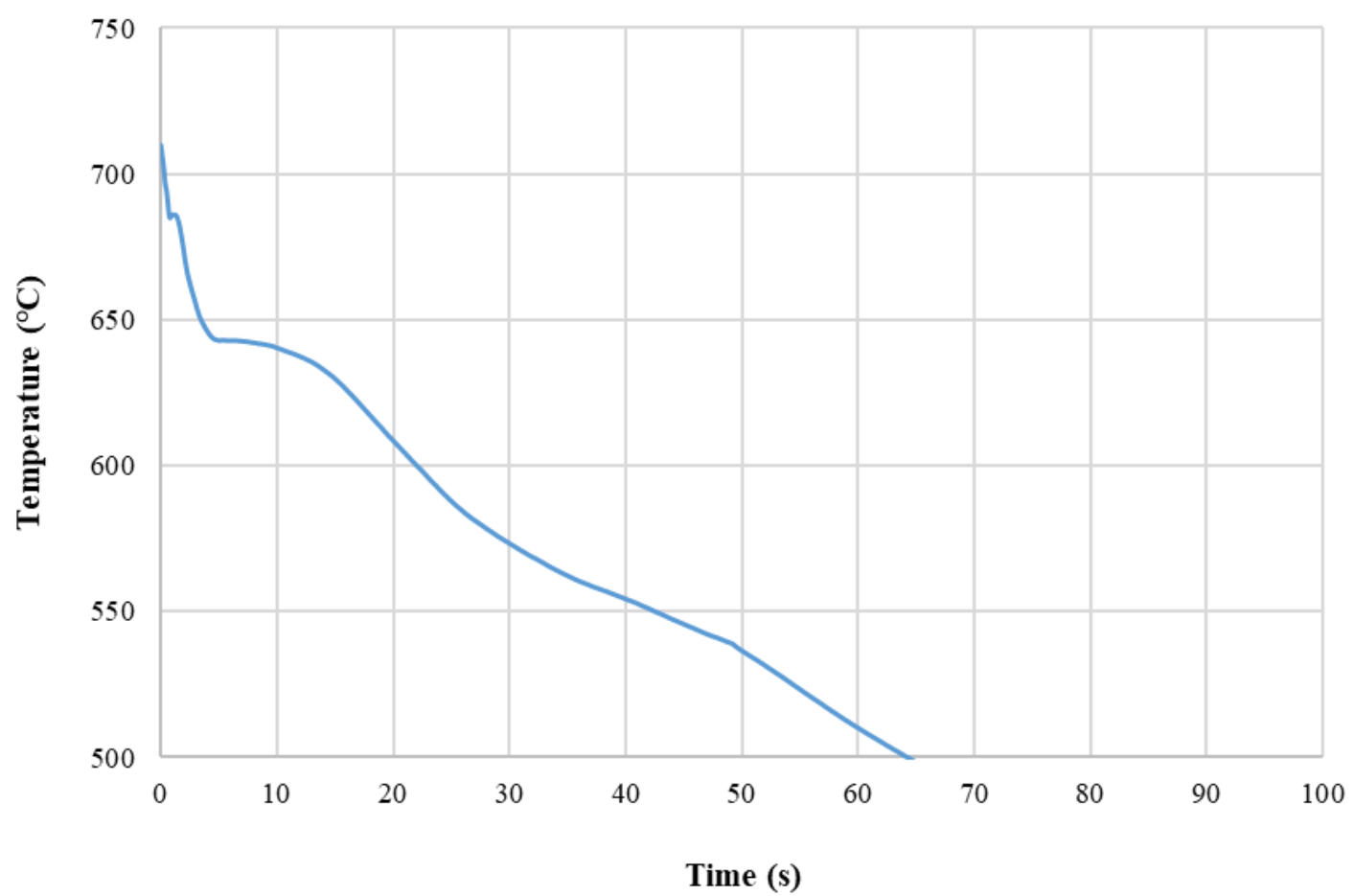

Figure B-4: HT200 $200{ }^{\circ} \mathrm{C}$ mould cooling curve. 


\section{C.X-Ray Diffraction Data}

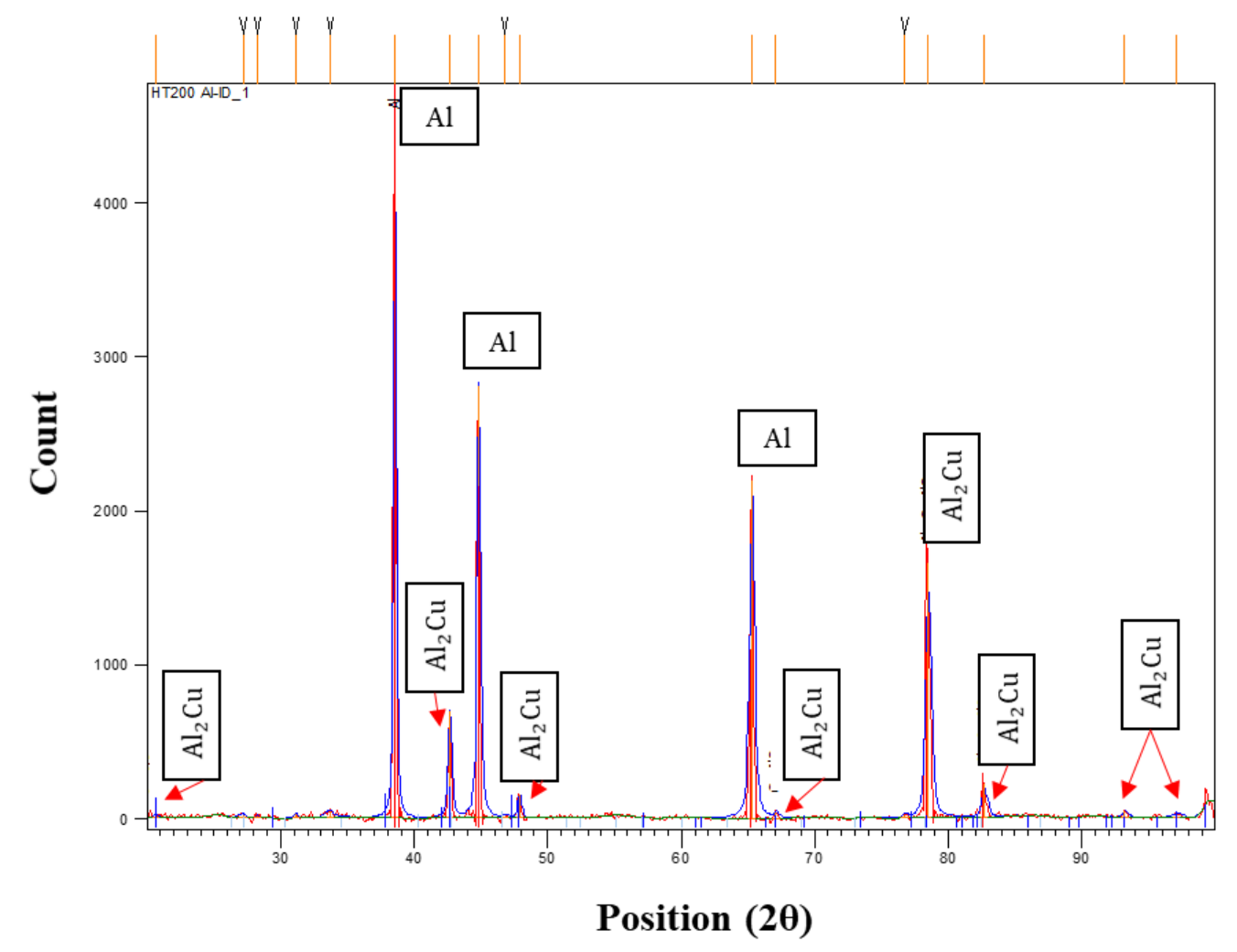

Figure C-1: X-ray diffraction analysis of HT200 alloy. 


\section{Effect of SHT on $\mathrm{Al}_{2} \mathrm{Cu}$ Morphology}

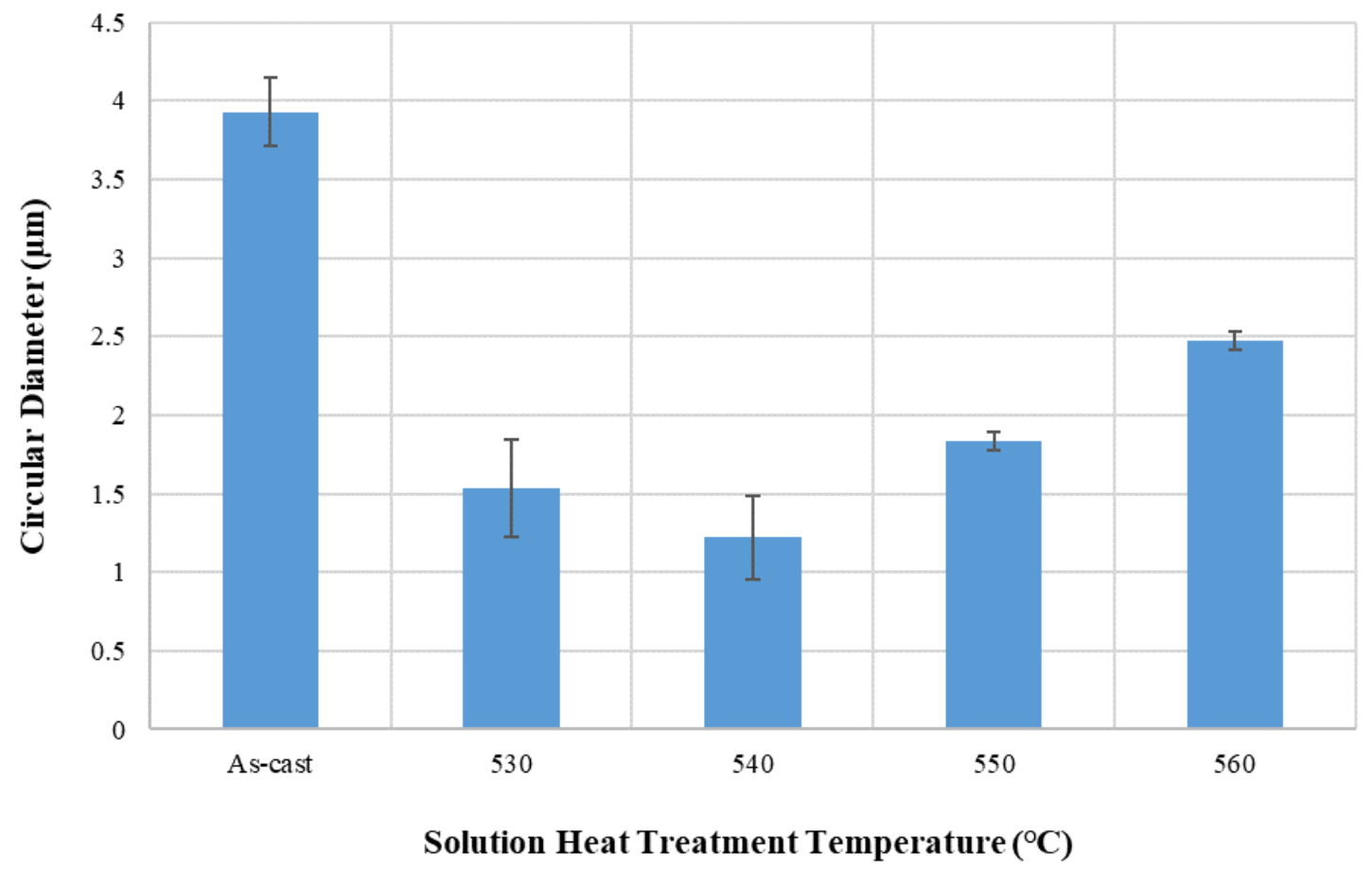

Figure D-1: Average circular diameter of $\mathrm{Al}_{2} \mathrm{Cu}$ as a function of SHT temperature. 


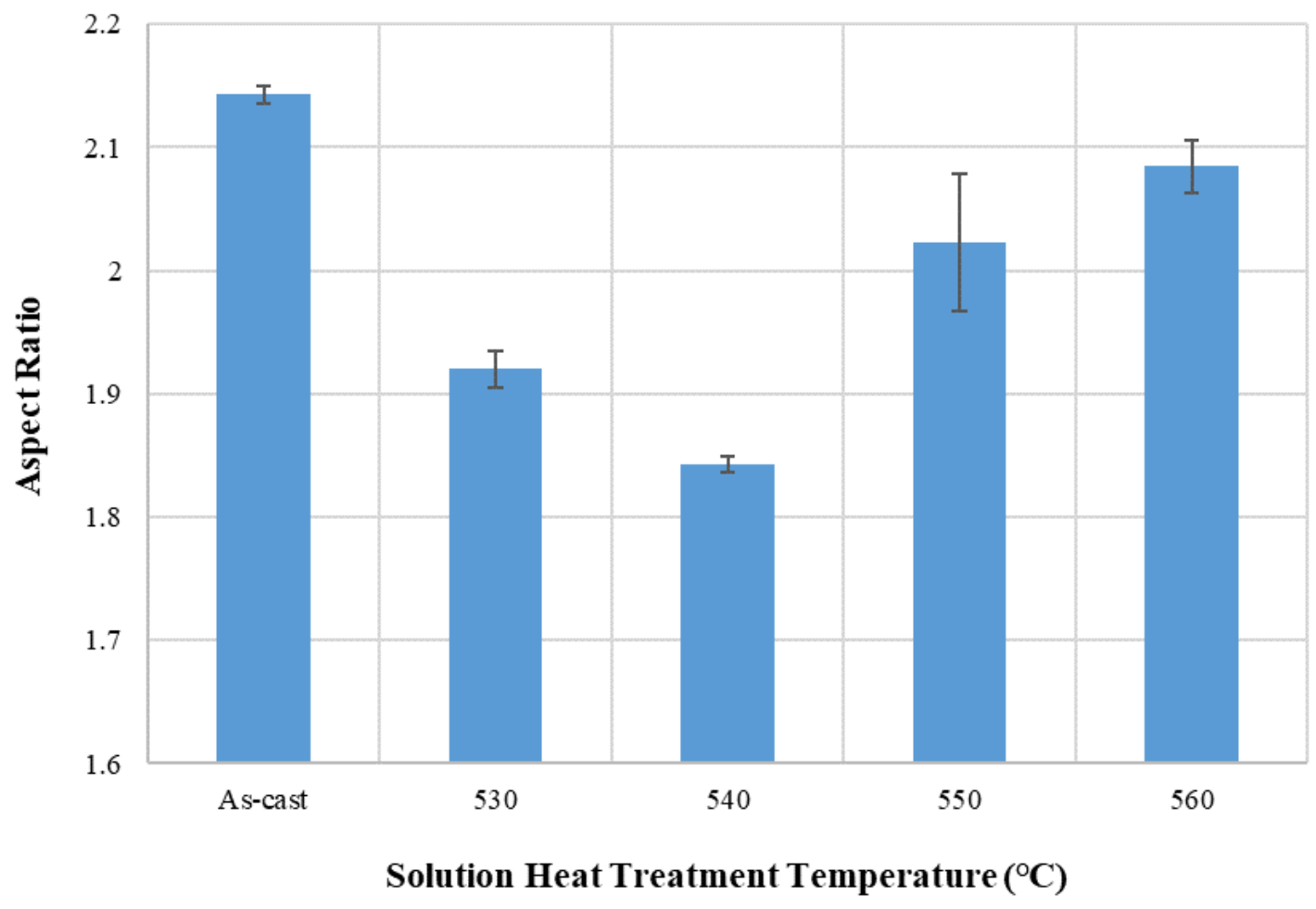

Figure D-2: Average aspect ratio of $\mathrm{Al}_{2} \mathrm{Cu}$ as a function of SHT temperature.

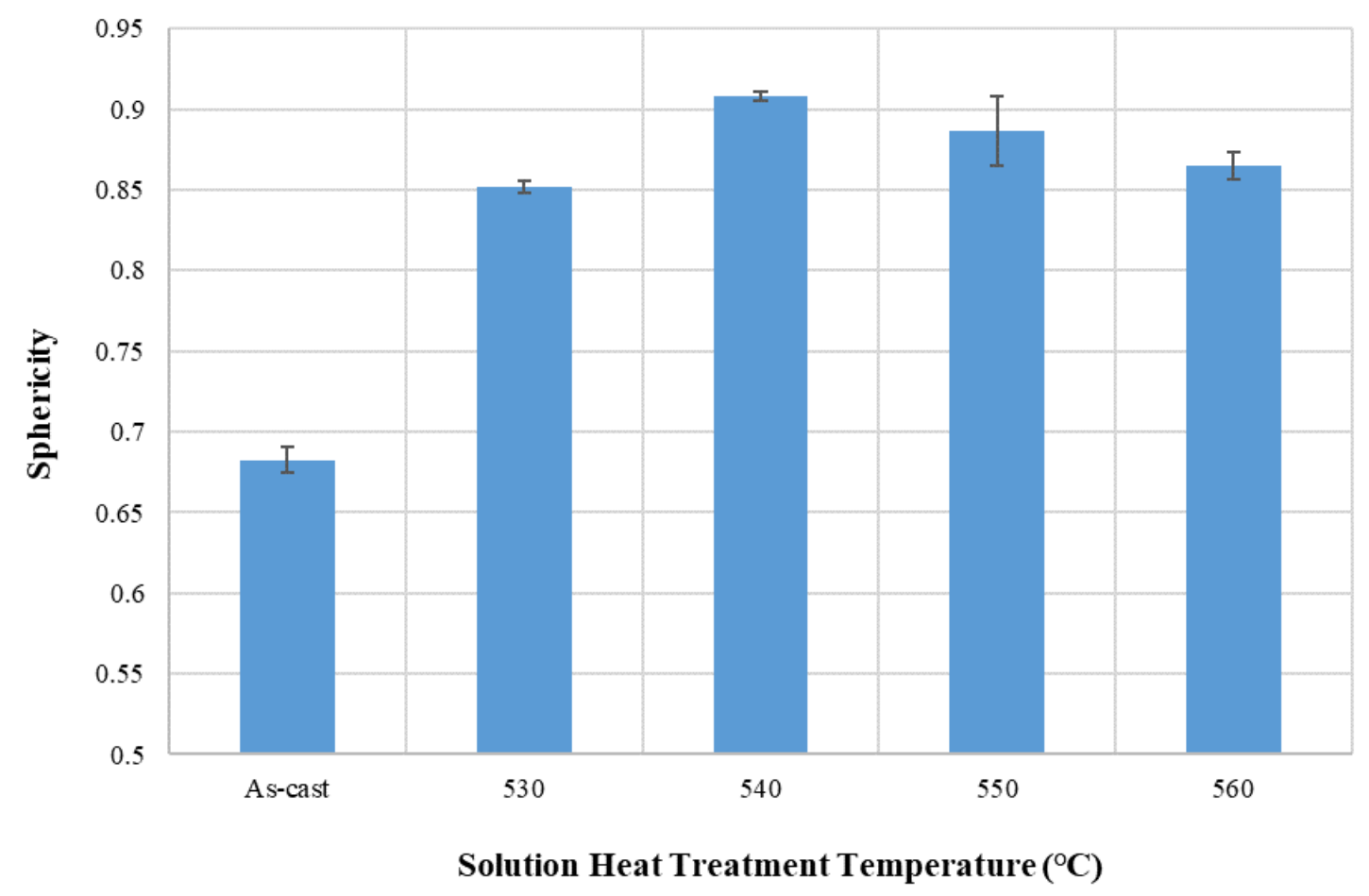

Figure D-3: Average sphericity of $\mathrm{Al}_{2} \mathrm{Cu}$ as a function of SHT temperature. 


\section{References}

[1] "VEHICLE TECHNOLOGIES OFFICE: LIGHTWEIGHT MATERIALS FOR CARS AND TRUCKS," U.S. Department of Energy, April 2017. [Online]. Available:

https://energy.gov/eere/vehicles/vehicle-technologies-office-lightweight-materials-carsand-trucks.

[2] D. Larouche and M. Javidani, "Application of cast Al-Si alloys in internal combustion engines," International Materials Reviews, vol. 59, no. 3, pp. 132-158, 2010.

[3] E. Rincona, H. Lopez, M. Cisnerosa and H. Manchac, "Temperature effects on the tensile properties of cast and heat treated aluminum alloy A319," Materials Science and Engineering A, vol. 519, p. 128-140, 2009.

[4] K. Kashyap, "Effect of zirconium addition on the recrystallization behaviour of commercial Al-Cu-Mg alloy," Bulletin of Materials Science, vol. 24, no. 6, pp. 643-648, 2001.

[5] G. Sigworth and M. J.F., "Factors influencing the mechanical properties of B206," TMS Light Metals, pp. 795-799, 2006.

[6] G. Sigworth and F. DeHart, "Recent developments in the high strength aluminum-copper casting alloy A206," AFS Transactions, vol. 111, pp. 314-45, 2003.

[7] F. D'Elia, C. Ravindran and D. Sediako, "Interplay among solidification, microstrcture, residual strain and hot tearing in B206 aluminum alloy," Materials Science and Engineering A, vol. 624, pp. 169-180, 2015.

[8] F. D'Elia, C. Ravindran, D. Sediako, K. Kainer and N. Hort, "Hot tearing mechanisms of B206 aluminum-copper alloy," Materials and Design, vol. 64, pp. 44-45, 2014.

[9] J. Davis, ASM Specialty Handbook: Aluminum and Aluminum Alloys, Materials Park, Ohio: ASM International, 1993.

[10] A. Lombardi, W. Mu, C. Ravindran, N. Dogan and M. Barati, "Influence of Al2Cu morphology on the incipient melting characteristics in B206 Al alloy," Journal of Alloys and Compounds, vol. 747, pp. 131-139, 2018. 
[11] N. Haghdadi, A. Phillion and D. Maijer, "Microstructure characterization and thermal analysis of aluminum alloy B206 during solidification," Metallurgical and Materials Transactions A, vol. 46, pp. 2073-2081, 2015 .

[12] H. Kamga, D. Larouche, M. Bournane and A. Rahem, "Solidification of aluminum-copper B206 alloys with iron and silicon additions," Metallurgical and Materials Transactions A, vol. 41, pp. 2844-2855, 2010.

[13] M. Talamantes-Silva, A. Rodriguez, J. Talamantes-Silva, S. Valtierra and R. Colas, "Characterization of an Al-Cu cast alloy," Materials Characterization, vol. 59, pp. 14341439, 2008.

[14] L. Backerud, L. Chai and J. Tamminen, Solidification Characteristics of Aluminum Alloys Volume 2: Foundry Alloys, Stockholm, Sweden: AFS/ SKANALUMINUM, 1990.

[15] W. D. Callister and D. G. Rethwisch, Materials Science and Engineering: An Introduction, Hoboken, NJ: Wiley, 2014.

[16] J. Gruzleski, Microstructure Development During Metalcasting, Des Plaines, Illinois: American Foundrymen's Society Inc., 2000.

[17] M. Gündüz and E. Çadirli, "Directional solidification of aluminum-copper alloys," Materials Science and Engineering A, vol. A327, pp. 167-185, 2002.

[18] A. Lombardi, C. Ravindran and R. MacKay, "Optimization of the solution heat treatment process to improve mechanical properties of 319Al alloy engine blocks using the billet casting method," Materials Science and Engineering A, vol. 633, pp. 125-135, 2015.

[19] A. Lombardi, C. Ravindran and R. MacKay, "Application of the Billet Casting Method to Determine the Onset of Incipient Melting of 319 Al Alloy Engine Blocks," Journal of Materials Engineering and Performance, vol. 24, no. 6, p. 2179-2184, 2015.

[20] Y. M. Han, A. M. Samuel, F. H. Samuel and H. W. Doty, "Dissolution of A12Cu phase in non-modified and Sr modified 319 type alloys," International Journal of Cast Metals Research, vol. 21, no. 5, pp. 387-393, 2008.

[21] A. Samuel, H. Doty, S. Valtierra and F. Samuel, "Defects related to incipient melting," Materials and Design, vol. 52, pp. 947-956, 2013. 
[22] A. Mohamed, F. Samuel and S. Al kahtani, "Influence of Mg and solution heat treatment on the occurrence of incipient melting in $\mathrm{Al}-\mathrm{Si}-\mathrm{Cu}-\mathrm{Mg}$ cast alloys," Materials Science and Engineering A, vol. 543, pp. 22-34, 2012.

[23] F. Samuel, "Incipient melting of $\mathrm{Al} 5 \mathrm{Mg} 8 \mathrm{Si} 6 \mathrm{Cu} 2$ and $\mathrm{A} 12 \mathrm{Cu}$ intermetallics in unmodified and strontium-modified Al-Si-Cu-Mg (319) alloys during solution heat treatment," Journal of Materials Science, vol. 33, pp. 2283-2297, 1998.

[24] A. Lombardi, W. Mu, C. Ravindran, N. Dogan and M. Barati, "In-situ investigation of incipient melting in a 319 type $\mathrm{Al}$ alloy using laser scanning confocal microscopy," Materials Characterization, vol. 141, pp. 328-337, 2018.

[25] S. Menargues, E. Martin, M. Baile and J. Picas, "New short T6 heat treatments for aluminum silicon alloys obtained by semi solid forming," Materials Science and Engineering A, vol. 621, pp. 236-242, 2015.

[26] S. K. Chaudhury, "Effects of Mg and Cu Content on Quench Sensitivity of Al-Si-Mg Alloy," International Journal of Metalcasting , vol. 10, no. 2, pp. 138-146, 2016.

[27] Y. C. Tzeng, C. T. Wu and S. L. Lee, "The effect of trace Sc on the quench sensitivity of AL-7Si-0.6 Mg alloys," Materials Letters, vol. 161, pp. 340-342, 2015.

[28] R. Sharma, Phase Transformations in Materials, New Delhi: CBS Publishers and Distributors, 2002.

[29] G. E. Dieter, Mechanical Metallurgy, New York: McGraw Hill, 1986, pp. 212-216.

[30] E. Sjölander and S. Seifeddine, "Artificial ageing of Al-Si-Cu-Mg casting alloys," Materials Science and Engineering A, vol. 528, pp. 7402-7409, 2011.

[31] T. Rajan, C. Sharma and A. Sharma, Heat Treatment Principles and techniques, New Delhi: Prentice Hall of India, 1999.

[32] V. Gerold, Precipitation Hardening. In: Nabarro, F.R.N. (Ed.), Dislocations in Solids, Amsterdam: North-Holland Publishing Company, 1979, p. 222.

[33] E. Sjölander and S. Seifeddine, "Influence of alloy composition, solidification rate and artificial aging on plastic deformation behaviour of $\mathrm{Al}-\mathrm{Si}-\mathrm{Cu}-\mathrm{Mg}$ casting alloys," International Journal of Cast Metals Research, vol. 26, no. 1, pp. 28-36, 2013. 
[34] W. Mu, P. Hedström, H. Shibata, P. Jönsson and K. Nakajima, "High-Temperature Confocal Laser Scanning Microscopy Studies of Ferrite Formation in Inclusion-Engineered Steels: A Review," Journal of Materials: Advanced Real Time Imaging, vol. 70, pp. 22832295, 2018.

[35] K. Miao, A. Haas, K. Sharma, W. Mu and N. Dogan, "In Situ Observation of Calcium Aluminate Inclusions Dissolution into Steelmaking Slag," Metallurgical and Materials Transactions B, vol. 49B, pp. 1612-1623, 2018.

[36] W. Mu, N. Dogan and D. Maijer, "Agglomeration of Non-metallic Inclusions at Steel/Ar Interface: In-Situ Observation Experiments and Model Validation," Metallurgical and Materials Transactions B, vol. 48B, pp. 2379-2388, 2017.

[37] M. Atallah, H. Terasaki, R. Moat, S. Bray, Y. Komizo and M. Preuss, "In-Situ observation of primary $\gamma^{\prime}$ melting in Ni-base superalloy using confocal laser scanning microscopy," Materials Characterization, vol. 62, pp. 760-767, 2011.

[38] E. Vandersluis, "Influence of Solidification Parameters on the Thermal Conductivity of Cast A319 Alloy," Ryerson University, Toronto, 2016.

[39] F. D'Elia, C. Ravindran, D. Sediako and R. Donaberger, "Solidification analysis of Al-5Cu alloy using in-situ neutron diffraction," Canadian Metallurgy Quarterly, vol. 54, no. 1, pp. 9-15, 2015.

[40] K. Liu, X. Cao and X. Chen, "Effect of Mn, Si, and Cooling Rate on the Formation of IronRich Intermetallics in 206 Al-Cu Cast Alloys," Metallurgical and Materials Transactions B, vol. 43B, pp. 1231-1240, 2012.

[41] J. Zhang, D. Ding, W. Zhang and S. Kang, "Effect of Zr addition on microstructure and properties of Al-Mn-Si-Zn-based alloy," Transactions of Nonferrous Metals Society of China, vol. 24, p. 3872-3878, 2014.

[42] N. Ridley, E. Cullen and E. Humphreys, "Effect of thermomechanical processing on evolution of superplastic microstructures in $\mathrm{Al}-\mathrm{Cu}-\mathrm{Zr}$ alloys," Materials Science and Technology, vol. 16, pp. 117-124, 2000. 
[43] S. Hu, M. Baskes, M. Stan and L. Chen, "Atomistic calculations of interfacial energies, nucleus shape and size of precipitates in Al-Cu alloys," Acta Materialia, vol. 54, p. 46994707, 2006.

[44] E. Brandes, Smithells Metals Reference Handbook, London: Butterworths, 1983.

[45] P. Pusey, "Freezing and Melting: Action at Grain Boundaries," Science, vol. 309, pp. 11981199, 2005.

[46] O. Reiso, H. Overlie and N. Ryum, "Dissolution and Melting of Secondary Al2Cu Phase Particles in an AlCu Alloy," Metallurgical Transactions A, vol. 21A, pp. 1689-1695, 1990. 